MÁRIO TONIZZA PEREIRA

\title{
PROPOSTA DE UM MODELO DE SIMULAÇÃO COMPUTACIONAL PARA A PROGRAMAÇÃO DE OPERAÇÕES EM SISTEMAS ASSEMBLY SHOP
}

Dissertação apresentada à Escola Politécnica da Universidade de São Paulo para obtenção do Título de Mestre em Engenharia 
MÁRIO TONIZZA PEREIRA

\title{
PROPOSTA DE UM MODELO DE SIMULAÇÃO COMPUTACIONAL PARA A PROGRAMAÇÃO DE OPERAÇÕES EM SISTEMAS ASSEMBLY SHOP
}

\author{
Dissertação apresentada à Escola \\ Politécnica da Universidade de São Paulo \\ para obtenção do Título de Mestre em \\ Engenharia \\ Área de Concentração: \\ Sistemas Logísticos \\ Orientador: \\ Prof. Dr. Miguel Cezar Santoro
}


Este exemplar foi revisado e alterado em relação à versão original, sob responsabilidade única do autor e com a anuência de seu orientador.

São Paulo, 12 de maio de 2009.

Assinatura do autor

Assinatura do orientador

FICHA CATALOGRÁFICA

Pereira, Mário Tonizza

Proposta de um modelo de simulação computacional para a programação de operações em sistemas assembly shop / M.T. Pereira. -- ed.rev. -- São Paulo, 2009.

$161 \mathrm{p}$.

Dissertação (Mestrado) - Escola Politécnica da Universidade de São Paulo. Departamento de Engenharia de Produção.

1. Produção intermitente 2. Scheduling 3. Otimização combinatória 4. Heurística I. Universidade de São Paulo. Escola Poli técnica. Departamento de Engenharia de Produção II. t. 
À minha família, Fabiana, Nícolas e Gustavo, minhas eternas fontes de inspiração. Aos meus pais, Eduardo (em memória) e Celina, pela dedicação de uma vida. 


\section{AGRADECIMENTOS}

Meu especial agradecimento ao Professor Dr. Miguel Cezar Santoro pela preciosa orientação, pelo incentivo, paciência e compreensão durante a execução deste trabalho.

À minha querida esposa Fabiana, pelo incansável estímulo, apoio, ajuda, paciência e compreensão.

Aos meus queridos filhos, Nícolas e Gustavo, pela compreensão quanto aos momentos que foram subtraídos de nossa convivência diária para que eu pudesse desenvolver este trabalho.

Aos meus pais, Eduardo (em memória) e Celina, por terem me preparado para a vida e por terem me ensinado a perseverar e a valorizar tanto a educação e o conhecimento.

A todos aqueles que, direta ou indiretamente, contribuíram para a realização deste trabalho. 
Dubito, ergo cogito, ergo sum.

(Questiono, logo penso, logo existo.)

(René Descartes) 


\section{RESUMO}

Esta dissertação estuda o problema da programação de operações em sistemas job shop de manufatura onde itens com estruturas de materiais são produzidos a partir de componentes fabricados e montados. Tais sistemas são denominados assembly shops. O caso geral do problema de programação de operações em sistemas job shop, no qual não existem restrições quanto ao número de operações a serem programadas nem quanto ao número de máquinas a serem alocadas, é considerado, até o presente momento, intratável do ponto de vista computacional devido à explosão combinatória inerente ao processo de programação, independente da escolha do critério de desempenho. Isto significa dizer que não existe nenhum método eficiente de programação que resolva globalmente instâncias de porte real do problema dentro de um tempo computacional considerado satisfatório. Devido a este fato, nas últimas três décadas, diversos métodos aproximados e heurísticos foram propostos e avaliados para o problema. Nesta pesquisa, é proposto e avaliado um novo método heurístico de programação. Fundamentado na pressuposição de que a melhoria na sincronização de operações de montagem em sistemas assembly shop leva ao melhor atendimento de datas de entrega de pedidos, o método implementa duas abordagens de programação: uma abordagem backward que satisfaz completamente as datas de entrega e outra forward que satisfaz completamente a restrição de capacidade de máquina. Ambas trabalham iterativamente dentro de dois modelos de simulação do sistema de produção - um determinístico e outro probabilístico - na busca pela melhoria da sincronização das operações e no atendimento das datas de entrega. Os resultados experimentais demonstraram que o desempenho do novo método foi em média melhor que os dos métodos não iterativos (regras) avaliados e tão bom quanto o desempenho do melhor método não iterativo (regra) testado.

Palavras-Chave: Programação Job Shop. Sistemas Assembly Shop. Otimização Combinatória. Heurísticas. Regras de Priorização. 


\begin{abstract}
This dissertation studies the problem of scheduling operations in manufacturing job shop environments where items with bill of materials are made of many fabricated and assembled components. Such systems are known as assembly shops. The general job shop scheduling problem, which no restrictions exist neither for the number of operations to be scheduled nor for the number of machines to be allocated, is considered at the present date intractable from the computational point of view, whatever the performance criterion used, due to the combinatorial explosion inherent to the scheduling process. It means that there is not an efficient computational method that solves globally real size instances of the problem within a satisfactory period of time. Due to this fact, in the last three decades several approximated and heuristic methods were created and evaluated for the problem. This research proposes and evaluate a new heuristic method which is based on the assumption that the improvement in operations synchronization at the assembly stations brings forth better achievement of due dates. The method implements two scheduling approaches: a backward approach satisfying due date completely and a forward approach satisfying capacity restriction completely. The two approaches work iteratively within two different simulation models of the production system - one deterministic and other probabilistic - in searching for operations synchronization improvement and due date achievement. The experimental results have shown the new method was better than the single-pass methods (rules) on average and as good as the better single-pass method (rule) tested.
\end{abstract}

Keywords: Job Shop Scheduling. Assembly Shop Systems. Combinatorial Optimization. Heuristics. Sequencing Rules. 


\section{LISTA DE ILUSTRAÇÕES}

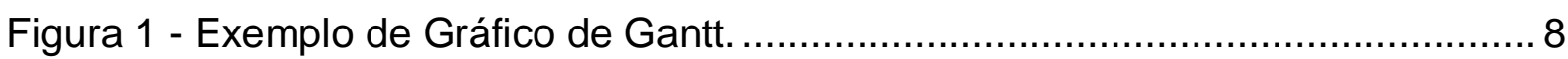

Figura 2 - Estrutura de materiais e operações. ……......................................... 19

Figura 3 - Grafo de estrutura de precedência de operações. ................................... 20

Figura 4 - Estruturas de materiais para as montagens A e B ................................... 21

Figura 5 - Gráfico da programação das montagens A e B. ................................... 23

Figura 6 - O sistema de produção estudado. ................................................... 27

Figura 7 - Programação job shop de duas ordens em três máquinas....................... 31

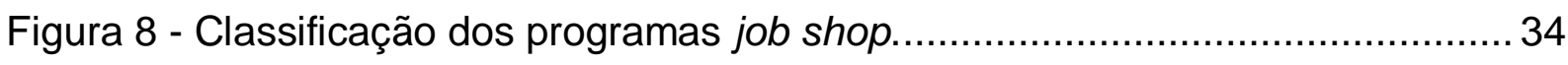

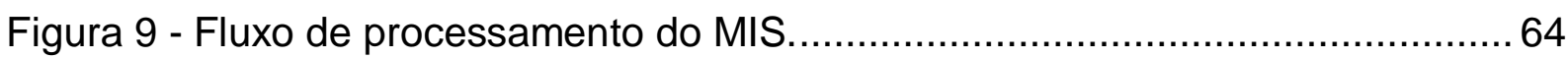

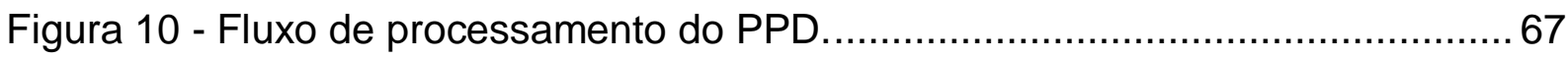

Figura 11 - Rolagem do horizonte e período de programação. ................................... 71

Figura 12 - Rotina geradora de operações...................................................... 73

Figura 13 - Estrutura de materiais e operações do exemplo................................... 75

Figura 14 - Modelo do sistema de programação iterativa.......................................... 94

Figura 15 - Modelo do sistema integrado de gestão da produção............................ 96

Figura 16 - O sistema de produção assembly-shop simulado ................................ 102

Figura 17 - Execuções do MIS no período de simulação. ..................................... 111

Figura 18 - Modelo de simulação computacional do sistema.................................. 112

Figura 19 - Fluxograma simplificado do modelo de simulação. ............................... 114

Figura 20 - Hierarquização da complexidade dos problemas job shop................... 161 


\section{LISTA DE GRÁFICOS}

Gráfico 1 - Estrutura Simples - Replicação № 1 ……….................................... 122

Gráfico 2 - Estrutura Simples - Replicação № 2 ……….................................. 123

Gráfico 3 - Estrutura Simples - Replicação № 3 ……….................................... 124

Gráfico 4 - Estrutura Simples - Replicação № 4............................................. 125

Gráfico 5 - Estrutura Simples - Replicação № 5 ……….................................. 126

Gráfico 6 - Estrutura Complexa - Replicação № 1 …………………................ 127

Gráfico 7 - Estrutura Complexa - Replicação № 2 ………................................ 128

Gráfico 8 - Estrutura Complexa - Replicação № 3 ………................................. 129

Gráfico 9 - Estrutura Complexa - Replicação № 4........................................... 130

Gráfico 10 - Estrutura Complexa - Replicação № 5 .............................................. 131 


\section{LISTA DE TABELAS}

Tabela 5.1 - Datas preliminares do exemplo. ................................................. 77

Tabela 5.2 - Valores da FO por regra.......................................................... 80

Tabela 5.3 - Parâmetros de execução do método................................................. 93

Tabela 6.1 - Fatores e níveis experimentais................................................ 99

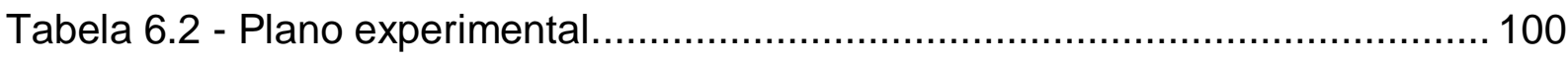

Tabela 6.3 - Valores dos parâmetros de execução. ....................................... 101

Tabela 6.4 - Funções de geração dos dados das instâncias................................ 106

Tabela 7.1 - Parâmetros complementares da simulação. .................................... 111

Tabela 7.2 - Atraso médio total (dias) - estruturas simples................................. 119

Tabela 7.3 - Atraso médio total (dias) - estruturas complexas............................ 120

Tabela 7.4 - Regras usadas no MIS - estruturas simples............................... 120

Tabela 7.5 - Regras usadas no MIS - estruturas complexas............................. 121

Tabela 7.6 - Estatísticas básicas - estruturas simples.................................... 132

Tabela 7.7 - Estatísticas básicas - estruturas complexas. .................................. 133

Tabela 7.8 - Análise de Variância - estruturas simples..................................... 134

Tabela 7.9 - Análise de Variância - estruturas complexas................................. 134

Tabela 7.10 - Teste de Tukey - estruturas simples............................................ 136

Tabela 7.11 - Teste de Tukey - estruturas complexas.................................... 137

Tabela 7.12 - Teste de Duncan - estruturas simples. .................................... 139

Tabela 7.13 - Teste de Duncan - estruturas complexas. .................................. 140 


\section{LISTA DE ABREVIATURAS}

\begin{tabular}{|c|c|}
\hline ATC & Apparent Tardiness Cost \\
\hline BD & Bottleneck Dynamics \\
\hline BDD & Earliest Job Due Date \\
\hline CAPM & Computer Aid Production Management \\
\hline CON & Constant \\
\hline CON-DYN & Dynamic Constant \\
\hline СРPT & Critical Path Processing Time \\
\hline CPPT-DYN & Dynamic Critical Path Processing Time \\
\hline CPFT & Critical Path Flow Time \\
\hline CPFT-ADJ & Adjusted Critical Path Flow Time \\
\hline COVERT & Cost over Time \\
\hline $\mathrm{CR}$ & Critical Ratio \\
\hline ECT & Earliest Completion Time \\
\hline EDD & Earliest Due Date \\
\hline EDF & Earliest Due Date First \\
\hline FEF & First Event First \\
\hline FIFO & First In First Out \\
\hline $\mathrm{GO}$ & Gerador de Ordens e Operações \\
\hline IR & Importance Ratio \\
\hline JDD & Job Due Date \\
\hline LBF & Low Bound on Flow Time \\
\hline LBT & Low Bound on Tardiness \\
\hline LFD & Latest Finish Time \\
\hline LF & Latest Finish Time \\
\hline LOF & Longest Operation Time First \\
\hline LP & Remaining Path Length \\
\hline LRF & Least Remaining Operation First \\
\hline LSF & Least Slack First \\
\hline
\end{tabular}




\begin{tabular}{ll} 
MIS & Mecanismo Iterativo de Simulação \\
MRF & Most Remaining Operation First \\
MS & Modified Slack \\
MSE & Mean Square Error \\
MSSM & Manufacturing System Simulation Model \\
NUSEG & Number of Unfinished Segments \\
ODD & Operation Due Date \\
ORIB & Number of Operations Remaining in Branch \\
OSD & Operation Synchronization Date \\
PPD & Procedimento de Programação Determinística \\
PPP & Procedimento de Programação Probabilística \\
PS & Período de Simulação \\
PT & Processing Time \\
RAND & Random \\
RAN & Random \\
RND & Random \\
ROPT & Remaining Operation Processing Time \\
ROPT & Remaining Operation Processing Time (versão 2) \\
RRO & Relative Number of Remaining Operations \\
RRP & Relative Remaining Processing Time \\
SPE & Selecionador de Parâmetros de Execução \\
SOF & Shortest Operation Time First \\
SOPN & Slack per Operation \\
SPT & Shortest Processing Time \\
TIS & Time in System \\
TWK & Dotal Work Content \\
TWK-DYN & Total Working Content Remaining \\
TWKR & \\
W & \\
& Teighted \\
\hline
\end{tabular}




\section{LISTA DE SÍMBOLOS}

\begin{tabular}{ll}
$i, i^{*}$ & Índice da operação \\
$j$ & Índice da ordem ou pedido \\
$k$ & Índice do recurso produtivo (máquina ou montador) \\
$t$ & Índice do instante ou data atual \\
$s$ & Índice do item ou segmento da estrutura de materiais \\
$\iota, \tau$ & Índice da iteração \\
$r_{j}$ & Data de liberação \\
$d_{j}$ & Data de entrega \\
$p_{j}, p_{i j}, p_{i s}^{j}$ & Tempo determinístico de processamento \\
$W_{j}, w_{i j}, w_{i s}^{j}, Q_{i}, w_{k}^{t}$ & Tempo de fila \\
$n_{j}, n_{k}^{t}$ & Número total de operações \\
$C_{j}$ & Data da conclusão \\
$F_{j}$ & Tempo de fluxo \\
$L_{j}$ & Desvio de data de entrega \\
$T_{j}$ & Atraso de conclusão ou de atendimento \\
$E_{j}$ & Atraso médio de atendimento \\
$\bar{F}$ & Tempo médio de fluxo \\
$N$ & Número total de ordens ou de componentes de uma montagem \\
$C_{\max }$ & Data máxima de conclusão (makespan) \\
$\bar{T}_{\text {max }}$ & Atraso de atendimento \\
\hline &
\end{tabular}




\begin{tabular}{|c|c|}
\hline J & Conjunto das ordens \\
\hline M & Conjunto das máquinas \\
\hline$O_{t}, O$ & Conjunto das operações \\
\hline $\mathrm{J}_{j}$ & Ordem \\
\hline $\mathrm{M}_{m}$ & Máquina \\
\hline $\mathrm{O}_{i j}, o_{i j k}$ & Operação \\
\hline$\overline{E M}$ & Espera media de montagem \\
\hline$d_{i s}^{j}$ & Data estimada de término da operação \\
\hline$R_{n}(j)$ & Ramificação \\
\hline$R_{n}^{*}(i, s, j)$ & Subconjunto das operações não iniciadas de $R_{n}(j)$ \\
\hline$R_{n}(i, s, j)$ & Subconjunto das operações não iniciadas de $R_{n}(j)$ \\
\hline$O R$ & Conjunto das operações restantes \\
\hline$O P$ & Conjunto das operações programáveis \\
\hline$P P$ & Programa parcial \\
\hline$a_{i}$ & Data-mais-cedo (potencial) de início da operação \\
\hline$\theta_{k}$ & Data de liberação do recurso produtivo \\
\hline$\sigma_{i}, \sigma^{*}$ & Data programada (potencial) de início da operação \\
\hline$d_{i^{i}}^{i n i}$ & Data programada de início da operação \\
\hline$d_{i^{r}}^{\text {term }}$ & Data programada de término da operação \\
\hline$N\left(R_{n}(i, s, j)\right)$ & Número de operações do conjunto $R_{n}(i, s, j)$ \\
\hline $\mathrm{H}$ & Horizonte de programação \\
\hline $\mathrm{T}$ & Período de programação \\
\hline$\overline{T_{H}^{-}}$ & Atraso médio total \\
\hline$N_{H}$ & Número de ordens atrasadas \\
\hline$F(l)$ & Valor da função-objetivo \\
\hline
\end{tabular}




$\begin{array}{ll}\varepsilon_{t} & \text { Percentual de melhoria } \\ \varepsilon_{\min } & \text { Percentual mínimo de melhoria } \\ \eta_{\lim } & \text { Número limite de iterações consecutivas } \\ \eta_{c o n s e c} & \text { Número de iterações consecutivas } \\ \eta_{t} & \text { Número atual de iterações } \\ \eta_{\max } & \text { Número máximo de iterações permitidas } \\ \mathscr{P}_{(.)} & \text {Distribuição normal de probabilidades } \\ f_{i s}^{j} & \text { Tempo determinístico de fluxo } \\ q_{s}^{j} & \text { Necessidade líquida (quantidade a produzir) } \\ s t_{i s} & \text { Tempo-padrão de ciclo } \\ \pi_{i s}^{j} & \text { Tempo probabilístico de processamento } \\ \delta_{i s} & \text { Variação estocástica sobre o tempo de processamento } \\ \phi_{i s}^{j} & \text { Tempo probabilístico de fluxo } \\ \lambda & \text { Fator de permissão } \\ \alpha & \text { Fator de suavização; nível de significância } \\ t_{f} & \text { Final do dia de simulação } \\ \bar{T}_{t_{f}} & \text { Númeraso médio de atendimento } \\ \mu & \text { Média populacional } \\ f & \text { Número de graus de liberdade } \\ a, p & \mathrm{n}\end{array}$




\section{SUMÁRIO}

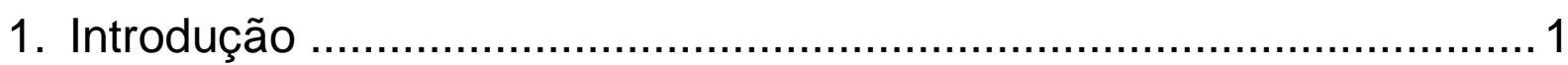

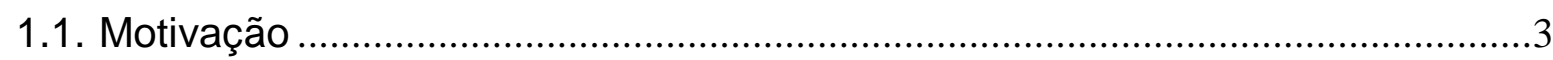

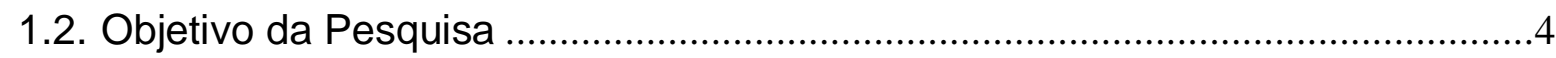

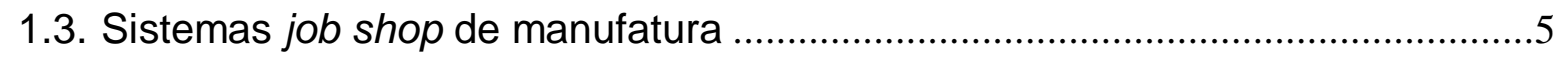

1.4. Programação de operações em sistemas job shop de manufatura .....................6

2. Conceitos-Chave ...................................................................... 9

2.1. Conceitos-chave e o caso geral do problema job shop......................................9

2.2. O efeito da estrutura de materiais na programação job shop: o caso dos

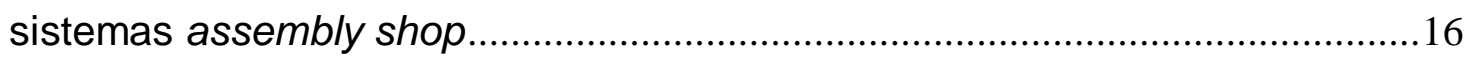

3. Definição do Problema ................................................................25

3.1. Características do sistema e restrições de roteiro e da fábrica ...........................25

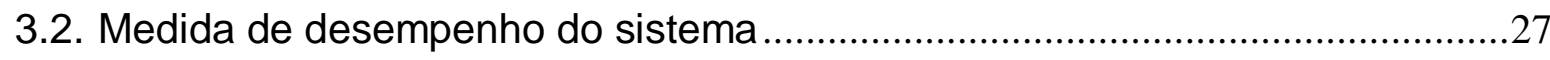

4. Métodos Heurísticos Baseados em Regras de Priorização para a Solução do Problema de Programação Assembly Shop....................28

4.1. Programação determinística de operações em sistemas job shop estáticos...29

4.2. Sequenciamento de operações em sistemas assembly shop estocásticos .....40

4.3. Abordagem estática de programação em sistemas assembly shop estocásticos.

5. Descrição do Método de Solução Proposto ...................................62

5.1. Mecanismo de simulação iterativa da programação ............................................63

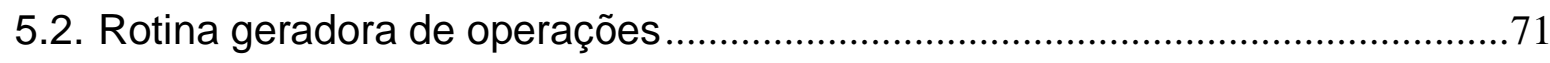

5.3. Rotina backward de programação de operações .................................................74

5.4. Rotina forward de programação de operações ……………………..................78

5.5. Regras de priorização usadas pela rotina forward................................................ 86

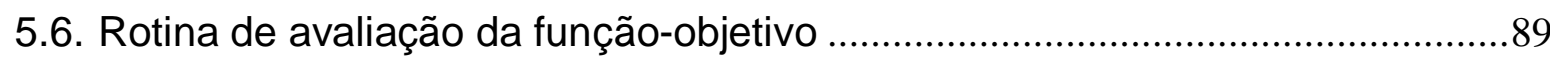

5.7. Atualização das estimativas de tempo de fila ....................................................

5.8. Parâmetros de execução do método ..................................................................92

5.9. Sistema de programação baseado em simulação iterativa..................................93 


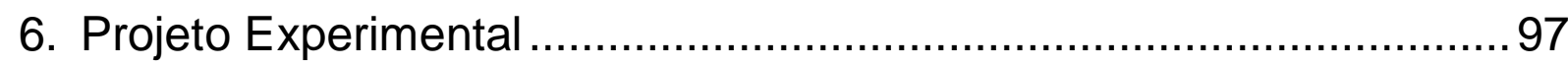

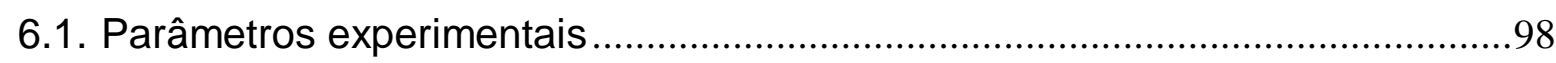

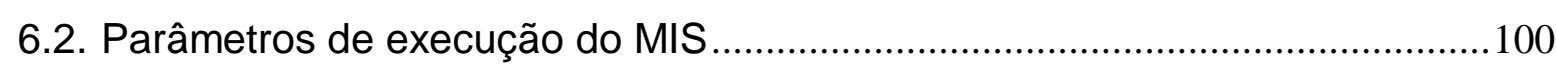

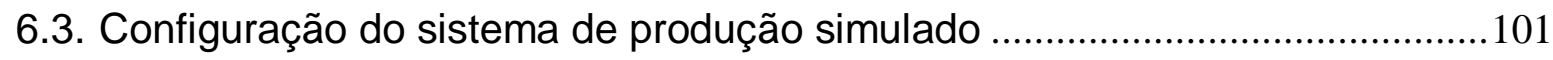

6.4. Especificação dos modelos de geração das instâncias .....................................103

7. Simulação e Análise dos Resultados............................................ 108

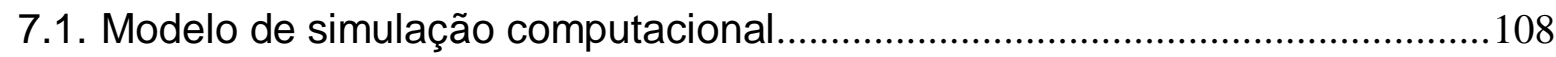

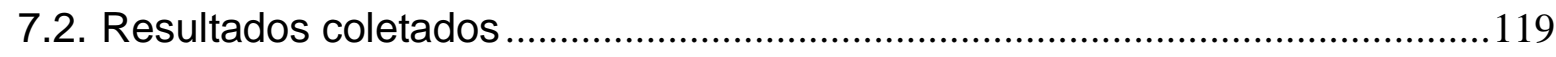

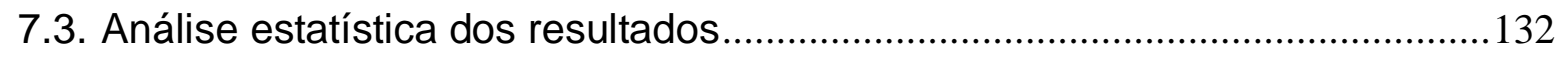

8. Conclusão e Proposições ......................................................... 142

9. Referências Bibliográficas.......................................................... 144

Apêndice A - Complexidade Computacional ................................... 151 


\section{Introdução}

A programação de operações (operations scheduling) em sistemas job shop de manufatura é um problema clássico da Pesquisa Operacional tendo recebido muita atenção da comunidade científica nas últimas cinco décadas, fato este traduzido em uma grande quantidade de pesquisa publicada neste período.

Segundo PINEDO (2002), a programação passou a ser considerada seriamente na manufatura no início do Século XX com o trabalho de Henry Gantt e outros pioneiros. Entretanto, passaram-se muitos anos para que as primeiras publicações que tratassem cientificamente do problema de programação aparecessem na literatura de Engenharia e Pesquisa Operacional. Os primeiros trabalhos apareceram em meados da década de 1950. Durante a década de 1960, uma quantidade significativa de pesquisa foi realizada usando a programação matemática como ferramenta de solução, notadamente pela aplicação das técnicas de programação dinâmica e inteira. Na década de 1970, influenciada pelos trabalhos da área da Complexidade Computacional, a pesquisa foi direcionada principalmente para a hierarquização da complexidade dos problemas de programação. A partir da década de 1980, diversas direções foram tomadas no âmbito acadêmico e na indústria para a solução do problema com o crescente aumento do interesse pelo problema de programação em sistemas dinâmicos e estocásticos.

Apesar de ser este um problema prático relevante, para HAX; CANDEA (1984, p.265), uma das principais razões que motivaram o meio acadêmico a despender grande esforço de pesquisa à programação job shop não está diretamente relacionada com a sua relevância prática, mas sim com a natureza combinatória do problema, que o torna intrinsecamente difícil de ser resolvido.

LAWLER et al. (1993) relatam que apenas para poucos casos especiais (instâncias) do problema existem algoritmos de solução exatos e eficientes, ou seja, 
algoritmos que resolvem o problema em tempo polinomial ou pseudo-polinomial, encontrando a solução exata (global). Infelizmente, para a indústria, os casos especiais são extremamente simples, longe de retratarem o problema real. O caso geral do problema - onde $n$ ordens quaisquer devem ser programadas em $m$ máquinas em um dado instante e sujeitas a um conjunto de restrições, o qual representa uma aproximação satisfatória dos sistemas reais, é intratável do ponto de vista computacional, independente da medida de desempenho (função-objetivo) adotada. Isto significa dizer que até o presente momento nenhum algoritmo eficiente foi desenvolvido para solucionar exatamente o problema.

Uma variante do problema job shop é a programação de operações em sistemas assembly shop. Neste tipo de sistema, itens com estruturas de materiais de variados níveis e com diversos componentes por nível são produzidos em sucessivas operações de fabricação e montagem. Devido às estruturas de materiais, as restrições de precedência resultam na redução do número de programas viáveis, o que poderia ser considerado uma vantagem. Entretanto, a otimização no caso assembly shop tende a ser mais árdua do que no caso job shop.

Esta dissertação está estruturada da seguinte maneira: nas Seções 1.1 e 1.2 são apresentados, respectivamente, a motivação e o objetivo da pesquisa; na Seção 1.3, é apresentada uma descrição resumida do ambiente job shop de manufatura. A Seção 1.4 apresenta o conceito de programação job shop. No Capítulo 2, são apresentados os conceitos-chaves para 0 entendimento do problema de programação em sistemas job shop e de sua variante, a programação em sistemas assembly shop, foco desta pesquisa. No Capítulo 3, o problema estudado na pesquisa é definido; o Capítulo 4 dedica-se a apresentar a revisão bibliográfica relevante para a condução do presente estudo. No Capítulo 5, o método heurístico proposto é apresentado e discutido. Os Capítulos 6, 7 e 8 descrevem, respectivamente, o método experimental, a simulação e análise dos resultados e, por fim, as conclusões do estudo. No Apêndice - A, o problema de programação job shop é discutido no âmbito da Teoria da Complexidade Computacional. 


\subsection{Motivação}

Apesar do grande número de artigos que investigam o problema de programação job shop, a maior parte aborda o problema para sistemas job shop simples. Neles, as operações de uma ordem são executadas em série, cada operação possui apenas uma única operação precedente e os itens não possuem estrutura de materiais, não ocorrendo operações de montagem.

Nos sistemas assembly shop, itens com estruturas de materiais de variados níveis e com diversos componentes por nível são produzidos em sucessivas operações de fabricação e de montagem. Cada item da estrutura possui um roteiro de produção específico. As operações são seriadas dentro de cada roteiro. Paralelamente às operações seriadas, ocorrem outras em outros itens que podem convergir para uma mesma operação de montagem. Devido às estruturas de materiais, as restrições de precedência resultam na redução do número de programas viáveis, o que poderia ser considerado uma vantagem. Entretanto, a otimização no caso assembly shop tende a ser mais árdua do que no caso job shop.

O estudo deste tipo de sistema de manufatura constitui o tema central desta pesquisa. $\mathrm{O}$ desafio imposto pela natureza combinatória do problema, sua relevância prática e o número relativamente pequeno de artigos publicados para este caso particular constituíram fontes de estímulo para o desenvolvimento deste estudo.

O autor considera que a investigação aprofundada deste tema em âmbito acadêmico é essencial para a busca de métodos cada vez mais eficientes de gestão e de controle de sistemas reais. 


\subsection{Objetivo da Pesquisa}

Nesta pesquisa é estudado o problema de programação em sistemas job shop de manufatura onde os itens finais são produzidos através de sucessivas operações de montagem a partir de componentes individuais fabricados. Tais sistemas são encontrados na literatura acadêmica sob a denominação de assembly shops.

O primeiro e principal objetivo da pesquisa é desenvolver um método heurístico que programe operações em sistemas assembly shop de modo a minimizar o atraso de entrega de pedidos.

O segundo objetivo da pesquisa é construir um modelo de simulação computacional de um sistema assembly shop com o propósito de avaliar o desempenho do método. 


\subsection{Sistemas job shop de manufatura}

O job shop de manufatura pode ser definido com um tipo de instalação fabril projetada para trabalhar com a máxima flexibilidade na produção de pequenos lotes de uma grande variedade de itens construtivamente diferentes, altamente especializados e personalizados, muitas vezes fabricados sob encomenda. A produção é executada por máquinas de propósito geral arranjadas por processo (layout por processo) e a mão-de-obra é intensiva (GROOVER, 2001, p.4). Em geral, o controle do fluxo de materiais é realizado com o auxílio de ordens de produção, sendo que cada ordem deve seguir um roteiro de produção pré-estabelecido. Basicamente, o roteiro de produção contém o conjunto de operações a ser executado, a sequência de execução das operações, as máquinas onde as operações devem ser executadas e os tempos de processamento (preparação e execução) das operações em cada máquina.

O sistema ou processo job shop de manufatura corresponde ao conjunto das máquinas, as ordens de produção e suas operações, as restrições relacionadas às ordens e à fábrica e os fluxos de materiais resultantes (CONWAY; MAXWELL; MILLER, 1967, p.5).

HAX; CANDEA (1984, p.261) distinguem entre dois tipos de sistemas job shop: o aberto e o fechado. No sistema job shop aberto, os itens são produzidos sob encomenda e normalmente nenhum estoque é mantido. Nos sistemas job shop fechados, a demanda pode ser prevista, os itens são produzidos em lotes e mantidos em estoque até a venda.

Os sistemas job shop de manufatura ocorrem comumente na prática em diversos tipos de indústria, tais como a indústria de móveis, o segmento metal-mecânico fornecedor das indústrias aeroespacial, de defesa, automotiva, de eletrodomésticos, de bens de capital, de entretenimento e lazer. São exemplos de produtos fabricados neste tipo de sistema ${ }^{1}$ :

\footnotetext{
${ }^{1}$ Vide GROOVER (2001) e BUFFA; SARIN (1987).
} 
a. Componentes de sistemas de combustão, transmissão de potência, resfriamento e frenagem de veículos automóveis, tais como, locomotivas, carros, caminhões e motocicletas.

b. Componentes de sistemas de propulsão a jato de aviões e foguetes.

c. Motores elétricos.

d. Componentes de satélites.

e. Componentes de sistemas de transmissão de navios e submarinos.

f. Componentes de bicicletas.

g. Subsistemas eletromecânicos de lavadoras de louças, lavadoras de roupas, fornos convencionais, fornos de microondas, processadores de alimentos, refrigeradores e outros utensílios domésticos.

h. Máquinas-ferramentas.

i. Bombas hidráulicas.

j. Equipamentos para construção civil.

k. Componentes de brinquedos eletromecânicos de grande porte usados em parques temáticos.

I. Móveis.

m. Lâmpadas especiais.

Os exemplos acima correspondem a uma pequena amostra de um universo bem maior de itens produzidos neste tipo de sistema de produção.

\subsection{Programação de operações em sistemas job shop de manufatura}

A programação é um processo de tomada de decisão que desempenha papel crucial na manufatura e nos serviços. No competitivo ambiente de negócio atual, a programação eficiente tornou-se pré-requisito para sobrevivência no mercado. As empresas devem esforçar-se para atender às datas de entrega firmadas com seus clientes, sob pena de perdas no relacionamento comercial. Concomitantemente, elas devem programar as atividades de maneira a alcançar o uso eficiente dos recursos disponíveis (PINEDO, 2002). 
Especificamente, em sistemas job shop de manufatura, a programação corresponde a associar uma data de início e uma data de término de execução a cada operação a ser realizada em um conjunto de máquinas, respeitando-se as relações de precedência entre as operações, assim como outras restrições operacionais.

$\mathrm{Na}$ literatura, os termos programação e sequenciamento estão ambos associados ao problema de programação job shop. O sequenciamento de operações corresponde a estabelecer a ordem de execução das operações que estão em fila aguardando processamento em frente à máquina (HAX; CANDEA, 1984, p.264).

A principal saída do processo de programação é o programa de produção que corresponde a uma ordenação das operações nas máquinas com as respectivas datas programadas de início e término (HAX; CANDEA, 1984, p.259).

Uma das formas mais utilizadas de representação dos relacionamentos entre operações e máquinas em um programa de produção é o gráfico de Gantt (BAKER, 1974, p.4). Na sua forma básica, o gráfico de Gantt mostra a alocação de recursos ao longo do tempo. A Figura 1 apresenta um exemplo de gráfico de Gantt extraído de BAKER (1974, p.180) onde é mostrado o perfil de alocação de três máquinas. Na figura, as máquinas aparecem ao longo do eixo vertical e a escala de tempo aparece ao longo do eixo horizontal. O gráfico consiste de uma coleção de blocos, cada qual identificado pela terna ordem-operação-máquina. O comprimento de cada bloco representa o tempo de processamento associado a cada operação. Os espaços não preenchidos por blocos ao longo da escala de tempo representam períodos de ociosidade dentro do qual a máquina não está executando nenhuma operação (BAKER, 1974, p.179).

BUFFA; SARIN (1987, p.286) apresentam alguns dos possíveis usos dos resultados do processo de programação:

i. No nível mais abrangente do planejamento de capacidade, simular a execução de ordens no chão-de-fábrica com o objetivo de revelar gargalos e a necessidade de capacidade.

ii. Em base diária, determinar a rotina de liberação de ordens. 
iii. Em decisões relacionadas à aceitação de pedidos, determinar datas de entrega (promising) e estabelecer mixes de produção.

iv. Desenvolver procedimentos de sequenciamento de operações nas máquinas.

O método heurístico desenvolvido nesta pesquisa tem o objetivo de servir aos quatro propósitos descritos acima. A discussão de como tais propósitos podem ser atendidos é feita ao longo dos capítulos seguintes.

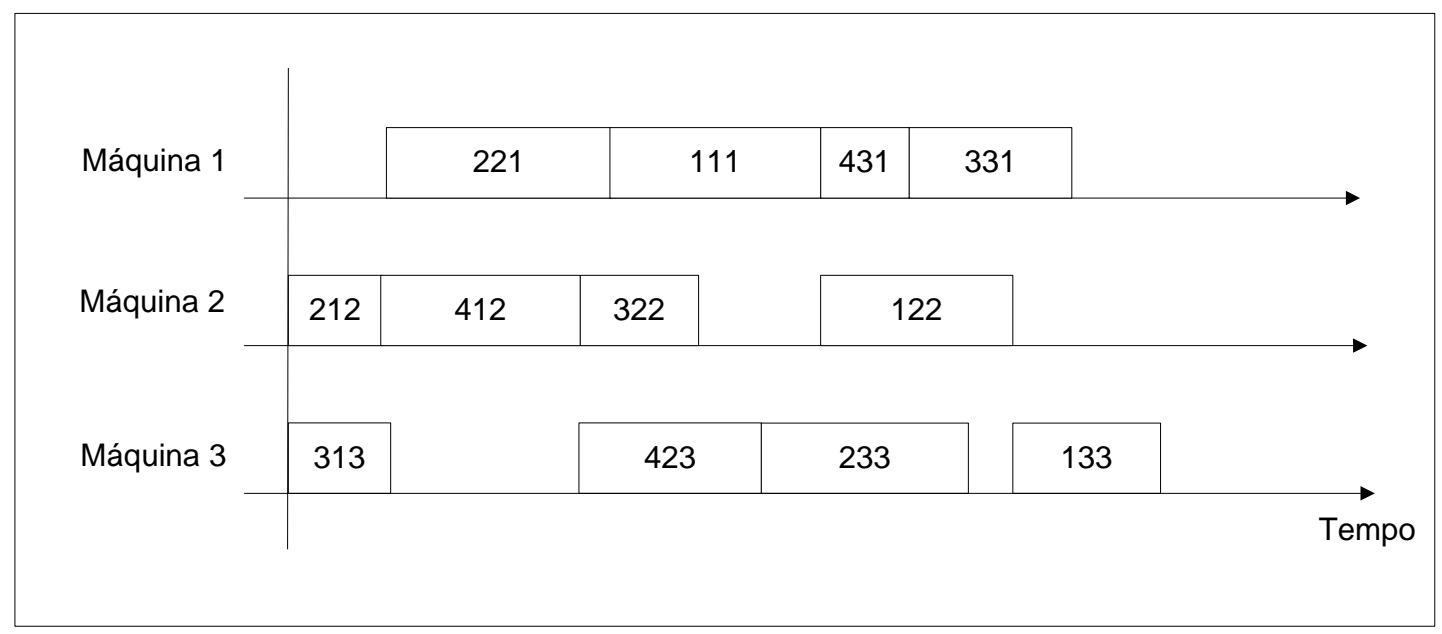

Figura 1 - Exemplo de Gráfico de Gantt. 


\section{Conceitos-Chave}

Neste capítulo é apresentado e discutido o caso geral do problema de programação job-shop e o efeito das restrições de precedência impostas pela estrutura de materiais na programação da produção, que é o caso específico dos sistemas assembly-shop.

\subsection{Conceitos-chave e o caso geral do problema job shop}

\subsubsection{Noções básicas}

No contexto dos sistemas assembly shop as seguintes definições podem ser feitas:

i. A operação é uma tarefa elementar a ser realizada.

ii. A fabricação é a operação de transformação de uma peça (item individual) por usinagem, conformação, tratamento térmico e outras formas que não a montagem.

iii. A montagem é a operação de reunir as peças (itens individuais) de um dispositivo, de um mecanismo ou de qualquer objeto suficientemente complexo, de modo a produzir um item montado (submontagem ou montagem final).

iv. A ordem é um conjunto de operações interrelacionadas por restrições de precedência derivadas de restrições tecnológicas. As restrições definem o roteiro de produção.

v. A ordem é constituída de um lote de itens idênticos cada qual devendo ser processado da mesma maneira. O tamanho do lote corresponde à quantidade de itens no lote. 
vi. O tempo de ciclo da operação é o tempo requerido para processar a operação em um único item do lote. O tempo de processamento da operação e a tempo requerido para processar o lote completo.

vii. A máquina é um dispositivo, aparelho ou recurso mecânico capaz de realizar a operação.

viii. O operador é o recurso humano que interage com a máquina na realização da operação, controlando a execução da operação na máquina e realizando tarefas complementares tais como, limpeza (teardown), inspeção e preparação (setup) de máquina, que podem ou não ser relevantes para o processo de programação.

ix. O montador é o recurso humano responsável pela operação de montagem.

x. A fábrica é uma instalação industrial, equipada com máquinas, operadores e montadores, arranjados em centros de produção, que executam operações de fabricação e montagem para produzir itens individuais e montados. Neste contexto, a fábrica corresponde à infra-estrutura do sistema assembly shop.

\subsubsection{O caso geral do problema job shop}

Segundo CONWAY; MAXWELL; MILLER (1967, p.103):

"O caso geral do problema de programação job-shop é um desafio fascinante. Apesar de ser facilmente definido, e de se visualizar o que é exigido (para solucioná-lo), é extremamente difícil realizar algum progresso qualquer que seja a direção tomada rumo a uma solução. Muitas pessoas proficientes estudaram 0 problema e todas elas saíram essencialmente de mãos vazias. Uma vez que tais frustrações não são relatadas na literatura, o problema continua a atrair pesquisadores, os quais não acreditam que um problema tão simples de ser estruturado possa ser tão difícil (de ser solucionado), até que seja enfrentado."

O problema de programação job shop pode ser definido resumidamente da seguinte maneira: ordenar as operações a serem processadas em cada máquina, respeitando-se a um conjunto de restrições de roteiro e/ou da fábrica, objetivando 
otimizar alguma medida de desempenho que seja função da ordenação das operações (SALVADOR, 1978 apud HAX; CANDEA, 1984, p.258). No caso mais geral do problema, existem $m$ máquinas nas quais um conjunto de $n$ ordens (e respectivas operações) deve ser processado. Cada ordem é liberada para o chãode-fábrica em um determinado instante (que pode ou não ser conhecido) e tem suas operações específicas, roteiro, data de entrega e outros atributos já definidos. $O$ problema consiste em criar um plano (ou mais especificamente um programa) onde as ordens individuais (ou, mais precisamente, as operações) são alocadas temporalmente de maneira a otimizar alguma medida de desempenho relacionada às ordens ou à fábrica (HAX; CANDEA, 1984, p.264).

\subsubsection{Restrições de roteiro e da fábrica}

Essencialmente, as principais restrições relacionadas ao roteiro ou a fábrica podem ser de sete tipos ${ }^{1}$ :

a. Ociosidade. As ordens são alocadas às máquinas de maneira a permitir ou não a inserção de intervalos de tempo ociosos, ou seja, sem alocação.

b. Precedência. As ordens são alocadas às máquinas respeitando-se as restrições de precedência tecnológica, ou seja, uma operação não pode ser iniciada na máquina enquanto sua(s) precedente(s) não for(em) concluída(s).

c. Interrupção. Quando a interrupção é permitida, a operação sendo processada na máquina pode ser interrompida, a qualquer instante de seu curso de execução, para dar lugar à outra operação mais prioritária. Quando a interrupção não é permitida, a operação deve ser executada até sua conclusão.

d. Sobreposição. A programação pode ser feita considerando ou não sobreposição entre operações. A sobreposição encurta o caminho crítico de execução das operações, produzindo programas mais enxutos. A sobreposição pode ser realizada através do fracionamento do lote de produção em lotes menores que são movidos para a próxima máquina do

\footnotetext{
${ }^{1}$ Esta classificação basea-se na compilação de trechos dos textos de (CONWAY et al., 1967); (HAX;CANDEA, 1984) e (PINEDO, 2002).
} 
roteiro tão logo sejam formados. Com isto, não é necessário que todo o lote de produção seja processado integralmente na máquina antes de ser transferido para a máquina subsequente.

e. Intercambialidade. Quando existe a possibilidade da operação ser executada em qualquer máquina de um grupo de máquinas elegíveis (alternativas), o sistema de produção é dito flexível. Neste caso a máquina onde a operação deverá ser executada não está preestabelecida (fixa) no roteiro de produção da ordem e pode ser escolhida de um conjunto finito de máquinas (elegíveis) no momento da alocação da ordem.

f. Disponibilidade. A máquina pode estar continuamente disponível (desconsiderando a existência de turnos, feriados, dias úteis e manutenções) ou respeitar a um calendário de programação no qual as paradas de produção são previstas.

g. Simultaneidade. Mais do que uma operação pode ser executada simultaneamente na máquina.

\subsubsection{Medidas de desempenho da ordem e do sistema}

CONWAY; MAXWELL; MILLER (1967, p.9) distinguem entre dois tipos de variáveis que compõem o problema e servem para o cálculo da medida de desempenho do sistema:

i. Variáveis que definem o problema.

ii. Variáveis que descrevem a solução do problema.

As variáveis que definem o problema são dadas como parte da descrição do problema e, em geral, aparecem como atributos (parâmetros) da ordem. São elas:

i. Data de liberação $\left(r_{j}\right)$ : instante de liberação da ordem para o chão de fábrica realizado por algum processo externo de geração.

ii. Data de entrega $\left(d_{j}\right)$ : instante no qual alguma entidade externa ao sistema desejaria ter a ordem concluída no chão de fábrica. 
iii. Tempo de processamento $\left(p_{j}\right)$ : intervalo de tempo necessário para que todas as operações da ordem sejam concluídas, sendo formulado como:

$$
p_{j}=\sum_{i=1}^{n_{j}} p_{i j}
$$

onde $p_{i j}$ é o tempo de processamento da operação $i$ da ordem $j$.

Segundo CONWAY; MAXWELL; MILLER (1967, p.11), a principal variável que descreve a solução de um problema de programação é a espera ou fila $\left(W_{j}\right)$. $O$ tempo de fila corresponde à soma dos intervalos de tempo nos quais as operações de uma ordem $j$ aguardam seus processamentos, desde o instante em que a ordem é liberada na fábrica até a execução de sua última operação, sendo formulado como

$$
W_{j}=\sum_{i=1}^{n_{j}} w_{i j}
$$

onde $w_{i j}$ é o tempo de fila da operação $i$.

O programa de produção pode ser completamente determinado se $W_{j}$ é dado. Com base nesta variável outras podem ser definidas. As principais variáveis que derivam de $W_{j}$ e, portanto, podem ser utilizadas para descrever a solução do problema são:

i. Data de conclusão $\left(C_{j}\right)$ : instante no qual efetivamente a ordem (ou operação) é concluída ou deixa o sistema, formulado como

$$
C_{j}=r_{j}+p_{j}+W_{j}
$$


ii. Tempo de fluxo $\left(F_{j}\right)$ : intervalo de tempo que a ordem (ou operação) leva para deixar o sistema desde o momento de sua liberação até a sua conclusão, formulado como

$$
F_{j}=C_{j}-r_{j}
$$

iii. Desvio da data de entrega $\left(L_{j}\right)$ : variação de tempo (positiva ou negativa) calculada pela diferença entre a data de conclusão da ordem (ou operação) e sua data de entrega, formulado como

$$
L_{j}=C_{j}-d_{j}
$$

iv. Atraso de conclusão ou atendimento $\left(T_{j}\right)$ : formulado como:

$$
T_{j}=\max \left\{0, L_{j}\right\}
$$

v. Antecipação de conclusão ou atendimento $\left(E_{j}\right)$ : formulado como

$$
E_{j}=\max \left\{0,-L_{j}\right\}
$$

HAX; CANDEA (1984, p.271) descrevem que em um sistema job shop, cada ordem (ou operação) é associada a um valor específico dado por cada uma das variáveis $W_{j}, C_{j}, F_{j}, L_{j}, T_{j}, E_{j}$. Portanto, o desempenho individual de cada ordem (ou operação) pode ser avaliado através destas variáveis. De modo a caracterizar o desempenho global do sistema, estes valores individuais devem ser somados para formar alguma medida agregada de desempenho. As medidas mais comumente usadas são: o valor médio, o valor máximo e algumas vezes a variância ou o desvio padrão do tempo de fluxo, do tempo de conclusão, do desvio da data de entrega e do atraso de conclusão calculados sobre todas as ordens do conjunto programado. O programa que minimiza uma destas medidas é ótimo com relação a 
ela. Se as ordens não são iguais em importância (ordens com maior prioridade de conclusão que outras), a cada uma delas é associado um fator ponderador que é, então, incorporado na medida de desempenho.

As formulações de algumas das medidas citadas acima são apresentadas a seguir.

i. Tempo médio de fluxo $(\bar{F})$, formulado como

$$
\bar{F}=\frac{1}{N} \sum_{j=1}^{N} F_{j}
$$

ii. Data máxima de conclusão ou makespan $\left(C_{\max }\right)$, formulada como:

$$
C_{\max }=\max \left\{C_{j}\right\}
$$

iii. Atraso médio de atendimento $(\bar{T})$, formulado como:

$$
\bar{T}=\frac{1}{N} \sum_{j=1}^{N} T_{j}
$$

iv. Atraso máximo de atendimento $\left(T_{\max }\right)$, formulado como:

$$
T_{\max }=\max \left\{T_{j}\right\}
$$

\subsubsection{Outras formas de definição do problema job shop}

PINSON (1995) apresenta uma definição restrita do caso geral do problema job shop: o conjunto $\mathrm{J}$ de $N$ ordens $\mathrm{J}_{1}, \mathrm{~J}_{2}, \mathrm{~J}_{j}, \ldots, \mathrm{J}_{N}$ deve ser processado, em um dado instante, no conjunto $M$ de $m$ diferentes máquinas $M_{1}, M_{2}, \ldots, M_{m}$. A ordem $J_{j}$ 
consiste de uma sequência de $n_{j}$ operações $\mathrm{O}_{1 j}, \mathrm{O}_{2 j}, \ldots, \mathrm{O}_{i j}, \ldots, O_{i n_{j}}$ que devem ser programadas nesta sequência. Além disso, cada operação pode ser processada apenas por uma máquina entre as $m$ disponíveis. A interrupção de operação não é permitida. A operação $O_{i j}$ tem o tempo de processamento $p_{i j}$. $O$ objetivo é encontrar uma sequência de operações para cada máquina tal que minimize alguma medida de desempenho e de tal maneira que duas operações nunca sejam processadas simultaneamente na mesma máquina.

Em uma definição mais geral, o problema pode ser descrito em termos das operações em vez das ordens da seguinte maneira: em um dado instante $\boldsymbol{t}$, denominado instante de programação, ordenar as operações do conjunto $O_{t}=\left\{o_{i j k}^{t} \mid i=1, \ldots, n_{j} ; j=1, \ldots, N ; k=1, \ldots, m\right\}$, respeitando-se a um conjunto preestabelecido de restrições de ociosidade, precedência, interrupção, intercambialidade, sobreposição, disponibilidade e simultaneidade, objetivando otimizar uma ou mais medidas de desempenho do sistema relacionadas à ordenação das operações. O conjunto $O_{t}$ corresponde a todas as operações

elegíveis (programáveis) no instante $\boldsymbol{t} ; o_{i j k}^{t}$ identifica unicamente a operação; $\boldsymbol{i}$ identifica a operação da ordem $\boldsymbol{j} ; \boldsymbol{k}$ identifica a máquina. A programação corresponde a determinar as datas viáveis de início e término de cada operação do conjunto $O_{t}$.

\subsection{O efeito da estrutura de materiais na programação job shop: o caso dos sistemas assembly shop}

CONWAY; MAXWELL; MILLER (1967, p.243) descrevem um tipo de sistema job shop onde são permitidos roteiros estruturados na forma de árvores. Tais sistemas são por eles denominados assembly shop. Apesar de ser esta uma definição genérica que não explicita a natureza das operações envolvidas no processo, os pesquisadores descrevem um estudo investigativo conduzido por Maxwell 
(MAXWELL, 1965) para analisar o desempenho de certas regras de priorização ${ }^{1}$ (dispatching) em um ambiente job shop onde são realizadas tanto operações de fabricação quanto de montagem.

Muitos pesquisadores sucessores de Conway, Maxwell e Miller adotaram a denominação assembly shop para descrever sistemas job shop onde são realizadas, além de operações de fabricação, também operações de montagem em diversos níveis (vide (RUSSELL; TAYLOR III, 1985a e 1985b); (ADAM; BERTRAND; SURKIS, 1987); (FRY et al., 1989); (PHILIPOOM; RUSSELL; FRY, 1991) e (REEJA; REJANDRAN, 2000a e 2000b)). Em vista disto, o mesmo termo é adotado nesta pesquisa.

Um sistema assembly shop pode ser considerado uma generalização de um sistema job shop onde: 1) os roteiros de produção são estruturados na forma de árvores e 2) tanto operações de fabricação quanto de montagem são permitidas (CONWAY; MAXWELL; MILLER, 1967, p.243).

Nos sistemas job shop simples ("clássicos"), as operações de uma ordem são executadas em série, cada operação possui apenas uma única operação precedente e os itens não possuem estrutura de materiais, não ocorrendo operações de montagem.

Nos sistemas assembly shop, as operações seriadas ocorrem dentro do roteiro de cada componente da estrutura do produto final. Paralelamente a estas operações, ocorrem outras operações em outros componentes. O paralelismo é resultado de diversas operações simultâneas que produzem, separadamente, itens que podem convergir para uma mesma operação de montagem. Os produtos finais possuem estruturas de materiais com variados níveis e com diversos componentes por nível, cada qual com um roteiro de produção específico. Um item de um nível mais alto da estrutura não pode iniciar seu processamento até que todos os seus componentes sejam processados. Este tipo de estrutura de precedência introduz problemas relacionados à coordenação, sincronização e cadência de operações não existentes

\footnotetext{
${ }^{1}$ As regras de priorização determinam a sequência de alocação das operações nos recursos produtivos. Elas são descritas nos Capítulos 4 e 5.
} 
nos sistemas job shop simples, trazendo, como consequência, o aumento da complexidade do processo de programação (ADAM; BERTRAND; SURKIS, 1987).

A Figura 2 adaptada de REEJA; RAJENDRAN (2000a) apresenta um exemplo de estrutura de materiais com dois níveis de montagem onde as operações do roteiro de cada item são também incluídas. Os círculos representam as operações e os blocos identificam os itens produzidos em cada nível, sendo M1 a montagem final, S1 uma submontagem e F1, F2 e F3 componentes individuais fabricados. A quantidade de cada item-filho para cada unidade do item-pai é mostrada acima de cada bloco. Por exemplo, são necessários duas (x2) unidades de S1 e três (x3) de F3 para cada unidade produzida de M1. Os roteiros de produção de F1 e F3 são compostos por três operações cada, os roteiros de produção de S1 e F2 são compostos por duas operações cada e o roteiro de produção de M1 possui apenas a operação de montagem. Cada item e respectivas operações determinam um segmento da estrutura. Os pares F1-F2 e S1-F3 são produzidos paralelamente sendo necessários para o início da montagem de S1 e M1 respectivamente. Ainda, a estrutura apresenta três ramificações de operações. A primeira ramificação é formada pelas sequências de operações de $M 1$, S1 e F1 que totalizam seis operações. A segunda ramificação é formada pelas sequências de operações de $M 1$, S1 e F2 que totalizam cinco operações. A terceira ramificação é formada pelas sequências de operações de M1 e F3 que totalizam quatro operações.

A Figura 3 apresenta outra representação gráfica da estrutura de precedência de operações do exemplo. Nesta representação, a estrutura é substituída por um grafo direcionado e aberto, na forma de uma árvore. Cada nó representa uma operação; os índices do par $(i, \jmath)$ representam, respectivamente, a operação e a ordem; os $\operatorname{arcos}(i, j) \rightarrow(i+1, j)$ representam a sequência das operações e seus comprimentos representam o tempo de processamento da operação $i$ na ordem $j$. A ordem $j=1$ é colocada para a produção de M1 e demais componentes. Os nós em cinza correspondem às operações iniciais do processo de montagem de S1 e M1. O nó C corresponde ao nó de conclusão da ordem de M1.

Em sistemas job shop simples, o tempo de fluxo de uma ordem é resultante da soma dos: 
- Tempos de processamento das operações;

- Tempos de fila causados pela concorrência entre operações independentes.

Em sistemas assembly shop, o tempo de fluxo total de uma ordem é resultante da combinação dos:

- Tempos de fluxo de componentes individuais;

- Tempos de montagem;

- Tempos de fila causados pela concorrência entre montagens independentes;

- Tempos de fila causados pela falta dos componentes necessários para o início da montagem.

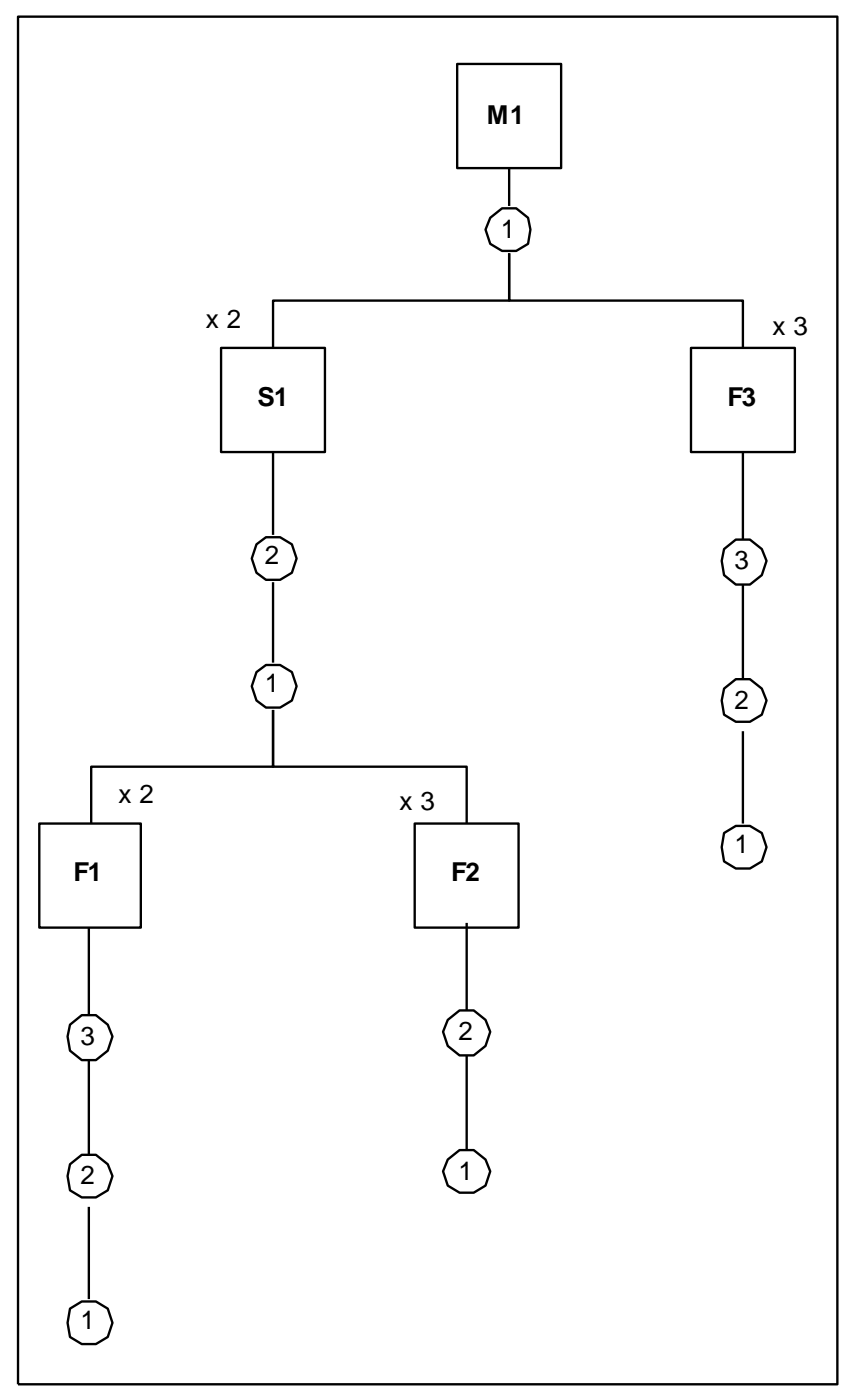

Figura 2 - Estrutura de materiais e operações. 
Esta última componente do tempo de fluxo total é denominada 'espera de montagem' por CONWAY; MAXWELL; MILLER (1967), sendo que este termo é adotado indistintamente para todos os níveis da estrutura de materiais onde ocorra a operação de montagem.

Segundo ADAM; BERTRAND; SURKIS (1987) e PHILIPOOM; RUSSEL; FRY (1991), a espera de montagem pode ser reduzida pela sincronização da conclusão dos componentes das montagens. Quanto maior a sincronização das operações nos diversos níveis da estrutura, menor deveria ser a espera de montagem e, por hipótese, menor deveria ser o atraso de atendimento das ordens de produção.

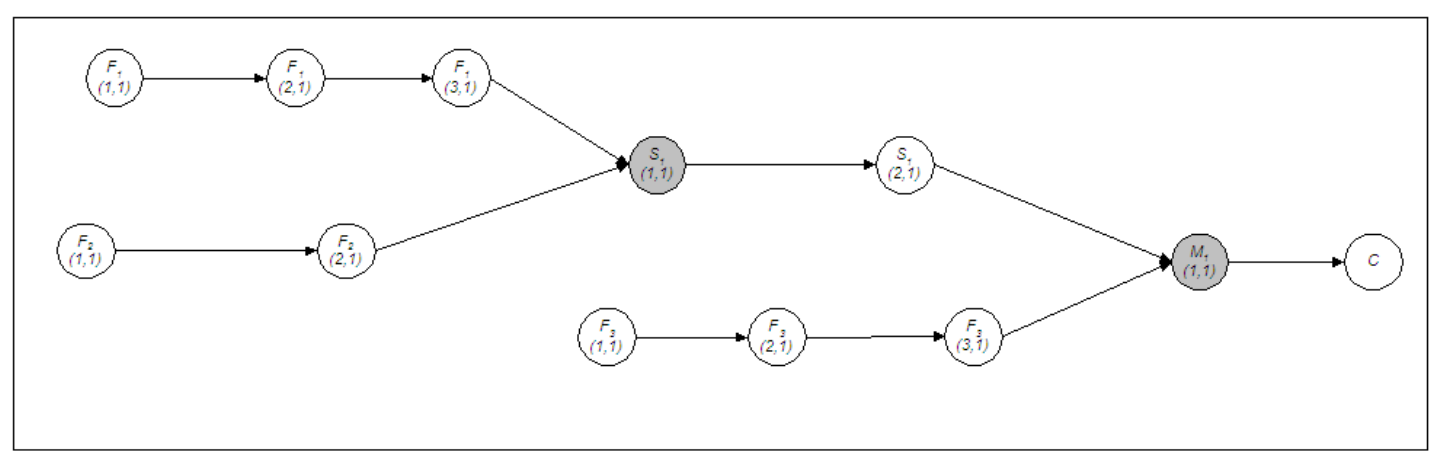

Figura 3 - Grafo de estrutura de precedência de operações.

O exemplo a seguir ilustra a ocorrência da espera de montagem na geração do programa de produção de duas montagens (A e B) que compartilham os mesmos recursos produtivos (máquinas e/ou mão-de-obra) e que estão disponíveis para programação no mesmo instante. As estruturas de ambas as montagens são apresentadas na Figura 4. A montagem A, por exemplo, é formada pelos componentes A1 e A2. As estruturas incluem as operações (círculos) e respectivas máquinas (M) ou centro de montagem (CM) onde devem ser executadas. Os tempos de processamento das operações nas máquinas $(\mathbf{M})$ e o tempo de montagem de $\mathbf{B}$ são todos iguais a uma unidade de tempo. O tempo de montagem de $\mathbf{A}$ é o dobro do tempo de montagem de $\mathbf{B}$.

No instante de liberação $\mathbf{t}$, uma ordem para cada uma das montagens é liberada no chão-de-fábrica $\left(r_{A}=r_{B}=t\right)$. As datas de entrega das ordens de $\mathbf{A}$ e $\mathbf{B}$ são, 
respectivamente, $d_{A}$ e $d_{B}$, sendo $d_{A}<d_{B}$. As ordens são alocadas nas máquinas seguindo a regra de priorização ORIB-BDD (FRY et al., 1989), a qual seleciona para execução na máquina a operação da ramificação com a menor quantidade de operações faltantes, usando a menor data de entrega da ordem como critério de desempate. Sendo esta uma regra de dispatching, uma operação disponível (na fila) deve ser sempre alocada à máquina quando esta se torna ociosa até que não existam mais operações para serem alocadas.

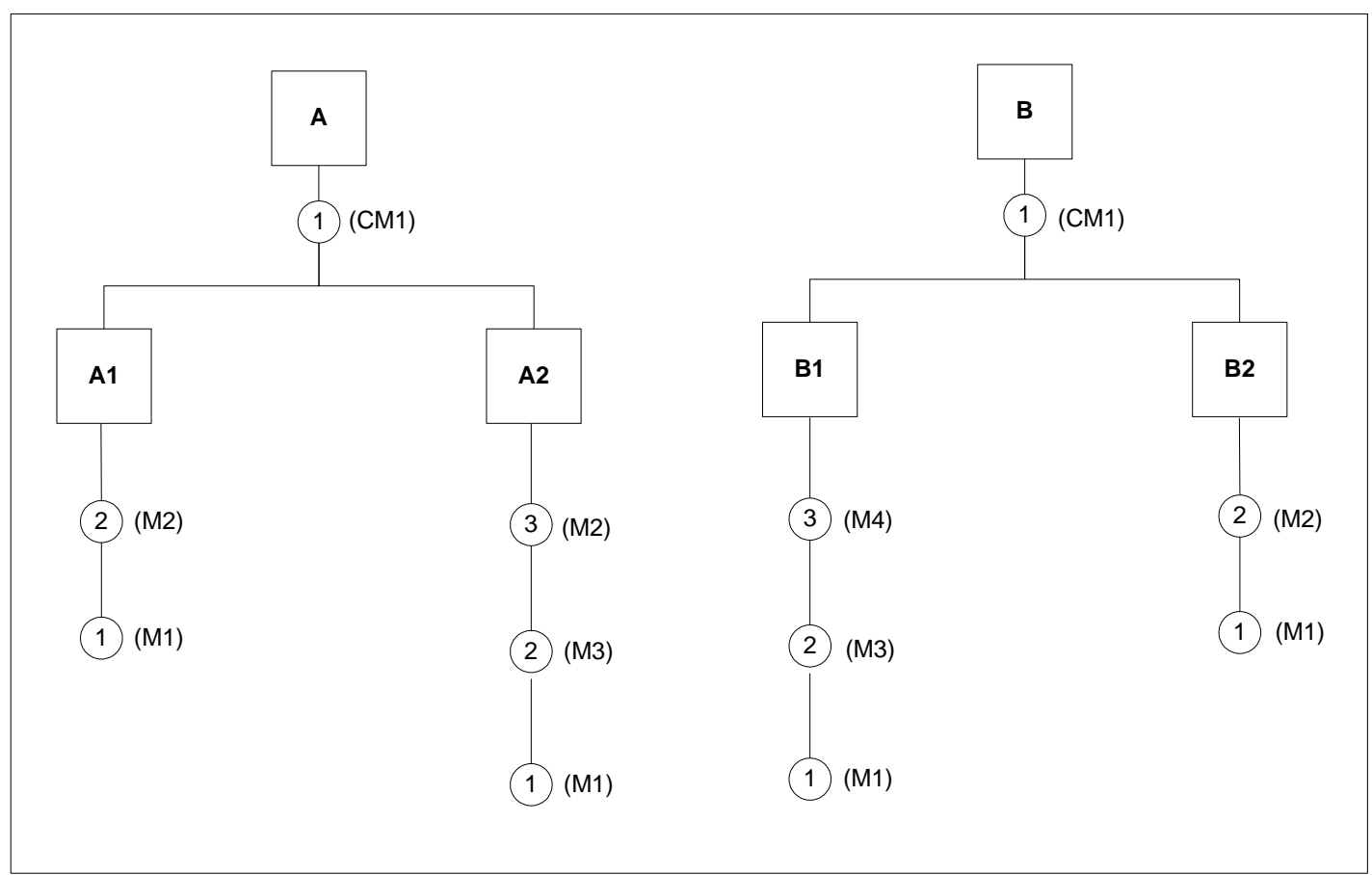

Figura 4 - Estruturas de materiais para as montagens A e B.

Cada estrutura de materiais possui duas ramificações, a saber:

a. A montagem A possui a ramificação formada pelas operações de $\mathbf{A}$ e $\mathbf{A} 1$, que totalizam três operações, e a ramificação formada pelas operações de $\mathbf{A}$ e $\mathbf{A} 2$, que totalizam quatro operações.

b. A montagem $\mathbf{B}$ possui a ramificação formada pelas operações de $\mathbf{B}$ e $\mathbf{B} 1$, que totalizam quatro operações, e a ramificação formada pelas operações de B e B2, que totalizam três operações. 
O programa de produção das duas montagens é apresentado graficamente na Figura 5.

Todas as máquinas estão disponíveis para alocação no início da programação.

O mecanismo de sequenciamento de operações é explicado a seguir, usando, como exemplo, as primeiras operações de todos os componentes.

Inicialmente, todos os componentes concorrem pela alocação na máquina M1. Aplicando-se apenas a regra ORIB, duas operações são selecionadas: a primeira operação de $\mathbf{A} 1$ (A1-1) e a primeira de B2 (B2-1). A1-1 pertence à ramificação que contém $\mathrm{A}$ (data de entrega $d_{A}$ ). B2-1 pertence à ramificação que contém $\mathbf{B}$ (com data de entrega $d_{B}$ ). Usando a regra de desempate BDD, A1-1 é selecionada primeiramente. B2-1 é a próxima selecionada para alocação na máquina M1. Em seguida, as operações A2-1 e B1-1 são alocadas sequencialmente em M1. O término de A1-1 libera A1-2 para execução. Neste instante, nenhuma outra operação está aguardando na fila de M2, portanto A1-2 é selecionada para ser executada em M2. A decisão de alocação de A1-2 em M2 ocorre simultaneamente à decisão de alocação B2-1 em M1. Até este instante, M3 e M4 continuam disponíveis e ociosas. A programação das demais operações segue exatamente o mesmo princípio. De fato, a regra de priorização é utilizada apenas na alocação das primeiras operações de A1-1, A2-1, B1-1 e B2-1, momentos onde ocorrem conflitos de alocação. Nos demais instantes de programação, apenas uma operação está disponível para alocação em cada máquina.

Este exemplo simples evidencia a ocorrência da espera de montagem em ambas as montagens A e $\mathbf{B}$. No caso de A, o componente $\mathbf{A} 1$ deve aguardar três unidades de tempo de execução até que o componente A2 esteja finalizado para que a montagem A possa iniciar. O caso de B é similar: o componente B2 deve aguardar o mesmo intervalo de tempo até que B1 esteja finalizado. Além da espera de montagem, a montagem $\mathbf{B}$ deve ainda aguardar o término da montagem $\mathbf{A}$ devido à concorrência pelo mesmo recurso CM1. Na Figura 4, os intervalos de espera máxima de montagem são graficamente mensurados pelos segmentos pontilhados. 
ADAM; BERTRAND; SURKIS (1987) formulam a espera de montagem como sendo a diferença entre a data de conclusão do primeiro componente que chega ao ponto de montagem e as datas de conclusão dos demais componentes. Eles introduzem também o conceito de espera média de montagem, aqui denotada por $\overline{E M}$ e formulada como

$$
\overline{E M}=\frac{1}{N} \times\left\{\left[C_{1}-C_{\min }\right]+\left[C_{2}-C_{\min }\right]+\ldots+\left[C_{N-1}-C_{\min }\right]\right\}
$$

onde $N$ é o número de componentes da montagem, $C_{\min }$ é a menor dentre todas as datas de conclusão dos $N$ componentes, $C_{1}$ é a segunda menor data de conclusão, e assim por diante. Obviamente, o impacto sobre o tempo de fluxo da montagem final é devido exclusivamente à parcela $\left[C_{N-1}-C_{\min }\right]$ a qual representa o intervalo entre a chegada do primeiro e do último componentes ao centro de montagem.

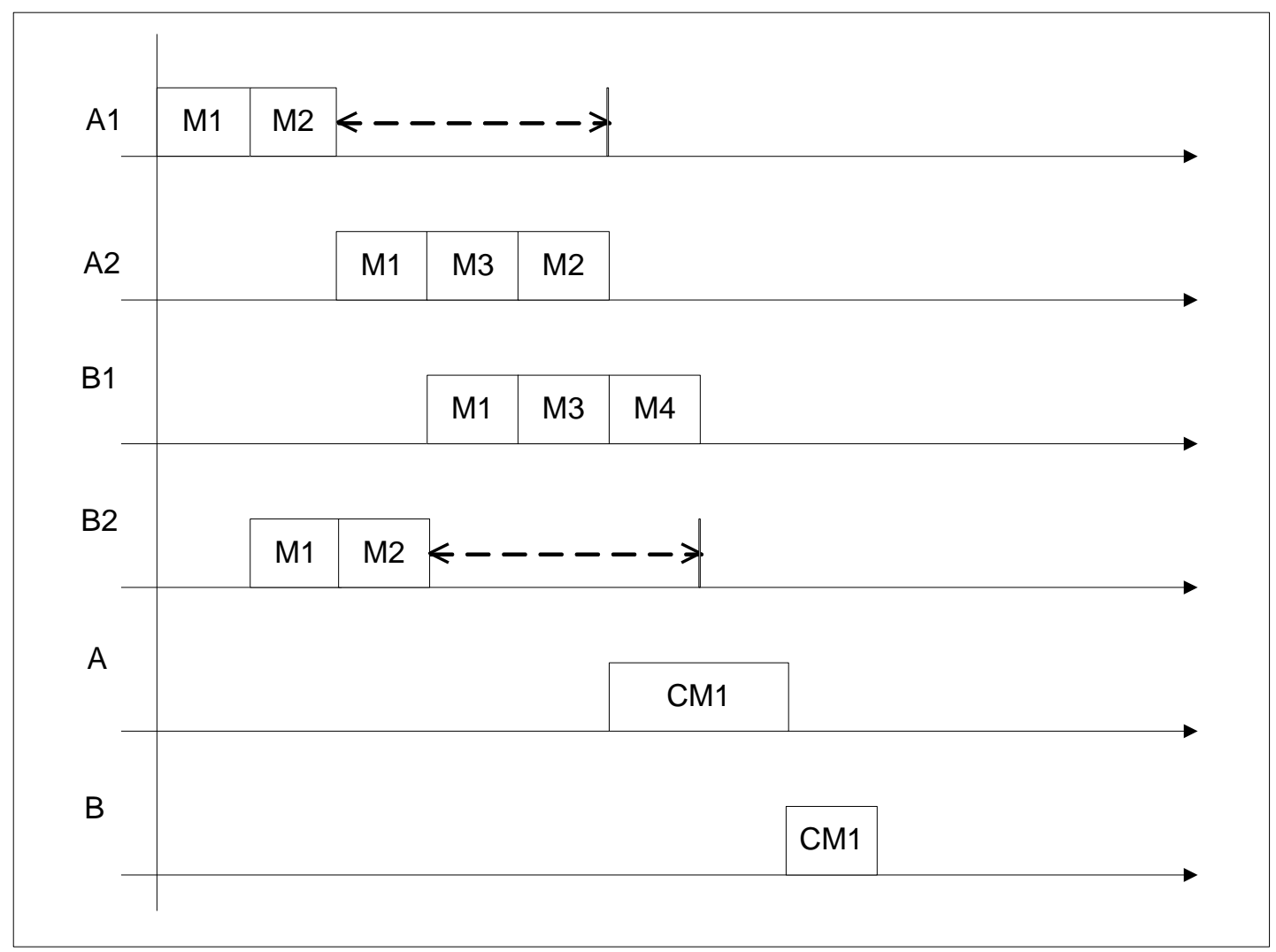

Figura 5 - Gráfico da programação das montagens A e B. 
A espera média de montagem é um critério de desempenho do sistema que objetiva mensurar o grau de sincronização na conclusão de operações de componentes de itens montados. Quanto maior a sincronização das operações nos diversos níveis de montagem menor deveria ser a espera para montagem e, por hipótese, menor deveria ser o atraso de atendimento das ordens de produção.

CONWAY; MAXWELL; MILLER (1967, p.243) sugerem que os sistemas assembly shops podem ser decompostos em subsistemas job shop simples e "independentes" os quais podem ser coordenados por meio de um sistema de datas de entrega. Apesar dos pesquisadores não evoluírem este raciocínio em seu estudo, o fato de sugerirem "[...] um sistema de datas de entrega [...]" define uma possível orientação no desenvolvimento de procedimentos de programação que busquem sincronizar a execução dos segmentos paralelos utilizando datas de entrega como parâmetros norteadores em sistemas assembly shop. Esta idéia é usada pelo método de programação proposto nesta pesquisa. 


\section{Definição do Problema}

Baseado nas definições do Capítulo 2, o problema estudado nesta pesquisa pode ser definido da seguinte maneira:

Em um sistema assembly shop, a cada instante $\boldsymbol{t}$, dito instante de programação, um conjunto $O_{t}$ de operações elegíveis deve ser programado, respeitando-se a restrições (de ociosidade, precedência, interrupção, intercambialidade, sobreposição, disponibilidade e simultaneidade) de roteiro e do sistema de produção, objetivando otimizar a medida de desempenho do sistema.

As características e restrições de roteiro e do sistema de produção, assim como a medida de desempenho do sistema, são apresentadas a seguir.

\subsection{Características do sistema e restrições de roteiro e da fábrica}

A programação das operações deve ser feita respeitando-se as seguintes características e restrições de roteiro e do sistema de produção:

a. O sistema de produção opera ininterruptamente.

b. Em intervalos pré-definidos (determinísticos), conjuntos de pedidos chegam ao sistema e devem ser programados e executados.

c. O número de pedidos de cada conjunto e a quantidade de itens finais (montagens) por pedido são variáveis aleatórias.

d. O sistema produz itens com estruturas de materiais. Os itens finais (montagens) são produzidos a partir de submontagens, estas a partir de subsubmontagens e assim por diante. Os componentes montados são também produzidos a partir de itens individuais também produzidos no sistema. 
e. Os itens finais e seus componentes são produzidos para atender exatamente as quantidades dos pedidos; nenhum estoque excedente é mantido no sistema.

f. O controle do fluxo de produção é feito com o auxílio de ordens de produção.

g. O padrão de liberação de ordens é determinístico e estático, ou seja, são conhecidos antecipadamente os instantes de liberação das ordens para o chão-de-fábrica e todas são liberadas ao mesmo tempo.

h. O sistema trabalha com dois tipos de recurso de manufatura: a máquina e o montador. Estes são os únicos recursos de capacidade limitada do sistema.

i. Os recursos estão continuamente disponíveis para alocação.

j. Os roteiros dos componentes individuais possuem várias operações. Os roteiros dos componentes montados e da montagem final possuem apenas a operação de montagem.

k. Os roteiros de produção são pré-definidos (fixos). Não existem recursos alternativos (intercambiáveis); cada operação pode ser executada somente no recurso pré-definido no roteiro de produção do item.

I. Os tempos de processamento das operações são variáveis aleatórias.

m. Os tempos de descanso dos operadores e montadores, de movimentação de materiais, preparação (setup), quebra, manutenção e limpeza das máquinas são variáveis aleatórias; quando relevantes para o processo de programação, estes tempos são incluídos como variações estocásticas dos tempos de processamento das operações.

n. Uma vez iniciada, a operação não pode ser interrompida.

o. Cada recurso pode realizar apenas uma operação por vez, ou seja, não existe processamento simultâneo de operações no recurso produtivo.

p. Não existe a possibilidade de inserção intencional de tempo ocioso na programação do recurso ou durante a sua operação; uma vez concluída uma operação outra deve ser alocada imediatamente.

q. A sobreposição de operações não é permitida, ou seja, o lote de produção do item deve ser processado integralmente no recurso antes de ser movido para o próximo recurso do roteiro.

r. A recirculação de ordens nos centros de produção é permitida, ou seja, o item pode retornar a um recurso já visitado antes se seu roteiro determinar. 
A Figura 6 esquematiza o sistema de produção estudado.

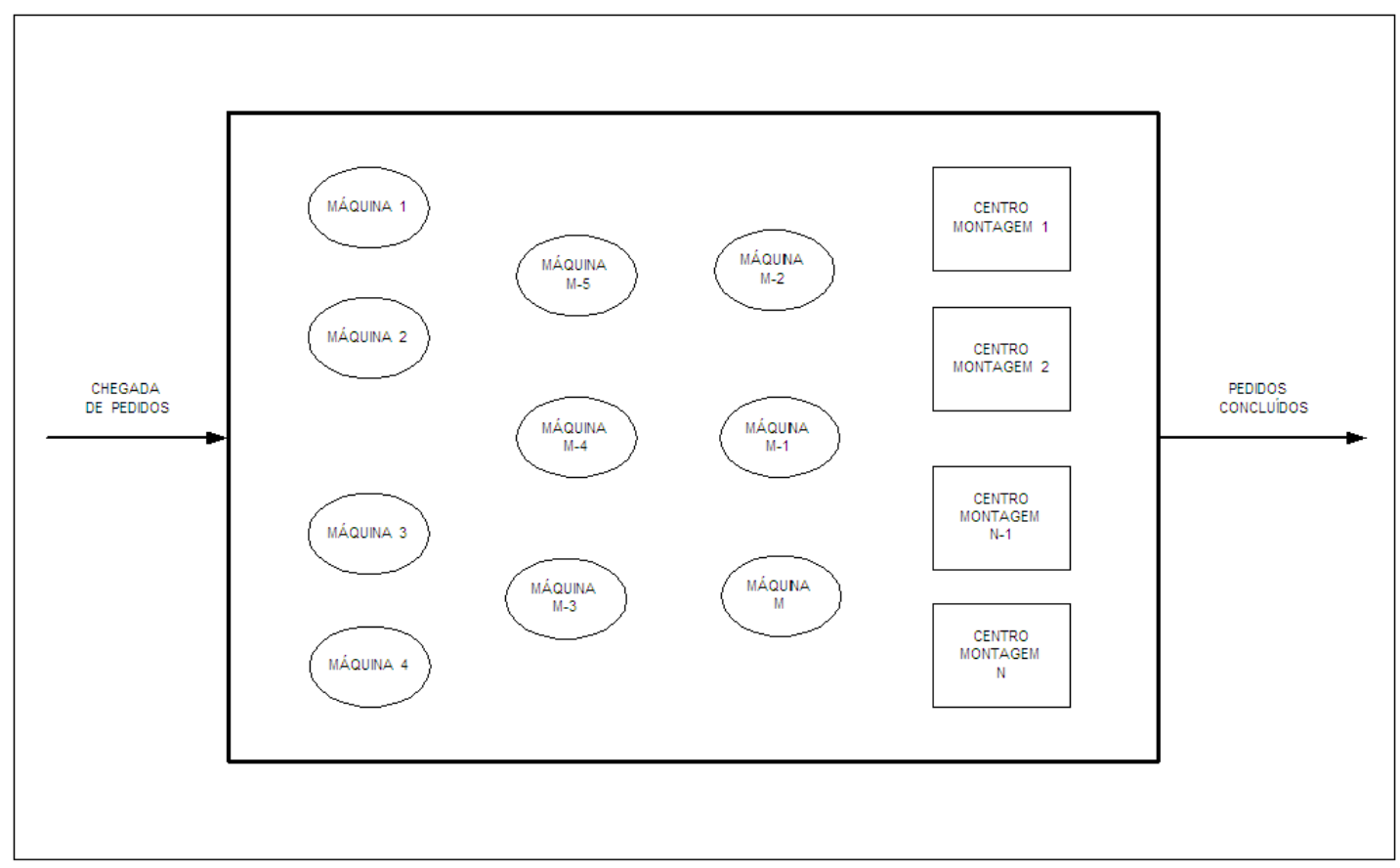

Figura 6 - O sistema de produção estudado.

\subsection{Medida de desempenho do sistema}

O critério de avaliação do desempenho do sistema de produção é o atraso médio de atendimento de pedidos $(\bar{T})$, formulado como:

$$
\begin{gathered}
\bar{T}=\frac{1}{N} \sum_{j=1}^{N} T_{j} \\
T_{j}=\max \left\{0, C_{j}-d_{j}\right\}
\end{gathered}
$$




\section{Métodos Heurísticos Baseados em Regras de Priorização para a Solução do Problema de Programação Assembly Shop}

Este capítulo apresenta a revisão bibliográfica dos estudos acadêmicos considerados relevantes para o desenvolvimento do método proposto nesta dissertação. Não é o intuito deste capítulo realizar uma apresentação exaustiva de todas as técnicas e métodos heurísticos e otimizantes desenvolvidos para solucionar o problema job/assembly shop. Para uma análise exploratória de outros métodos heurísticos e otimizantes desenvolvidos nas últimas quatro décadas para a solução do problema job shop, vide MORTON; PENTICO (1993) e JAIN; MEERAN (1998).

Como já mencionado anteriormente neste trabalho, o caso geral do problema de programação de operações em sistemas assembly shop é uma variante do caso geral do problema de programação de operações em sistemas job shop na qual as restrições de precedência entre operações são definidas de tal forma que inserem mais complexidade ao problema.

Como descrito no Apêndice-A, o caso geral do problema de programação job shop é NP-completo e, portanto, intratável do ponto de vista computacional, não existindo nenhum método eficiente de solução exata (global) desenvolvido até o presente momento.

O enfoque aqui é dado aos métodos heurísticos baseados em regras de priorização desenvolvidos ao longo das duas últimas décadas.

Uma regra de priorização é um procedimento heurístico concebido para usar determinadas informações contextuais do sistema de produção e selecionar uma e somente uma operação do conjunto de operações elegíveis e concorrentes para ser executada na máquina em um determinado instante do processo de programação. $A$ regra de priorização define um índice de prioridade que é associado a cada 
operação. As operações são então programadas (ou executadas) na máquina em ordem crescente ou decrescente dos valores do índice de prioridade. Os métodos que fazem uso de regras de priorização sempre solucionam aproximadamente o problema, ou seja, estabelecem programas viáveis, mas não necessariamente ótimos. Alguns autores também utilizam os termos regra de sequenciamento, regra de urgência, disciplina de fila e disciplina de seleção. Nesta dissertação, o termo adotado é regra de priorização; o termo sequenciamento é reservado ao processo de ordenação de operações na máquina, o qual usa o índice de prioridade calculado pela regra de priorização.

Baseados em estudos realizados por vários outros pesquisadores (alguns deles descritos neste capítulo), PHILIPOOM; RUSSEL; FRY (1991) apresentam as seguintes conclusões relacionadas ao uso de regras de priorização na programação assembly shop:

i. Regras de priorização eficientes em ambientes job shop simples (clássicos) não são necessariamente apropriadas para ambientes assembly shop.

ii. O uso de regras de priorização mais complexas não necessariamente produz melhores resultados que o uso de regras mais simples.

iii. Não existe nenhuma regra de priorização dominante para sistemas assembly shop.

Este capítulo é divido em três grandes seções, a saber:

i. Programação determinística em sistemas job shop estáticos.

ii. Sequenciamento de operações em sistemas assembly shop estocásticos.

iii. Abordagem estática de programação em sistemas assembly shop estocásticos.

\subsection{Programação determinística de operações em sistemas job shop estáticos}

Em sistemas job shop estáticos, $n$ ordens (ou operações) estão disponíveis para programação no instante zero. Todos os tempos de processamento são 
determinísticos. O problema consiste em construir um programa de produção que otimize uma dada medida de desempenho do sistema (HAX; CANDEA, 1984).

Para esta categoria de sistemas, abordagens otimizantes incluem os métodos de geração de programas ativos por enumeração exaustiva ou pela aplicação de métodos branch-and-bound. Outras abordagens consistem do uso de heurísticas de programação (HAX; CANDEA, 1984).

A seguir, é apresentada uma descrição sumarizada destes métodos.

\subsubsection{Algoritmos de geração de programas ativos}

Estes algoritmos geram programas ativos iterativamente, partindo de um programa inicial sem operações ("vazio"). Eles operam sobre o conjunto operações programáveis (sem restrições de precedência), selecionando uma operação por vez e associando uma data de início a cada uma delas. A cada iteração, o programa parcial é aumentado pela inclusão da operação selecionada. O programa completo é obtido tão logo todas as operações sejam programadas. A ordem na qual as operações são selecionadas e a maneira pela qual as datas de início são determinadas caracterizam o algoritmo de geração do programa (CONWAY; MAXWELL; MILLER, 1967).

Algoritmos deste tipo cobrem um grande espectro de opções de geração, indo desde a enumeração exaustiva de todos os possíveis programas, dentre os quais o melhor é selecionado, até técnicas de geração de um único programa viável, não necessariamente o ótimo (HAX; CANDEA, 1984).

A concepção desses algoritmos baseia-se nos conceitos de programas com tempo ocioso em excesso, programas semiativos, programas ativos e programas sem espera (HAX; CANDEA, 1984). Como o próprio nome o diz, estes algoritmos são concebidos para sempre gerarem programas ativos. 
Uma discussão sobre a estrutura destes quatro tipos de programas é apresentada a seguir. Esta discussão é relevante, pois o método proposto nesta pesquisa utiliza-se destes conceitos. A Figura 7, retirada de HAX; CANDEA (1984, p.302), ilustra cada tipo de programa para duas medidas de desempenho, a saber: data máxima de conclusão (makespan - M) e tempo médio de fluxo $(\bar{F})$.

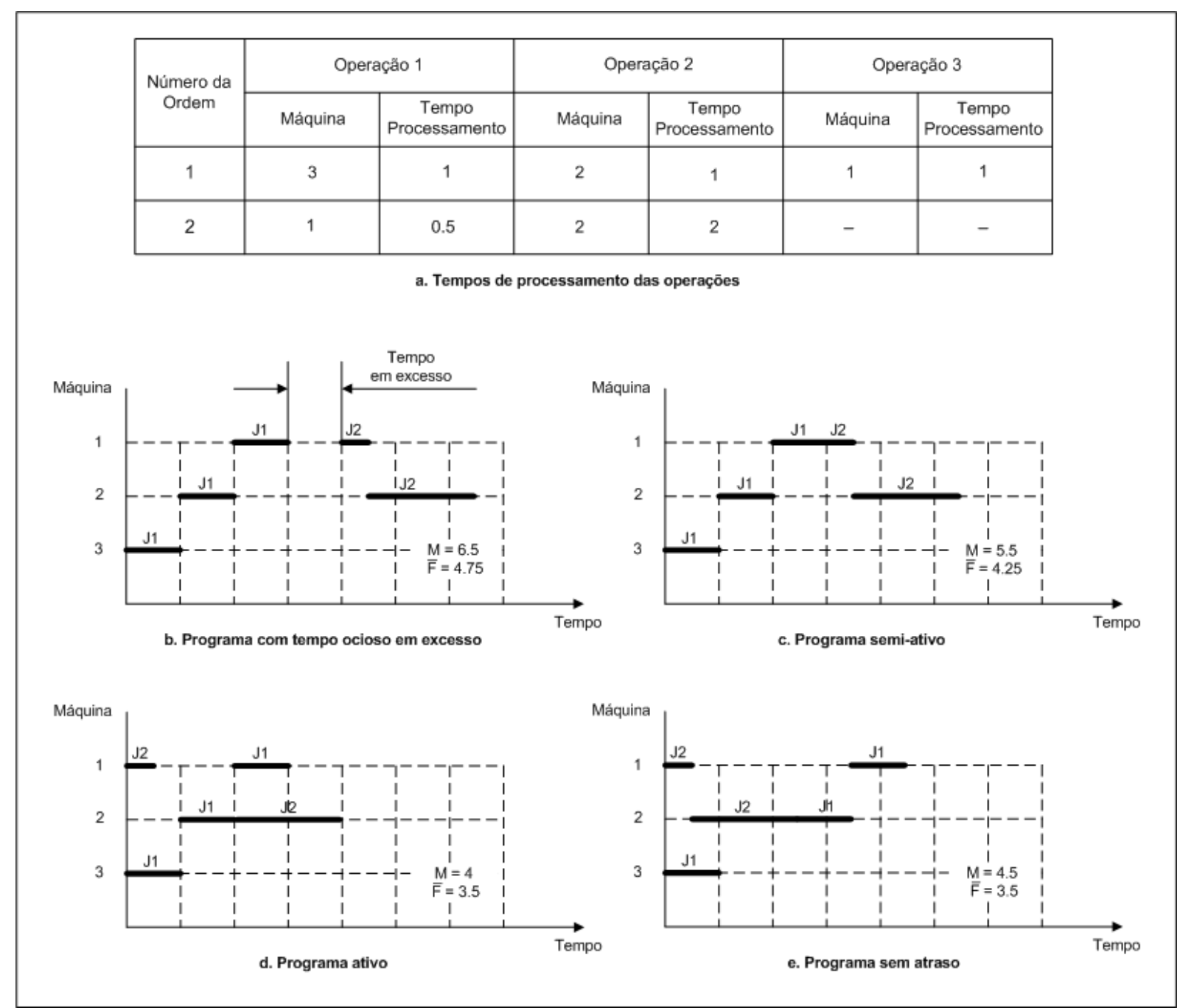

Figura 7 - Programação job shop de duas ordens em três máquinas.

O entendimento dos quatro tipos de programa é obtido intuitivamente através da visualização da programação das operações em gráfico de Gantt. Por esta abordagem gráfica, as operações são programadas da esquerda para a direita em cada máquina, respeitando-se as restrições de precedência entre operações e inserindo-se quanto tempo ocioso for necessário para se criar um programa viável. 
Em princípio, pode-se construir um número infinito de programas viáveis, isto porque uma quantidade arbitrária de tempo ocioso pode ser inserida entre quaisquer pares de operações em quaisquer máquinas (BAKER, 1974).

Devido ao fato dos tempos ociosos prejudicarem qualquer medida de desempenho, busca-se sempre a construção de um programa viável onde as operações sejam programadas da forma mais compacta possível (BAKER, 1974).

Um programa possui tempo ocioso em excesso se contem alguma operação que pode iniciar mais cedo sem alterar as sequências de execução das demais operações nas respectivas máquinas (Figura 7b). Ajustar o instante de início de uma operação para retirar o excesso de tempo ocioso, preservando as sequências das demais operações, corresponde a mover a operação mais para a esquerda no gráfico de Gantt. Este ajuste é denominado mudança local para esquerda. Dada a sequência de operações de cada máquina, existe apenas um programa no qual nenhuma mudança local para esquerda pode ser feita. Ao programa gerado através deste ajuste se dá o nome de programa semiativo (Figura 7c). Um programa semiativo não contém nenhum tempo ocioso (BAKER, 1974).

O conjunto dos programas semiativos domina o conjunto de todos os programas viáveis, o que significa dizer que basta considerar apenas os programas semiativos para otimizar qualquer medida de desempenho. Porém, apesar do número de programas semiativos ser limitado, este ainda é grande (BAKER, 1974).

Um dado programa semiativo pode ainda ser melhorado se, no gráfico de Gantt, for possível mover para a esquerda algumas operações sem que as demais operações tenham que ser processadas mais tarde do que inicialmente programadas. Este tipo de ajuste - no qual alguma operação é iniciada mais cedo sem atrasar qualquer outra - é chamado mudança global para esquerda. Os programas onde não é possível realizar nenhuma mudança global para esquerda são denominados de programas ativos (Figura 7d). Eles formam claramente um subconjunto dos programas semiativos (BAKER, 1974). 
Na geração de programas ativos a partir de programas semiativos, a mudança da sequência de operações de cada máquina a partir de uma dada sequência inicial deve ser sempre considerada desde que não gere atraso.

O conjunto dos programas ativos domina o conjunto dos programas semiativos, o que significa dizer que basta considerar apenas os programas ativos para otimizar qualquer medida de desempenho. Porém, apesar do número de programas ativos ser menor do que o de semiativos, ele tende ainda a ser grande (BAKER, 1974).

GLIFFER; THOMPSON (1960) apresentam um algoritmo para a geração de programas ativos para o caso geral do problema job shop. O algoritmo realiza a enumeração exaustiva de todas as possíveis soluções do problema, a partir das quais a solução ótima é selecionada.

Por vezes, é conveniente focar em um subconjunto ainda menor de programas denominado programas sem espera (Figura 7e). Em um programa sem espera, uma máquina nunca é mantida ociosa se existe alguma operação que pode ser processada nela (BAKER, 1974).

Todos os programas sem espera são programas ativos uma vez que nenhuma mudança global a esquerda é possível. Por outro lado, muitos programas ativos podem não ser programas sem espera. Isto significa dizer que o número de programas sem espera pode ser significativamente menor que o número de programas ativos (BAKER, 1974).

Apesar do conjunto de programas sem espera ser menor que o de programas ativos, aquele não é dominante sobre este, pois não existe garantia de que o conjunto dos programas sem espera contenha um programa ótimo para determinada media de desempenho (BAKER, 1974).

A Figura 8, adaptada de HAX; CANDEA (1984, p.303), apresenta a classificação dos programas job shop. 


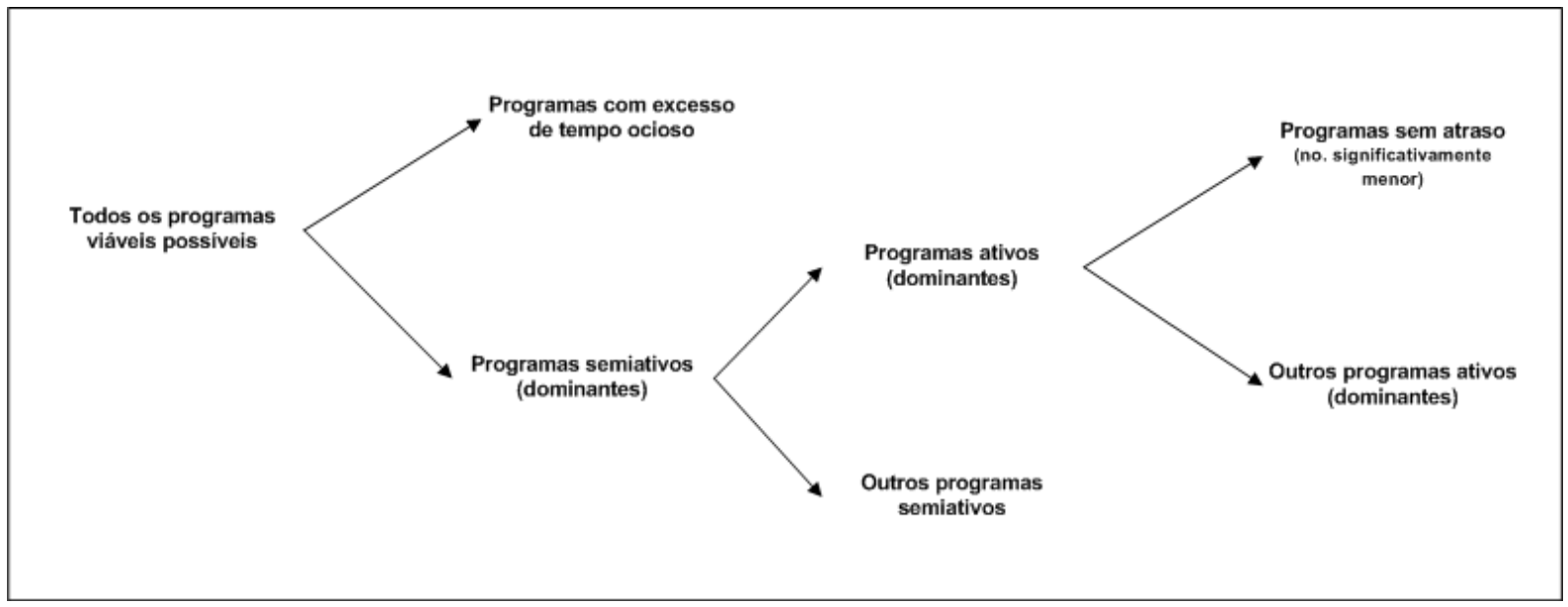

Figura 8 - Classificação dos programas job shop.

BAKER (1974) apresenta uma modificação do algoritmo de GLIFFER; THOMPSON (1960) para a geração de programas sem espera. Seu algoritmo também realiza a enumeração exaustiva de todas as soluções.

Os algoritmos de enumeração exaustiva de GLIFFER; THOMPSON (1960) e BAKER (1974) não são implementáveis na prática, pois a enumeração exaustiva é proibitiva para problemas de porte real. Porém, o conhecimento de suas estruturas algorítmicas é de grande valia para a concepção de métodos aproximados de geração de programas. O método proposto nesta pesquisa faz uso deste conhecimento.

Uma alternativa a enumeração exaustiva é a utilização da técnica denominada branch-and-bound descrita a seguir.

\subsubsection{Métodos Branch-and-Bound ${ }^{1}$}

Branch-and-bound (BB) é o nome genérico de uma estratégia de propósito geral adotada para a construção de diversos algoritmos exatos (otimizantes) que

\footnotetext{
${ }^{1}$ Esta seção foi escrita a partir da compilação de trechos dos textos de (BAKER, 1974), (MORTON; PENTICO, 1993) e (WINSTOM, 1994) e descreve a estratégia BB para o caso de minimização da função-objetivo.
} 
objetivam reduzir a enumeração de soluções em problemas de otimização combinatória e programação matemática inteira.

Os algoritmos baseados nesta estratégia utilizam o princípio da enumeração implícita ou não exaustiva "eficiente" de todas as soluções viáveis do problema.

Para que a enumeração implícita seja realizada, o algoritmo decompõe o espaço de soluções à medida que o explora, concentrando a busca em determinadas regiões que por inferência são consideradas promissoras.

A decomposição ou partição transforma o espaço de soluções em uma estrutura lógica graficamente semelhante a uma árvore que é dinamicamente construída durante as iterações do algoritmo.

As regiões classificadas como não promissoras são desconsideradas pelo algoritmo. As regiões promissoras sofrem nova partição e avaliação.

Pela partição, avaliação e escolha de regiões promissoras, o algoritmo tenta explorar implicitamente todo o espaço de soluções sem incorrer na busca exaustiva.

A abordagem branch-and-bound, como o próprio nome indica, fundamenta-se em dois procedimentos ou rotinas: a ramificação (branching) e a limitação (bounding).

O procedimento de ramificação substitui (decompõe) o problema original por um conjunto de novos problemas que são:

a. Subproblemas do problema original, mutuamente exclusivos.

b. Versões parcialmente solucionadas do problema original.

c. Menores e menos complexos que o problema original.

Basicamente, os métodos branch-and-bound fazem uso de duas táticas de ramificação para escolher os próximos subproblemas a serem resolvidos e decompostos. Na tática denominada busca em profundidade (depth-first-search ou backtracking), o algoritmo escolhe para solucionar o subproblema criado mais recentemente, prosseguindo até o nível mais inferior da árvore ao longo de 
determinada ramificação buscando alguma solução-candidata. Uma vez encontrada uma solução, o algoritmo retorna pela ramificação até alcançar o subproblema não resolvido criado mais recentemente de onde reinicia o processo. Na tática denominada busca em abrangência (best-first-search ou jumptracking), o algoritmo resolve todos os subproblemas gerados pelo evento de ramificação mais recente. Então, ele ramifica novamente a partir do nó de menor valor. Este procedimento faz o algoritmo "saltar" de um lado a outro da árvore na tentativa de encontrar boas soluções parciais sem, no entanto, aprofundar a busca em uma ramificação específica. Em geral, os métodos branch-and-bound realizam ambos os procedimentos muitas vezes no decorrer de suas execuções.

O procedimento de limitação é responsável por:

a. Atualizar o limite-inferior dentre todas as soluções-candidatas encontradas até a iteração atual do algoritmo.

b. Comparar cada solução-candidata e parcial (incompleta) com o limite-inferior, descartando aquelas cujos valores sejam superiores ao valor do limite-inferior.

O limite-inferior (lower bound) corresponde à melhor solução encontrada até a iteração atual do algoritmo. Seu cálculo é realizado pela aplicação da função-objetivo. No caso de um problema de minimização, nenhuma solução-candidata encontrada até a iteração atual é menor que o limite-inferior. Em geral, a primeira soluçãocandidata encontrada é assumida como sendo o primeiro limite-inferior.

Além do limite-inferior, o algoritmo BB calcula soluções parciais (incompletas) através de funções de inferência ou limitação (bounding functions). A solução parcial é calculada para cada nó da árvore de soluções e corresponde a melhor solução dentre todas as que o algoritmo encontraria (calcularia) caso o processo de ramificação seguisse a partir do nó para o qual a solução parcial foi calculada. Se a solução parcial for pior que o limite-inferior, o nó e, consequentemente, todos os ramos "abaixo" dele são descartados. Tal procedimento é denominado de poda (pruning) e é usado para que o algoritmo não tenha que realizar a ramificação a partir de um nó não promissor, minimizando o esforço de busca. Se a solução parcial for melhor que o limite-inferior, o algoritmo mantém o nó para imediata ou posterior ramificação. 
Obviamente, a eficiência dos métodos branch-and-bound reside no quão bem elaboradas são as rotinas de ramificação e as funções de limitação.

Os algoritmos branch-and-bound receberam substancial atenção da comunidade acadêmica nas últimas quatro décadas. Os vários algoritmos desenvolvidos para o problema de programação job shop diferem primariamente com respeito à tática de ramificação e as funções de limitação. A maior parte da pesquisa concentra-se na otimização do tempo máximo de conclusão (HAX; CANDEA, 1984).

BAKER (1974, p.193) apresenta resumidamente o método branch-and-bound proposto por BROOK; WHITE (1965) para a construção de programas ativos.

Em uma revisão recente sobre o estado-da-arte das técnicas de programação job shop, incluindo os últimos desenvolvimentos em algoritmos branch-and-bound, JAIN; MEERAN (1998) concluem que a melhoria na eficiência computacional relatada em estudos de aplicação ocorridos durante a década de 1990 deve-se mais a tecnologia de informação disponível do que ao método de solução em si. Em geral, tais métodos são inadequados para problemas de grande porte e suas execuções necessitam de grande conhecimento do domínio do problema devido ao uso de regras de limitação e ramificação altamente especializadas.

Além da limitação computacional no tratamento de problemas de grande porte, os algoritmos BB são concebidos assumindo-se como hipótese que o sistema de produção a ser programado tem comportamento determinístico. Por não considerarem explicitamente a característica estocástica do ambiente de produção real, as soluções propostas pelos algoritmos BB podem tornar-se obsoletas rapidamente. Este fato expõe ainda mais a questão da eficiência computacional deste método, pois em ambientes de produção reais, dinâmicos e estocásticos por natureza, para contornar a rápida obsolescência da solução, o algoritmo deveria ser executado várias vezes. 


\subsubsection{Métodos heurísticos de geração de programas ativos}

O termo 'heurística' deriva do termo grego 'heuristiké' que significa 'arte de encontrar'.

Em uma acepção mais aderente ao contexto da análise de decisão e otimização, define-se heurística como um conjunto de regras, método ou algoritmo usado para solucionar um determinado problema por meios que, embora não matematicamente rigorosos, geralmente refletem o conhecimento humano específico do problema e permitem obter uma solução satisfatória para ele.

As heurísticas são uma classe de métodos aproximados que englobam tanto algoritmos diretos (não iterativos) quanto algoritmos iterativos (MÜLLER-MERBACH, 1981). Elas podem ter construções algorítmicas simples, correspondendo a subrotinas diretas inseridas em algoritmos exatos, ou ainda, constituírem-se de construções algorítmicas iterativas mais sofisticadas.

Alguns dos motivos que fizeram das heurísticas uma atraente alternativa aos métodos otimizantes ${ }^{1}$ :

a. Muitos algoritmos otimizantes, sofisticados e bem construídos sobre fundações matemáticas rígidas, falharam em prover soluções confiáveis para muitos problemas da prática.

b. As descobertas da teoria da complexidade computacional demonstraram a intratabilidade de muitos problemas de otimização, especialmente aqueles de natureza combinatória, levando ao redirecionamento da "energia intelectual" antes devotada à otimização para o estudo das heurísticas.

c. Em geral, as heurísticas não levam à modelagem restritiva do problema de otimização, muitas vezes imposta pelos métodos exatos através de hipóteses simplificadoras artificialmente introduzidas no modelo. Como resultado, as heurísticas permitem o uso de modelos que são mais representativos do problema real.

\footnotetext{
${ }^{1}$ Compilados a partir de trechos dos textos de (MÜLLER-MERBACH, 1981); (FISHER; RINNOOY KAN, 1988); (GLOVER; GREENBERG, 1989) e SILVER (2002).
} 
d. As heurísticas podem ser construídas de maneira a monitorar e direcionar mais facilmente as habilidades, a experiência e o conhecimento humanos adquiridos do problema estudado.

No que se refere à geração de programas ativos, os métodos heurísticos são diferentes dos esquemas de enumeração apresentados anteriormente, pois, em uma árvore de enumeração, a heurística segue um único caminho do nó inicial até algum nó final correspondente a uma solução completa. Desta maneira, ela constrói um único programa em uma única passagem pela árvore (HAX; CANDEA, 1984, p.306).

Os procedimentos de enumeração exaustiva ramificam cada nó da árvore de programas, gerando a cada ramificação, um novo programa parcial, até que os últimos nós da árvore, correspondentes a programas finais, sejam alcançados. Os métodos branch-and-bound testam os nós ramificando-os até certa profundidade antes de decidir se são ou não promissores, abandonando aqueles que não são. Em contraste, a heurística construtiva seleciona uma e somente uma operação programável por nó, prosseguindo ao longo da corresponde ramificação (HAX; CANDEA, 1984, p.306). Portanto, em cada nó, uma única operação deve ser selecionada do conjunto de operações programáveis.

As heurísticas construtivas utilizam diferentes procedimentos na geração do programa ativo. Dentre os procedimentos mais usados pela indústria e reportados pela literatura acadêmica estão aqueles que fazem uso de regras de priorização.

Em termos práticos, uma regra de priorização é uma fórmula matemática através da qual um índice é calculado para cada operação programável (elegível para execução) na máquina em um determinado instante. Em seguida, usando-se o índice, as operações são ordenadas. A primeira operação da lista ordenada (dita a mais prioritária) é selecionada para ser executada na máquina. Tão logo a máquina se torna ociosa, o índice é recalculado para todas as operações programáveis, uma nova ordenação é realizada e uma nova operação é selecionada. Não necessariamente a segunda operação mais prioritária na ordenação anterior tornarse-á a mais prioritária na nova ordenação, pois novas operações podem chegar à máquina quando esta se torna ociosa. O procedimento é re-executado a cada 
liberação da máquina até que todas as operações da fila sejam processadas. A regra de priorização leva em consideração algum atributo da operação, da ordem ou do sistema.

\subsection{Sequenciamento de operações em sistemas assembly shop estocásticos}

Em um sistema job shop estocástico, ordens (ou operações) chegam aleatoriamente e continuamente ao longo do tempo ao sistema. À frente de cada máquina, formam-se filas de ordens (ou operações) aguardando por processamento. Após ser processada em uma máquina, a ordem segue para a fila de outra máquina e assim sucessivamente até que seja concluída e deixe o sistema.

Segundo HAX; CANDEA (1984, p.309), no contexto dos sistemas job shop estocásticos, não é possível construir efetivamente um programa completo no que se refere a determinar para cada operação uma data de início e uma data de término na máquina correspondente. O problema de programação deve ser decomposto em diversos subproblemas de sequenciamento de operações em uma única máquina. Quando a máquina fica ociosa, uma operação de sua fila deve ser selecionada para processamento.

A decisão de qual operação executar primeiro é tomada pelo processo de sequenciamento. Usando uma ou mais regras de priorização, um valor de índice de prioridade é calculado para cada ordem ou operação da fila da máquina ociosa imediatamente antes da alocação. A ordem ou operação com o melhor índice será primeiramente alocada. Este procedimento será repetido todas as vezes que uma máquina do sistema ficar ociosa. São os índices de prioridade os responsáveis por mover as ordens através do sistema. Sob a luz desta definição, a essência dos estudos de programação de operações em sistemas assembly shop estocásticos baseados em regras de priorização é determinar a eficácia de várias regras de priorização em termos da otimização de uma determinada medida de desempenho para diversas configurações do sistema e do item. 
HAX; CANDEA (1984, p.310) apresentam duas abordagens para os estudos de impacto de regras de priorização no desempenho de sistemas job shop, a saber: a analítica e a experimental. A abordagem experimental pode ainda ser subdivida em três linhas de pesquisa: 1) experimentos em sistemas reais; 2) simulação conduzida em sistemas reais para determinar parâmetros operacionais e 3) simulação de sistemas hipotéticos (com ou sem similaridades com determinado sistema real) para propósito de pesquisa.

Segundo HAX; CANDEA (1984, p.312), os estudos de simulação de sistemas hipotéticos têm o propósito de testar um conjunto de regras de priorização no contexto de vários processos job shop para diferentes medidas de desempenho do sistema.

A simulação de sistemas hipotéticos tem sido a abordagem experimental mais adotada em âmbito acadêmico para a condução de pesquisas de desempenho de sistemas assembly shops. Esta é a abordagem adotada nesta pesquisa. No Capítulo 6 , são apresentadas as diretrizes necessárias para a condução de experimentos de simulação computacional de sistemas assembly shops.

A seguir, são apresentados estudos realizados em sistemas assembly shop estocásticos que foram considerados relevantes para o desenvolvimento do método heurístico de programação e para a concepção do modelo de simulação para teste do método proposto.

A literatura acadêmica na área de programação de operações (operations scheduling) em sistemas assembly shop remonta à década de 1960 com os estudos seminais de CARROLL (1965) apud HUANG (1984) e MAXWELL (1965) apud CONWAY; MAWELL; MILLER (1967). Nestes dois estudos, os pesquisadores definiram os primeiros conceitos-chave relacionados à programação assembly shop que estabeleceram as bases conceituais para estudos subsequentes. Ambos apresentam as seguintes similaridades em seus experimentos que são repetidas em praticamente todos os estudos documentados posteriormente:

a. Usam modelos de simulação estocástica com veículo de investigação. 
b. Analisam regras de priorização que obtiveram bons desempenhos reportados em estudos anteriores de sequenciamento em sistemas job shop simples (clássicos).

c. Comparam a eficiência de diversas regras de priorização tendo como base diferentes medidas de desempenho do sistema.

d. Simulam o impacto de diferentes tipos de estruturas de materiais na eficiência das regras de priorização.

Os estudos apresentados nesta seção da dissertação podem ser agrupados em três categorias, a saber:

i. Estudos de análise de desempenho de métodos de atribuição de datas de entrega (promising).

ii. Estudos de análise da interação entre métodos de atribuição de datas de entrega e regras de priorização.

iii. Estudos de análise de desempenho de regras de priorização.

As seguintes similaridades foram encontradas entre os estudos pesquisados:

a. Usam modelos de simulação estocástica como veículos de investigação.

b. Os estudos que analisam a eficiência de diversas regras de priorização, com base em medidas de desempenho do sistema, usam apenas um método de atribuição de datas de entrega.

c. Os estudos que analisam a interação entre métodos de atribuição de datas de entrega e regras de priorização comparam diversos métodos de atribuição de datas de entrega com diversas regras de priorização.

d. Propõem novas regras de priorização e testam seus desempenhos contra regras já existentes que obtiveram bons resultados em estudos anteriores reportados tanto para sistemas job shop simples quanto para sistemas assembly shop.

e. Algumas das regras propostas são variações de regras homônimas criadas para ambientes job shop simples.

f. Simulam o impacto de diferentes tipos de estruturas de materiais na eficiência das regras de priorização; basicamente três tipos diferentes de estruturas são usados: de um, dois e três níveis de montagem; as estruturas são criadas a 
partir de distribuições uniformes de probabilidade; alguns estudos também simulam itens sem estrutura de materiais.

g. As configurações dos sistemas de produção são, em sua maioria, hipotéticas, não têm similaridade com nenhum sistema real e contêm de quatro a quinze máquinas e centros de montagem.

h. As máquinas estão disponíveis continuamente para alocação.

i. Os roteiros são criados a partir de distribuições uniformes de probabilidade que determinam o número de operações por roteiro e a máquina associada.

j. Os intervalos entre chegadas das ordens no sistema seguem distribuições gaussiana, exponencial ou de Poisson.

k. Os tempos de processamento são determinados antecipadamente e seguem as distribuições gaussiana, exponencial ou de Poisson.

I. O número de replicações de cada experimento varia de 5 a 50 .

m. As regras de priorização são analisadas para níveis de utilização do sistema iguais a $85 \%, 90 \%$ e $95 \%$, sendo $95 \%$ o nível mais utilizado.

A seguir, são apresentados estes estudos divididos nas três categorias citadas anteriormente.

\subsubsection{Estudos de análise de desempenho de métodos de atribuição de datas de entrega}

Segundo CONWAY; MAXWELL; MILLER (1967, p.229), das várias medidas de desempenho consideradas na pesquisa de programação, certamente aquela que desperta maior interesse para aqueles que lidam com problemas práticos de sequenciamento é a satisfação de datas de entrega de pedidos. A habilidade de atender em dia as entregas prometidas, indubitavelmente, domina todas as demais medidas de desempenho. Entretanto, o atraso de uma ordem depende de sua data de conclusão e de sua data de entrega. Portanto, a investigação de medidas de desempenho relacionadas ao atraso deve considerar não somente a eficácia dos métodos que pretendem atender a datas de entrega, mas também a maneira pela qual tais datas são atribuídas. 
Em sistemas job shop reais, a atribuição de datas de entrega e o sequenciamento de ordens representam, conjuntamente, um problema de ordem prática que afeta profundamente o desempenho global do sistema, qualquer que seja o critério ou medida de desempenho adotado.

Apesar da importância prática da interação entre a atribuição de datas de entrega e sequenciamento, poucos estudos foram encontrados analisando a influência conjunta destes dois determinantes de desempenho em sistemas assembly shop. A quase totalidade dos estudos aborda ambas as questões separadamente.

Diferentes métodos de atribuição de datas de entrega foram propostos e estudados com diferentes propósitos, incluindo: (i) analisar o desempenho de regras de priorização, (ii) determinar a data de entrega ótima e a sequência ótima de execução de ordens em sistema job shop estáticos, (iii) comparar o desempenho de diferentes métodos de atribuição de datas de entrega e (iv) encontrar o valor ótimo para o fator de permissão (estimação dos tempos de fila) para processar ordens em sistemas job shop dinâmicos.

CHENG; GUPTA (1989) apresentam uma revisão destes métodos para sistemas job shop simples com ênfase nos itens (iii) e (iv) descritos acima. Segundo estes pesquisadores, os procedimentos de atribuição de datas de entrega podem ser agrupados em duas categorias:

- Procedimentos exógenos. Neste caso, as datas de entrega são atribuídas por algum processo gerador externo. Claramente, estes métodos ignoram inteiramente qualquer informação sobre as ordens em liberação, futuras ordens, ordens em processamento, o status ou a estrutura do sistema de produção.

- Procedimentos Endógenos. Neste caso, as datas de entrega são atribuídas internamente para cada ordem durante sua liberação em função de características da ordem (número total de operações, número de operações faltantes), status do chão-de-fábrica (nível de utilização), estimativas de tempo de fluxo e fila, dentre outros critérios.

A seguir, são apresentados outros dois estudos desta categoria. 
GOODWIN; GOODWIN (1982) apresentam um estudo de análise de eficiência de dois métodos de atribuição de datas de entrega em um sistema assembly shop estocástico. No estudo, são testados os procedimentos TWK e CON. Os resultados do estudo indicaram que TWK opera melhor que CON para a configuração do sistema estudado.

FRY; PHILIPOOM; MARKLAND (1989) analisam o impacto de sete diferentes métodos de atribuição de datas de entrega no desempenho de um sistema assembly shop estocástico. Eles compararam métodos que incorporavam uma medida da dinâmica do chão-de-fábrica na atribuição da data de entrega da ordem recémliberada (carga nos centros de trabalho no momento da liberação da ordem) com métodos "estáticos", que incorporavam apenas características da ordem (número de operações faltantes totais ou no caminho crítico), e métodos mistos, que incorporavam ambas as características. Os métodos foram analisados para medidas do atraso de atendimento (tardiness) e desvio de data de entrega (lateness) do sistema. Os resultados mostraram que os procedimentos que incorporavam a carga dos centros de trabalho, com ou sem características específicas da ordem, alcançaram melhores desempenhos.

Os artigos desta seção tiveram relevância para esta pesquisa, pois auxiliaram na escolha do método de atribuição de datas usado durante o procedimento experimental.

\subsubsection{Estudos de análise da interação entre métodos de atribuição de datas de entrega e regras de priorização}

ADAM et al. (1993) descrevem um extenso estudo de análise do impacto da combinação de sete métodos de atribuição de datas de entrega conjuntamente com duas regras de priorização de operações no desempenho de um sistema assembly shop estocástico para estruturas de materiais de um, dois e três níveis. 
As medidas de desempenho de sistema escolhidas para analisar a eficiência das regras e dos métodos de atribuição de datas foram o lead time da ordem, o atraso de atendimento (tardiness), percentual de ordens atrasadas (percentage of tardy jobs) e o desvio de data de entrega (lateness). Durante o experimento, esta última medida foi monitorada e ajustada continuamente para que seu valor fosse sempre próximo de zero ou estatisticamente igual à zero.

Três dos métodos de atribuição de datas estudados (CON, TWK e CPPT) foram modificados, gerando-se versões dinâmicas (CON-DYN, TWK-DYN e CPPT-DYN) onde os parâmetros de controle eram atualizados cada vez que uma ordem era liberada para o chão de fábrica. Um quarto método (CPFT-ADJ), também dinâmico, foi desenvolvido no estudo e comparado com os demais.

Dentre os resultados alcançados pela pesquisa, citam-se:

a. As versões dinâmicas CON-DYN, TWK-DYN e CPPT-DYN foram superiores as suas contrapartidas estáticas para a maioria das medidas de desempenho. Isto se verificou tanto para ordens sem estrutura quanto para aquelas com estrutura (um, dois e três níveis).

b. O método CPFT-ADJ obteve desempenho tão bom quanto às versões dinâmicas CPPT-DYN e TWK-DYN. Isto se verificou tanto para ordens sem estruturas quanto para aquelas com estrutura (um, dois e três níveis).

c. A atualização contínua dos parâmetros utilizados para estimar o lead time reduziu significativamente as diferenças de eficiência entre os métodos CONDYN, TWK-DYN e CPPT-DYN. Estudos conduzidos anteriormente com as versões estáticas levaram a conclusão que o método TWK era significativamente superior aos métodos CON e CPPT. Os resultados deste artigo contradisseram os estudos anteriores.

O estudo também determinou significativas diferenças de eficiência entre as regras EDD e ODD para determinadas medidas de desempenho e para certos métodos de atribuição de datas. EDD mostrou ser superior a ODD para as medidas de lead time e atraso (tardiness) para todos os métodos de atribuição de datas tanto para produtos sem estruturas quanto para produtos com estruturas de um, dois e três níveis. 
Este artigo foi relevante para a pesquisa, pois: 1) apresenta conceitos-chaves relacionados ao processo de sequenciamento de operações em sistemas assembly shops; 2) descreve uso de técnicas de coleta instantânea de medidas de desempenho do sistema ao longo do processo de simulação buscando recalibrar dinamicamente alguns parâmetros do modelo; 3) auxiliou na seleção das regras utilizadas nesta dissertação (EDD e ODD). Um ponto negativo relacionado ao estudo é que ele não descreve satisfatoriamente o procedimento experimental.

\subsubsection{Estudos de análise da eficiência de regras de priorização}

ADAM; BERTRAND; SUKIS (1987) descrevem um estudo investigativo do efeito da estrutura de materiais na eficiência de oito regras de priorização, em um sistema assembly shop estocástico hipotético. Quatro das oito regras estudadas foram propostas pelos pesquisadores para o estudo.

As medidas de desempenho do sistema escolhidas para analisar a eficiência das regras foram o desvio padrão e a média das medidas de lead time da ordem, tempo de fluxo da ordem e espera de montagem.

O modelo de simulação criado para o sistema foi composto por um número preestabelecido de máquinas (não discriminado no estudo) continuamente disponíveis para alocação. No modelo, cada ordem representava uma montagem final contendo uma estrutura de materiais e respectivas operações. As estruturas de montagem foram geradas através de funções da distribuição uniforme de probabilidades. O modelo de simulação permitiu quatro classes diferentes de ordens (itens finais): ordens sem estrutura de materiais e ordens com um, dois e três níveis de montagem.

As ordens eram liberadas no chão-de-fábrica a intervalos que seguiam distribuição exponencial com média escolhida para alcançar um nível médio de utilização do sistema (não discriminado no estudo). 
As quatro regras proposta no estudo (NUSEG-RRO, NUSEG-RRP, TWKR-RRO, TWKR-RRP) fazem uso de dois índices desenvolvidos no estudo: o número relativo de operações restantes $(\mathrm{R} R \mathrm{O})$ e o tempo relativo de processamento restante (RRP). Os dois índices consideram explicitamente a complexidade das estruturas de materiais no cálculo de seus valores. O objetivo das regras que os utilizam é melhorar a coordenação da cadência (pacing) de execução dos componentes (segmentos) do interior de uma ordem (estrutura). A sua concepção parte do pressuposto que a espera de montagem pode ser reduzida se os diferentes segmentos da ordem têm o mesmo número de operações restantes ou a mesma quantidade de trabalho restante em qualquer nível de montagem. Se um segmento tem muitas operações restantes ou uma grande quantidade de trabalho restante se comparado a outros segmentos da ordem, a ele deveria ser dada maior prioridade.

Os resultados da pesquisa concluíram que, em termos do desempenho de ordens com dois e três níveis, as regras propostas mostraram uma significativa melhoria sobre as regras usadas como benchmark com relação à medida de espera média de montagem. Para ordens com estruturas de um único nível, o desempenho das regras propostas foi tão bom quanto à melhor regra existente.

Este artigo foi relevante para a pesquisa, pois: 1) apresenta conceitos-chaves relacionados ao processo de sequenciamento de operações em sistemas assembly shops; 2) descreve satisfatoriamente o procedimento experimental.

FRY et al. (1989) descrevem um abrangente estudo investigativo do efeito da estrutura de materiais na eficiência de quatorze regras de priorização em um sistema assembly shop estocástico. Dez das quatorze regras foram propostas e avaliadas.

As medidas de desempenho do sistema escolhidas para analisar a eficiência das regras foram o tempo de fluxo, o atraso médio de atendimento, o desvio médio absoluto do atraso de atendimento e o percentual de ordens atrasadas.

O modelo de simulação do sistema foi composto por seis máquinas e quatro centros de montagem. No modelo, uma ordem representava uma montagem final contendo uma estrutura de componentes e respectivas operações. Dez diferentes 
estruturas de materiais foram utilizadas, divididas em três grandes grupos: estruturas de um nível e vários componentes ("curtas"), estruturas de 2 a 6 níveis e dois componentes ("alongadas") e estruturas 2 a 3 níveis e vários componentes ("complexas"). As ordens eram liberadas para o chão-de-fábrica a intervalos que seguiam uma distribuição exponencial com média escolhida para alcançar $85 \%$ de utilização do sistema. Para cada ordem liberada, uma estrutura de componentes era aleatoriamente vinculada, tendo cada estrutura a mesma chance de seleção.

Os resultados do estudo indicaram:

a. A existência de um forte relacionamento entre a forma da estrutura de materiais e a eficiência da regra de priorização para uma determinada medida de desempenho do sistema.

b. O desempenho das regras orientadas a data de entrega melhora à medida que as estruturas de materiais se tornam mais alongadas.

c. A regra EDD obteve um desempenho consistentemente eficiente para todos os tipos de estruturas e três medidas de desempenho do sistema.

Este artigo foi relevante para a pesquisa, pois: 1) apresenta onze novas regras baseadas explicitamente na estrutura de materiais e seus tempos; 2) descreve satisfatoriamente o procedimento experimental.

PHILIPOOM; RUSSEL; FRY (1991) descrevem um estudo investigativo do efeito da estrutura de materiais na eficiência de oito regras de priorização em um sistema assembly shop estocástico hipotético. Quatro das oito regras foram propostas e avaliadas.

As medidas de desempenho de sistema escolhidas para analisar a eficiência das regras foram o tempo de fluxo médio, o atraso médio de atendimento, o atraso médio absoluto de entrega, raiz quadrada do atraso médio de atendimento, 0 percentual de ordens atrasadas, o atraso máximo de entrega e o nível de estoque médio do sistema.

O modelo de simulação do sistema foi composto por dez máquinas e uma estação de montagem. O tempo médio de processamento foi escolhido para resultar 
em uma utilização do sistema igual a $90 \%$. No modelo, uma ordem representava uma montagem final contendo uma estrutura de materiais e respectivas operações. Para cada ordem liberada, uma estrutura era associada segundo uma distribuição de probabilidades (não especificada) tal que todas as estruturas tivessem igual probabilidade de seleção. A quantidade da ordem era uniformemente distribuída.

Três tipos de estruturas de materiais foram testados ("curta", "alongada" e "complexa"), cada qual com cinco diferentes produtos totalizando 15 estruturas diferentes. As estruturas "curtas" possuíam um único nível de montagem e de três a sete componentes por nível. As estruturas "alongadas" possuíam de dois a seis níveis de montagem e exatamente dois componentes por nível. As estruturas "complexas" possuíam de dois a três níveis de montagem e de dois a três componentes por nível.

Os roteiros eram predefinidos e gerados aleatoriamente. O número de operações necessárias para produzir cada componente era determinado segundo uma distribuição uniforme de probabilidades. Os tempos de execução nas máquinas seguiam distribuição normal com média diretamente proporcional à quantidade da ordem. Os tempos de execução nos centros de montagem foram assumidos como iguais à zero.

As quatro regras novas propostas no estudo (IR-SOPN, IR-TWKR, TWK-IR, MSIR) utilizaram um índice denominado razão de importância (IR) também proposta no estudo. Por este índice, o item é priorizado de acordo com a razão entre o número de operações restantes na ramificação da estrutura onde se encontra (até a conclusão da ordem) e o número de operações faltantes na ramificação mais longa da estrutura (até a conclusão da ordem), valor calculado em um determinado instante.

As regras SOPN (benchmark), MS-TWK, TWK-FIFO e TWK-RRO foram analisadas conjuntamente com as quatro regras novas.

Os resultados do estudo mostraram que: 
a. Em geral, a incorporação simultânea de atributos de ambos os ambientes job shop simples e assembly shop em regras de priorização não necessariamente produzem melhores desempenhos.

b. Variações na regra TWK (TWK-RRO e TWK-IR) que incorporam atributos específicos de ambientes de montagem não superaram a regra TWK.

c. Variações na regra MS (MS-IR e MS-TWK) que incorporam atributos específicos de ambientes de montagem não ofereceram melhoria significativa sobre SOPN.

d. As regras TWR-RRO (ADAM, BERTRAND e SUKIS, 1987), IR-SOPN e IRTWK especialmente projetadas para ambientes de assembly shop, significativamente superam a regra SOPN para várias medidas de desempenho de sistema.

e. A regra IR-TWK desempenhou-se tão bem quanto à regra TWK-RRO (ADAM; BERTRAND; SUKIS, 1987) para todas as medidas de desempenho e superou TWK-RRO para estruturas "alongadas".

Este artigo foi relevante para a pesquisa, pois: 1) apresenta quatro novas regras baseadas explicitamente na estrutura de materiais e seus tempos; 2) descreve satisfatoriamente o procedimento experimental.

REEJA; RAJENDRAN (2000a) descrevem um estudo investigativo do efeito da estrutura de materiais na eficiência de seis regras de priorização em um sistema assembly shop estocástico hipotético. Três das seis regras foram propostas no estudo.

As medidas de desempenho de sistema escolhidas para analisar a eficiência das regras foram o tempo médio de fluxo, o desvio padrão do tempo de fluxo (método de ADAM; BERTRAND; SUKIS, 1987), o tempo máximo de fluxo, o desvio padrão do fluxo máximo (método de ADAM; BERTRAND; SUKIS, 1987), a espera média de montagem e a espera máxima de montagem.

O modelo de simulação do sistema foi composto por dez centros de trabalho (fabricação e montagem). No modelo, uma ordem representava uma montagem final contendo uma estrutura de materiais e respectivas operações. As ordens eram 
liberadas a intervalos que seguiam a uma distribuição exponencial com média escolhida para alcançar $85 \%$ e $95 \%$ de utilização do sistema.

Três tipos de estruturas de materiais foram testados: estruturas de um, dois e três níveis. O número de componentes por nível da estrutura foi determinado através de uma distribuição uniforme de probabilidades. Os roteiros de produção eram predefinidos e gerados por uma distribuição de probabilidades não mencionada no estudo.

As três regras novas (OSD, TWKR-OSD, ECT-OSD) fazem uso de um índice denominado data de sincronização de operação (OSD) também proposto no estudo. Através dele, as datas de entrega das operações são determinadas em duas fases. Na primeira, a data-mais-cedo de conclusão da ordem é calculada para frente no tempo (forward) a partir da data de liberação da ordem, usando as operações do caminho crítico da ordem. Na segunda fase, o índice OSD é então calculado para trás no tempo (backward) a partir da data-mais-cedo de conclusão, para todas as operações da estrutura de materiais.

As regras IR-TWKR, TWKR-RRP e LP+ROPT ${ }^{2}$ (segunda versão da regra ROPT) foram testadas juntamente com as novas regras.

Os resultados deste estudo mostraram que:

a. Para os níveis de utilização analisados (85\% e 95\%), as regras ECT-OSD e OSD desempenham-se muito bem com respeito a muitas das medidas, especialmente com relação à minimização das duas medidas de tempo de fluxo máximo e o atraso máximo de espera de montagem.

b. O índice OSD assegurou maior coordenação e sincronização das operações paralelas tanto para componentes individuais quanto para as submontagens.

c. A utilização do índice OSD resultou em mínimos tempos de espera de montagem e de fila para os componentes das operações de submontagem e montagem.

d. As regras OSD, TWKR-OSD e ECT-OSD obtiveram desempenhos superiores às regras TWKR-RRP, $L P+R O P T^{2}$ e IR-TWKR para as medidas de 
minimização de tempo de fluxo médio, tempo de fluxo máximo, desvio padrão do tempo de fluxo e espera de montagem.

REEJA; RAJENDRAN (2000b) descrevem um estudo investigativo do efeito da estrutura de materiais na eficiência de cinco regras de priorização em um sistema assembly shop estocástico hipotético. Três das cinco regras foram propostas no estudo.

As medidas de desempenho de sistema escolhidas para analisar a eficiência das regras foram o tempo médio de fluxo, o tempo máximo de fluxo, o atraso médio de atendimento, o atraso máximo de atendimento, o atraso médio condicional de atendimento, o percentual de ordens atrasadas, a antecipação média, a espera média de montagem (ADAM; BERTRAND; SUKIS (1987)), todos avaliando os níveis de submontagem e montagem final.

O modelo de simulação seguiu as mesmas condições experimentais definidas para o estudo anterior (REEJA; RAJENDRAN (2000a)).

As três regras novas (ODD, TWKR-ODD, JDD-ODD) fazem uso de um índice denominado data de entrega da operação (ODD) também proposto no estudo. Através dele as datas de entrega das operações são determinadas em duas fases. Na primeira, a data-mais-cedo de conclusão da ordem (última operação) é calculada pelo método CPPT a partir da data de liberação da ordem (primeira operação), dentro de seu caminho crítico. Na segunda fase, o índice ODD é então calculado da frente para trás (backward) para todas as operações da estrutura de componentes a partir da data-mais-cedo de conclusão.

As regras IR-TWKR, TWKR-RRP e LP+ROPT ${ }^{2}$ foram testadas juntamente com as novas regras.

Acompanhando os resultados do estudo anterior (REEJA; RAJENDRAN, 2000a), os resultados deste estudo também mostraram, de forma geral, um excelente desempenho das novas regras baseadas na nova fórmula de cálculo de ODD. Isto é 
explicado pelo efeito positivo causado pelo fator ODD na sincronização e cadência do fluxo de produção.

Os dois artigos anteriores de Reeja e Rejandram foram muito importantes para a pesquisa, pois utilizam conceitos de programação forward e backward na elaboração das regras de sequenciamento. Estes dois artigos inspiraram o desenvolvimento dos procedimentos de programação inseridos no método proposto nesta dissertação.

MOHANASUNDARAM et al. (2002) descrevem um estudo investigativo do efeito da estrutura de materiais na eficiência de seis regras de priorização em um sistema assembly shop estocástico hipotético. Quatro das seis regras foram propostas no estudo.

Duas das quatro novas regras (ECT-FIFO e LF-ECT) foram avaliadas por objetivos baseados em lead time. As medidas de desempenho deste grupo foram a espera média de montagem, a espera máxima de montagem, o tempo médio de fila, o tempo máximo de fila, o tempo médio de fluxo e o tempo máximo de fluxo. A regra de benchmark para este grupo foi a TWKR-RRP.

As outras duas novas regras (JDD-FIFO e LFD-JDD) foram avaliadas por objetivos baseados em data de entrega. As medidas de desempenho deste grupo foram o atraso médio de atendimento condicional, o atraso máximo de atendimento condicional, o número de ordens atrasadas, o desvio médio absoluto de data de entrega e o desvio máximo absoluto de data de entrega. A regra de benchmark para este grupo foi a JDD-RAN.

O modelo de simulação do sistema foi composto por nove centros de trabalho (fabricação) e um centro montagem. No modelo, uma ordem representava uma montagem final contendo uma estrutura de materiais e respectivas operações. As ordens eram liberadas a intervalos que seguiam a uma distribuição exponencial com média escolhida para alcançar $80 \%$ e $90 \%$ de utilização do sistema. 
Três tipos de estruturas de materiais foram testados: estruturas de um, dois e três níveis. As estruturas foram determinadas utilizando-se de distribuições discretas de probabilidades.

Os roteiros de produção eram predefinidos e gerados por uma distribuição de probabilidades não mencionada no estudo.

Os resultados deste estudo mostraram que:

a. Para ambos os níveis de utilização e todos os tipos de estrutura, as regras ECT-FIFO e LF-ECT obtiveram melhor desempenho que a regra TWKR-RRP com respeito à minimização da espera média e máxima de montagem, do tempo de fila máximo e do tempo de fluxo máximo.

b. Para ambos os níveis de utilização e todos os tipos de estrutura, as regras JDD-FIFO e LFD-JDD obtiveram melhor desempenho que a regra JDD-RAN com respeito à minimização de todas as medidas de desempenho.

O artigo anterior foi importante para a pesquisa, pois auxiliou na escolha tanto das regras de priorização quanto das técnicas de análise estatística dos resultados.

THIAGARAJAN; RAJENDRAN (2003) descrevem um estudo investigativo do efeito da estrutura de materiais na eficiência de dez regras de priorização em um sistema estocástico hipotético. Três das dez regras foram propostas no estudo.

As medidas de desempenho do sistema escolhidas para analisar a eficiência das regras foram divididas, segundo a classificação dos pesquisadores, em:

a. Medidas primárias: custo médio de programação, custo médio ponderado de programação, custo máximo total de programação, variância do custo total de programação e variância ponderada do custo total de programação.

b. Medidas secundárias: tempo de fluxo médio ponderado, tempo de fluxo máximo ponderado, variância de tempo de fluxo, o atraso médio ponderado de atendimento, o atraso máximo ponderado de atendimento, variância do atraso de atendimento. 
A distinção entre as medidas primárias e secundárias foi importante no estudo, pois todas as novas regras de priorização foram desenvolvidas baseadas nas medidas primárias de desempenho de sistema.

As medidas primárias relacionam-se ao custo total de programação, definido no estudo como sendo a soma dos custos de manutenção de estoques em processo e os custos de atraso de atendimento. Quanto maior o tempo de fluxo da ordem maior é seu custo de manutenção. Quanto maior o atraso da ordem maior é seu custo de atraso. Ambas as medidas são ponderadas diferentemente; este foi o enfoque do estudo.

O modelo de simulação do sistema foi composto por dez máquinas ou estações de trabalho. Os roteiros eram predefinidos (não existiam roteiros alternativos) e gerados aleatoriamente, com cada centro de trabalho tendo a mesma probabilidade de seleção. No modelo, uma ordem representava uma montagem final contendo uma estrutura de materiais e respectivas operações. O número de componentes por nível da estrutura (exceto para montagens finais) era determinado através de uma distribuição uniforme. As estruturas de materiais foram agrupadas de acordo com suas complexidades construtivas em três categorias (um, dois e três níveis) para análise em conjunto. As ordens eram liberadas a intervalos que seguiam uma distribuição exponencial com média escolhida para alcançar $85 \%$ e $95 \%$ de utilização do sistema.

As três novas regras (W(PT-BY-TIS), W(TWKR-BY-TIS), W(LBF + LBT)) propostas no estudo incorporam os custos de manutenção e atraso de atendimento calculados especificamente para cada ordem/operação programada. Um novo índice $\left(Z_{i}\right)$ é proposto. Seu calculo incorpora o tempo (padrão) de processamento da operação, o tempo em processamento da ordem no instante da programação, os custos de manutenção e de espera de montagem, as datas de conclusão estimada da ordem, a data de liberação da ordem e a data de entrega da ordem.

As demais regras analisadas no estudo conjuntamente com as novas regras (TWKR, COVERT, ATC, SPT, EDD, FIFO, ECT), já existentes, foram alteradas pela 
ponderação dada pela soma dos fatores de penalização por atraso e custo de manutenção.

Os resultados do estudo mostraram que:

a. A regra $\mathrm{W}(\mathrm{TWKR})$ teve o melhor desempenho com relação à minimização do custo médio ponderado de programação e tempo de fluxo médio ponderado.

b. A regra W(TWKR-BY-TIS) teve excelente desempenho com relação à minimização do atraso médio ponderado e junto com a regra $W(L B F+L B T)$ obteve os melhores desempenhos com relação ao atraso máximo ponderado, custo máximo total de programação e tempo de fluxo máximo ponderado.

Este artigo foi relevante para a pesquisa, pois: 1) os pesquisadores propõem novas medidas de desempenho e regras de priorização baseadas explicitamente em custos de processamento de ordens; 2) descreve detalhadamente o procedimento experimental.

HICKS; PONGCHAROEN (2006) descrevem um estudo investigativo abrangente dos efeitos da estrutura de materiais na eficiência de oito regras de priorização conhecidas avaliadas em um sistema assembly shop real que produz bens de capital.

Três tipos de estruturas de materiais foram testados: estruturas de montagens finais contendo até oito níveis, estruturas de materiais de produtos subcontratados (submontagens) e de reposição (submontagens), contendo até dois níveis cada. $\mathrm{O}$ que variava entre as estruturas de até dois níveis eram o número de componentes individuais. Todas as estruturas pertenciam a produtos reais.

Nenhuma nova regra de priorização foi proposta no estudo. As regras avaliadas foram as seguintes: EDF, FEF, LOF, LRF, LSF, MRF,RND e SOF.

A medida de desempenho utilizada para avaliar o desempenho das regras foi o atraso médio de atendimento.

Quatro fatores operacionais foram selecionados para serem avaliados conjuntamente com os tipos de estrutura e regras de priorização, a saber: tempo de 
preparação (setup), tempo de processamento, tempo de transferência e intervalo entre coleta e atualizações de dados no sistema de informações de gestão da produção (CAPM).

O estudo teve como principal entrada (input) o plano agregado de produção para 18 meses. Os dados operacionais e de planejamento foram obtidos do sistema de gestão da produção (CAPM).

O modelo de simulação do sistema de manufatura (MSSM), um módulo do CAPM, foi utilizado na realização das rodadas de simulação.

O projeto experimental foi dividido em duas fases (cenários):

- Na primeira fase, analisou-se o efeito dos fatores operacionais em um ambiente sem restrições de capacidade e com tempos de processamento estocásticos. Nesta fase, os objetivos almejados foram: (i) encontrar a importância relativa dos fatores operacionais; (ii) identificar 0 melhor desempenho possível alcançável pelo sistema de produção sem restrições de capacidade; (iii) identificar a viabilidade dos planos (programas) de produção.

- Na segunda fase, analisou-se o efeito das regras de priorização conjuntamente com os fatores operacionais em um ambiente com restrições de capacidade e com tempos de processamento estocásticos. Nesta fase, os objetivos almejados foram: (i) identificar a importância relativa das regras de priorização e outros parâmetros operacionais (ii) identificar a melhor regra de priorização para cada família de produto nos níveis dos componentes e montagens; (iii) avaliar o impacto das restrições de capacidade nos planos (programas) de produção.

No tocante a avaliação das regras de priorização, os resultados do estudo mostraram que:

a. As regras EDF e LSF obtiveram os melhores desempenhos tanto para o nível das submontagens quanto para o nível das montagens finais.

b. As regras SOF e MRF obtiveram os melhores desempenhos para os submontagens de reposição. 
c. As regras LOF e SOF obtiveram os melhores desempenhos para os produtos subcontratados.

Este artigo foi relevante para a pesquisa, pois: 1) auxiliou na seleção das regras de priorização avaliadas nesta dissertação; 2) descreve a aplicação do método científico na avaliação de regras de priorização e parâmetros operacionais em um sistema de produção real.

\subsection{Abordagem estática de programação em sistemas assembly shop estocásticos.}

HAX; CANDEA (1984, p.309) descrevem um tipo de abordagem para o problema de programação de operações em sistemas job shop estocásticos onde um programa de produção poderia ser construído se fosse limitado ao um número finito de ordens (aquelas que existissem no sistema no momento que o programa fosse gerado) e seus tempos de processamento ou suas estimativas fossem conhecidos. Tal feito constituiria em uma abordagem estática para um problema estocástico. Como consequência, o programa sofreria uma obsolescência acelerada e deveria ser refeito continuamente. O problema de programação tornar-se-ia, então, um problema de reprogramação no qual um mecanismo de atualização do programa por computador seria essencial. Os autores não avançam além deste ponto.

Segundo PINEDO (2002, p.392), em geral, os modelos teóricos não enfatizam o problema da reprogramação. Em sistemas reais de manufatura (naturalmente estocásticos):

i. A programação deve ser feita sem o conhecimento prévio sobre o futuro próximo. Portanto, algumas "provisões" devem ser criadas para preparar o sistema para eventos imprevistos. A natureza dinâmica do sistema requer que, por exemplo, tempos de folga sejam adicionados ao programa, objetivando acomodar filas, quebras de máquinas, e a chegada de ordens prioritárias (rush jobs). 
ii. Eventos aleatórios ocorrem frequentemente, demandando por modificações de menor ou maior grau no programa existente. $O$ processo de reprogramação deve satisfazer a certas restrições que não somente aquelas funcionais, tais como, a realização de alterações mínimas, mesmo que um programa ótimo não possa ser gerado. Isto implica na construção de programas mais robustos em contraposição a programas mais frágeis.

A robustez é uma propriedade do programa de produção. Ela procura mensurar o quanto o programa de produção original poderia "absorver" de alterações de programação ocasionadas por mudanças de ordem estocástica no ambiente de produção com a menor alteração da função-objetivo. PINEDO (2002, p.202) apresenta formas de mensurar quantitativamente a robustez.

O impacto da aleatoriedade encontrada nos sistemas reais pode ser minimizado através de diversos mecanismos. Um destes mecanismos estabelece um período dentro do qual o programa de produção (estático) não pode ser re-gerado (reprogramado). Caso seja necessário regerá-lo dentro deste período, negociações necessitam ocorrer. Tal período é definido por alguns autores com período de congelamento do programa.

Segundo VOLLMAN; BERRY; WHYBARK (1997, p.246), o período de congelamento estabelece um objetivo estável para a manufatura alcançar. Quanto maior o período maior será a estabilidade do processo, porém maior também será a obsolescência das informações.

A abordagem estática é a adotada por grande parte dos sistemas modernos de programação informatizados. Partindo-se de posições atualizadas da produção, da carteira de pedidos e de previsões de demanda coletados, respectivamente, das bases de dados do sistema de controle da produção e processamento de pedidos, o sistema de programação re-gera (re-programa) parcial ou integralmente o programa de produção, fazendo uso de mecanismos que buscam isolar o sistema de produção de efeitos estocásticos, tais como, as flutuações aleatórias da demanda, absenteísmo e quebra de máquina. Nestes sistemas, o intervalo de tempo que define o período de congelamento é controlado pelo programador da produção ou 
gestor do sistema de produção e é definido para ser compatível com os objetivos táticos da organização.

KUTANOGLU; SABUNCUOGLU (2001) propõem um modelo de simulação da programação da produção e avaliam os efeitos estocásticos na sua eficácia. O modelo proposto tem o objetivo de reproduzir a execução da produção no sistema real e avaliar alternativas de políticas de programação, auxiliando o tomador de decisão nas seguintes tarefas: 1) seleção de regras de priorização (as melhores para um dado cenário de simulação); 2) na construção, implementação e re-geração do programa de produção; 3) na atualização de parâmetros de execução da produção. No estudo, os autores avaliam (confrontam) três técnicas de programação que foram propostas em estudos anteriores com o propósito de minimizar o impacto da obsolescência das decisões de programação devido ao efeito estocástico do ambiente real. As técnicas selecionadas no estudo são: 1) procedimento de uma só passagem usando regras de priorização simples (single-pass procedure), 2) procedimento de múltiplas passagens para seleção da melhor regra (multi-pass procedure) e 3) iteração de lead time. Tais técnicas são inseridas na forma de algoritmos computacionais dentro um modelo estocástico de simulação de um sistema job shop simples. Os autores propõem ainda a inserção do modelo de simulação em um sistema de apoio a decisão.

Este artigo foi particularmente importante para a esta pesquisa, pois o modelo de simulação computacional desenvolvido por eles inspirou o desenvolvimento dos procedimentos de programação inseridos no método heurístico proposto nesta dissertação. 


\section{Descrição do Método de Solução Proposto}

O método de programação desenvolvido nesta pesquisa é fundamentado no seguinte raciocínio: a melhoria na sincronização de operações de montagem em sistemas de produção assembly shop leva ao melhor atendimento de datas de entrega de pedidos. Este raciocínio pressupõe que se fosse possível fazer chegar simultaneamente a cada centro de montagem todos componentes individuais necessários para que as montagens fossem realizadas sem espera por falta de componentes, o sistema de produção alcançaria um nível de fluência de materiais que ocasionaria o atendimento otimizado das datas de entrega.

Outra pressuposição adotada na concepção do método é a de que a simulação iterativa da programação em modelos determinísticos e probabilísticos do sistema de produção leva à criação de programas de produção mais robustos.

Baseado nas pressuposições anteriores, o método de programação proposto foi desenvolvido para implementar, em uma única estrutura algorítmica, um mecanismo iterativo de simulação que programa operações dentro de dois modelos de simulação do sistema assembly shop, a saber:

i. O modelo determinístico, onde todas as variáveis que descrevem o sistema têm comportamentos determinísticos;

ii. O modelo probabilístico, onde a variável descritiva 'tempo de processamento' tem comportamento estocástico enquanto que as demais variáveis descritivas mantêm comportamentos determinísticos.

A programação em ambos os modelos de simulação é realizada utilizando duas abordagens:

i. A primeira abordagem, denominada backward, programa as operações para trás no tempo a partir das datas de entrega dos pedidos, atendendo completamente a estas datas. 
ii. A segunda abordagem, denominada forward, programa as operações para frente no tempo a partir das datas de chegada dos pedidos ao sistema, satisfazendo completamente as restrições de capacidade dos recursos produtivos.

Resumidamente, o mecanismo iterativo de simulação implementa dois modelos de simulação (determinístico e probabilístico) e duas abordagens de programação (backward e forward) que, trabalhando iterativamente, buscam melhorar a sincronização das operações e, consequentemente, construir um programa de produção teoricamente mais robusto.

O funcionamento do mecanismo iterativo de simulação é apresentado a seguir.

\subsection{Mecanismo de simulação iterativa da programação}

A Figura 9 ilustra o fluxo de processamento de informações do mecanismo de simulação iterativa da programação assembly shop.

O Mecanismo Iterativo de Simulação (MIS) é uma estrutura algorítmica subdividida em três funções ou rotinas principais:

1. A primeira rotina, denominada rotina geradora, é responsável pela geração do conjunto de operações a programar. Ela usa as quantidades dos pedidos de venda, os roteiros de produção e as estruturas de materiais para gerar (1) o conjunto de operações que deve ser programado, (2) a estrutura de precedência das operações e (3) os tempos padrões de processamento das operações.

2. A segunda rotina, denominada rotina backward, é responsável por programar as operações através da abordagem backward. Ela usa as datas de entrega dos pedidos, a estrutura de precedência, os tempos padrões de processamento e as estimativas de tempo de fila das operações para programar o conjunto de operações para trás no tempo a partir das datas de entrega dos pedidos, gerando um sistema de datas preliminares de término 
das operações. Esta rotina atende completamente as datas de entrega dos pedidos. Entretanto, ela não considera as restrições de capacidade dos recursos produtivos.

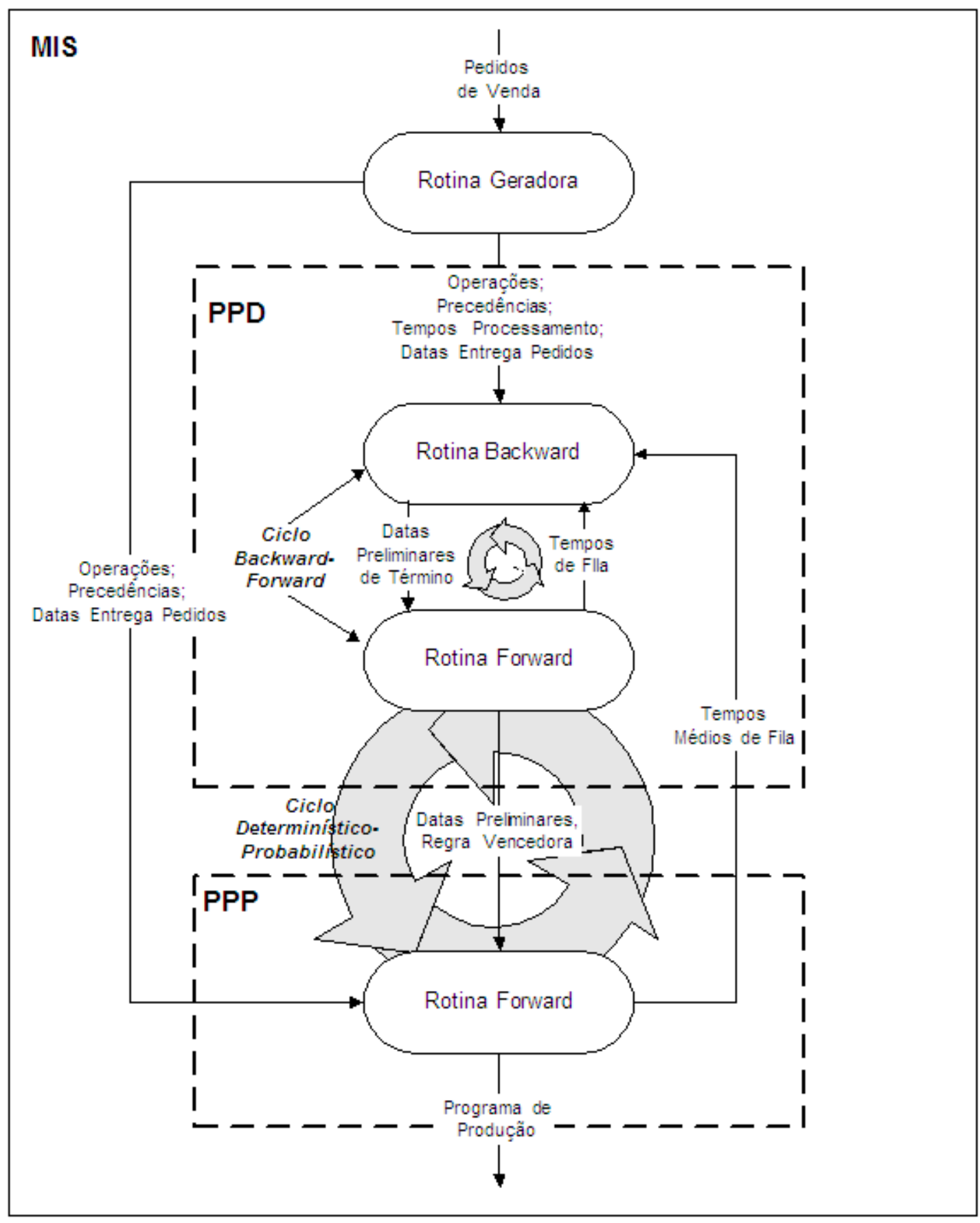

Figura 9 - Fluxo de processamento do MIS. 
3. A terceira rotina, denominada rotina forward, é responsável por programar as operações através da abordagem forward. Ela usa a estrutura de precedência e os tempos de processamento das operações para programar o conjunto de operações para frente no tempo a partir da data de chegada das ordens no sistema. Esta rotina considera as restrições de capacidade dos recursos produtivos. Ela usa regras de priorização orientadas por data de entrega para solucionar os eventos de conflito de alocação de operações concorrentes nos recursos produtivos. Entretanto, esta rotina não atende necessariamente a todas as datas de entrega dos pedidos.

O detalhamento das rotinas geradora, backward e forward é feito mais adiante neste capítulo.

O MIS executa as rotinas backward e forward sucessivas vezes dentro de dois procedimentos de programação, a saber:

1. O primeiro procedimento, denominado Procedimento de Programação Determinística (PPD), é executado dentro do modelo computacional de simulação determinística do sistema assembly shop. O PPD é uma subestrutura algorítmica responsável pela programação determinística das operações.

2. O segundo procedimento, denominado Procedimento de Programação Probabilística (PPP), é executado dentro do modelo computacional de simulação estocástica do sistema assembly shop. O PPP é uma subestrutura algorítmica responsável pela programação probabilística das operações.

Na Figura 9, o PPD e o PPP são definidos pelos quadrados tracejados.

O funcionamento detalhado de ambos os procedimentos de programação é apresentado a seguir. 


\subsubsection{Procedimento de programação determinística (PPD)}

Este procedimento realiza a programação das operações assumindo que todas as variáveis e atributos que descrevem o sistema (as datas de entrega dos pedidos, as datas de liberação das ordens, a quantidade de ordens que chegam ao sistema, o intervalo entre chegadas, os tempos de processamento das operações, os roteiros de produção, o conjunto de máquinas disponíveis, dentre outras variáveis e atributos descritivos) têm valores fixos e conhecidos com antecedência.

Na Figura 9, o ciclo iterativo backward-forward é representado pelas três setasem-giro menores. A Figura 10 esquematiza o PPD. As rotinas backward e forward são destacadas em cinza.

Para ser executado, o PPD recebe informações (entradas) provenientes da rotina geradora e do PPP. As principais entradas provenientes da rotina geradora são: (i) o conjunto de operações a programar; (ii) a estrutura de precedência das operações; (iii) os tempos padrões de processamento das operações; (iv) as datas de entrega dos pedidos. A principal entrada proveniente do PPP são os tempos médios de fila dos recursos produtivos.

O PPD gera como principais saídas:

1. As datas preliminares de término das operações determinadas na melhor iteração do ciclo backward-forward.

2. A regra de priorização que foi executada na melhor iteração do ciclo backward-forward, denominada regra vencedora.

O PPD executa as rotinas backward e forward iterativamente. Em cada execução do MIS, o PPD realiza várias execuções destas duas rotinas. Elas trocam informações entre si objetivando melhorar sucessivamente o processo de programação determinística. As iterações realizadas entre estas duas rotinas definem o ciclo iterativo backward-forward. 


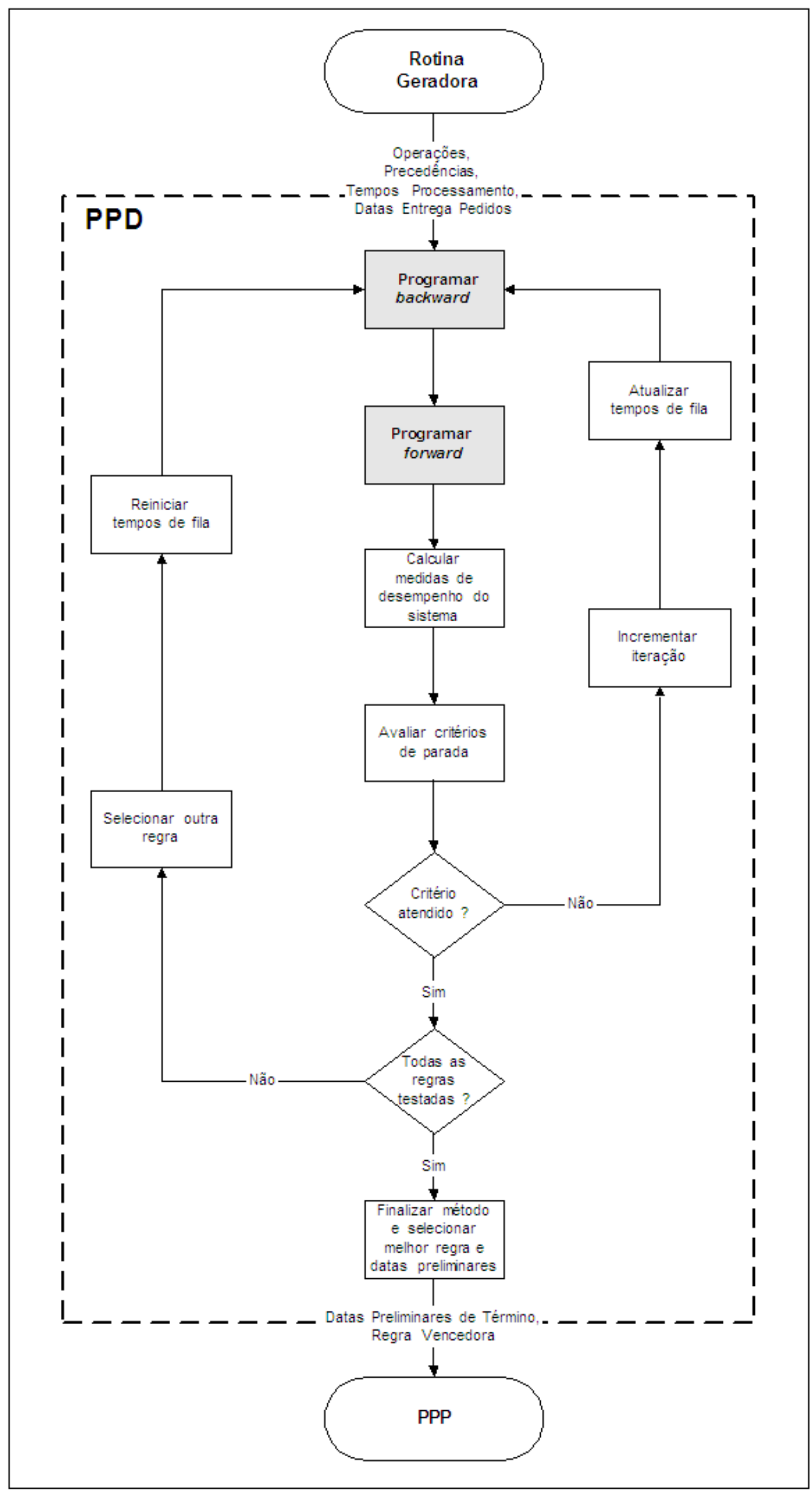

Figura 10 - Fluxo de processamento do PPD. 
Durante o processo iterativo backward-forward, o PPD executa todas as regras de priorização do conjunto, selecionando uma regra por vez e construindo um programa de produção para cada regra e para cada iteração. Em cada iteração, o valor da função-objetivo é calculado e armazenado junto com a informação da regra que o gerou. Cada regra é testada várias vezes (por várias iterações) até que um critério de parada seja atendido. Em outras palavras, o PPD executa várias vezes as rotinas backward e forward para cada regra de priorização até que o critério de parada seja atendido. O critério de parada é avaliado por outra rotina do MIS denominada rotina de avaliação incremental do valor da função-objetivo, descrita mais adiante neste capítulo. Todas as vezes que o MIS troca de regra, os tempos de médios de fila, provenientes da execução anterior do PPP, são utilizados na primeira iteração da nova regra. Ao final do processo iterativo do PPD, a regra que obteve o melhor desempenho dentre todas as iterações é eleita vencedora. A regra vencedora é então passada para o PPP junto com as datas preliminares de término das operações geradas na iteração que definiu a regra vendedora.

\subsubsection{Procedimento de programação probabilística (PPP)}

Este procedimento realiza a programação das operações assumindo que os tempos de processamento das operações têm comportamento estocástico e todas as demais variáveis descritivas do problema têm comportamento determinístico, ou seja, têm valores fixos e conhecidos com antecedência.

Para ser executado, o PPP recebe informações (entradas) provenientes da rotina geradora e do PPD. As principais entradas provenientes da rotina geradora: (i) 0 conjunto de operações a programar; (ii) a estrutura de precedência das operações; (iii) as datas de entrega dos pedidos. As principais entradas provenientes do PPD são: (a) as datas preliminares de término das operações geradas na melhor iteração do ciclo backward-forward; (b) a regra de priorização que foi executada na melhor iteração do ciclo backward-forward, denominada regra vencedora.

O PPP gera como principais saídas: 
1. Os tempos (probabilísticos) médios de fila dos recursos produtivos.

2. O programa de produção.

O PPP e o PPD trabalham iterativamente. As informações (saídas) geradas pelo PPP são retornadas ao PPD para serem usadas em uma nova execução de ambos os procedimentos. As iterações realizadas entre o PPD e o PPP definem o ciclo iterativo determinístico-probabilístico. Na Figura 9, o ciclo iterativo determinísticoprobabilístico é representado pelas três setas-em-giro maiores.

O PPP executa apenas a rotina forward. As datas preliminares de término e a regra vencedora gerados pelo PPD são passadas para a rotina forward que as utiliza, conjuntamente com os tempos de processamento probabilísticos das operações, para programar a produção para frente no tempo. Os tempos probabilísticos de processamento são selecionados de distribuições de probabilidades predefinidas, vinculadas às operações dos roteiros de produção.

No final de sua execução, o PPP gera um novo conjunto de tempos (probabilísticos) de fila das operações que são usados para calcular os tempos (probabilísticos) médios de fila dos recursos. Os tempos médios de fila são, então, passados para o PPD para serem usados na primeira iteração backward-forward, iniciando assim um novo ciclo iterativo determinístico-probabilístico.

Dentro de uma mesma execução do MIS, várias iterações do ciclo determinísticoprobabilístico podem ocorrer. Após um número pré-definido de iterações do ciclo determinístico-probabilístico e diversos programas de produção intermediários criados, o MIS gera o programa de produção final a ser implementado no chão-defábrica. O número-limite de iterações deste tipo $\left(\tau_{\lim }\right)$ é um parâmetro de execução do MIS. Vale salientar que o mesmo conjunto de operações é programado em todas as iterações determinístico-probabilísticas. 


\subsubsection{Horizonte e período de programação}

O MIS usa intervalos de tempo distintos em cada procedimento de programação. Ele limita a programação determinística pelo intervalo de tempo denominado horizonte de programação $(\mathbf{H})$. A programação probabilística, por sua vez, é executada dentro do período de programação $(\mathrm{T})$. O horizonte de programação corresponde a vários períodos de programação. Tanto o horizonte de programação quanto o período de programação são parâmetros de execução do MIS.

O MIS pode ser executado em um contexto baseado na estratégia de rolagem dos horizontes de programação ((HAX; CANDEA, 1984, p.76); (VOLLMAN; BERRY; WHYBARK, 1997, p.213)). Dentro desta estratégia, ao final da execução do MIS para o período de programação atual, novas informações (pedidos novos e status da produção) tornam-se disponíveis e são usadas na re-execução do MIS para os períodos seguintes. Esta estratégia é adotada no procedimento experimental descrito nos Capítulos 6 e 7.

A Figura 11 apresenta graficamente a relação entre $\mathbf{H}$ e $\mathbf{T}$ para $\mathbf{n}$ execuções do MIS. Na figura, os horizontes de programação $\left(H_{1}, H_{2}, \ldots, H_{n}\right)$ projetam-se vários intervalos temporais a frente dos períodos de programação $\left(T_{1}, T_{2}, \ldots, T_{n}\right)$. Cada instante $\mathbf{t}_{\mathbf{i}}$ corresponde a um ponto de início de uma nova execução do MIS. Cada ciclo começa com a (re)programação determinística, onde os tempos médios de fila e o estado do sistema assembly shop (operações finalizadas, em execução ou não iniciadas), determinados ao final do período de programação probabilística anterior, são usados pelo PPD. A programação determinística é executada dentro do próximo $\mathrm{H}_{\mathrm{i}}$ que, ao final, passa a regra de priorização vencedora e as respectivas datas preliminares para a subsequente (re)execução da programação probabilística pelo PPP, limitada por $T_{i}$. Vale observar que os horizontes e períodos de programação não necessitam ser fixados, podendo variar a cada execução do MIS. 


\subsection{Rotina geradora de operações}

A rotina geradora é responsável por:

a. Realizar a explosão de necessidades a partir dos registros de pedidos de venda das montagens finais, calculando as quantidades de produção de cada item.

b. Gerar as operações de todos os itens produzidos, ou seja, dos itens montados, de seus componentes, dos componentes de seus componentes e assim por diante.

c. Gerar a estrutura de precedência das operações.

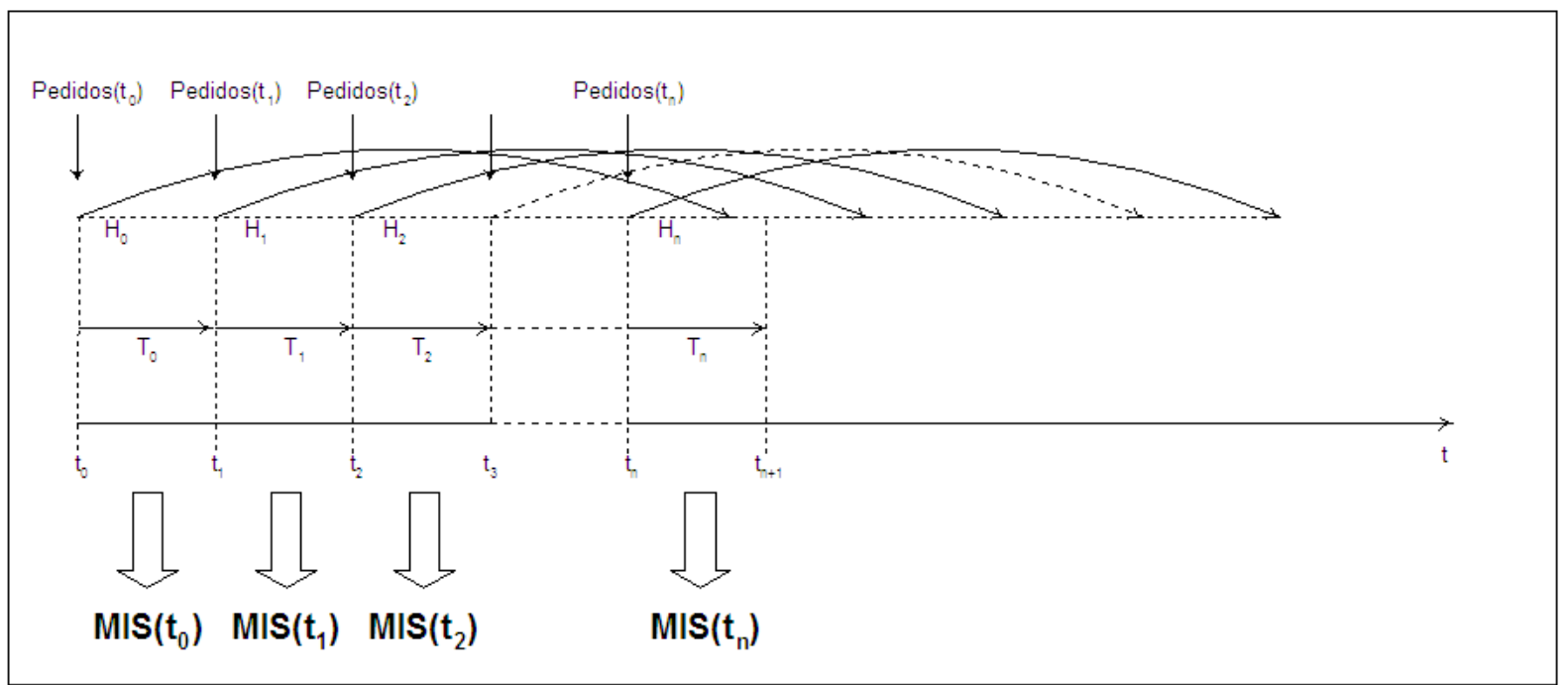

Figura 11 - Rolagem do horizonte e período de programação.

A rotina utiliza três entidades (estruturas) de dados de entrada principais para a geração das necessidades líquidas, do conjunto de operações e de suas precedências, a saber: o pedido de venda, o roteiro de produção e a estrutura de materiais.

O pedido de venda define a demanda colocada para a montagem final em determinado período. Os principais atributos do pedido de venda utilizados pela 
rotina são: a data de entrega, a quantidade requerida e o código (identificador) da montagem final.

O roteiro de produção define as operações que devem ser executadas para a obtenção do item produzido. Os principais atributos do roteiro de produção utilizados pela rotina são: o código do item, a sequência de execução da operação no roteiro e o tempo-padrão de ciclo de cada operação no recurso produtivo.

A estrutura de materiais define a composição de cada item montado e, em última instância, a estrutura de precedência entre o item, seus componentes, os componentes de seus componentes e assim por diante. Os principais atributos da estrutura de materiais utilizados pela rotina são: o código da montagem, o código do componente e a quantidade-padrão de cada componente, necessária para a produção de cada unidade do item montado.

Uma vez selecionados os registros de dados destas três entidades, a rotina executa o processo de cálculo (ou explosão) de necessidades de materiais. Através deste processo, a quantidade demandada (bruta) de determinado item montado é traduzida (explodida) para as quantidades necessárias de seus componentes. Neste processo, o tamanho do lote de produção de cada componente é determinado através de alguma técnica de dimensionamento de lotes (lot sizing), como por exemplo, a técnica denominada 'lote-a-lote'. O resultado da explosão de necessidades são as quantidades (líquidas) a produzir dos itens individuais, das submontagens e das montagens finais.

O cálculo de necessidades de materiais foi primeiramente proposto por Orlicky. Uma descrição detalhada deste processo é apresentada em HAX;CANDEA (1984, p.440 ), PLOSSL (1994, p.69) e VOLLMAN; BERRY; WHYBARK (1997, p.21).

Concomitantemente ao processo de explosão de necessidades, a rotina geradora:

a. Cria as operações de cada item produzido. Cada operação tem como principais atributos: 1) o número do pedido, 2) um identificador que the 
garante unicidade dentro do conjunto de todas as operações, 3) a sequência de execução dentro do roteiro, 4) as operações precedentes, e 5) o tempo de processamento.

b. Cria a estrutura de precedência de operações. As estruturas de precedência são criadas com base nas estruturas de materiais e roteiros de produção de cada componente.

c. Calcula o tempo-padrão de processamento de cada operação. O tempopadrão de processamento é calculado multiplicando a quantidade (líquida) a produzir, calculada pela explosão de necessidades, pelo tempo-padrão de ciclo da operação.

Ao final de sua execução, a rotina geradora passa o conjunto de operações a programar, a estrutura de precedência das operações e os tempos padrões de processamento para o PPD e o PPP.

A Figura 12 ilustra a estrutura da rotina geradora e seu relacionamento com 0 PPD e o PPP.

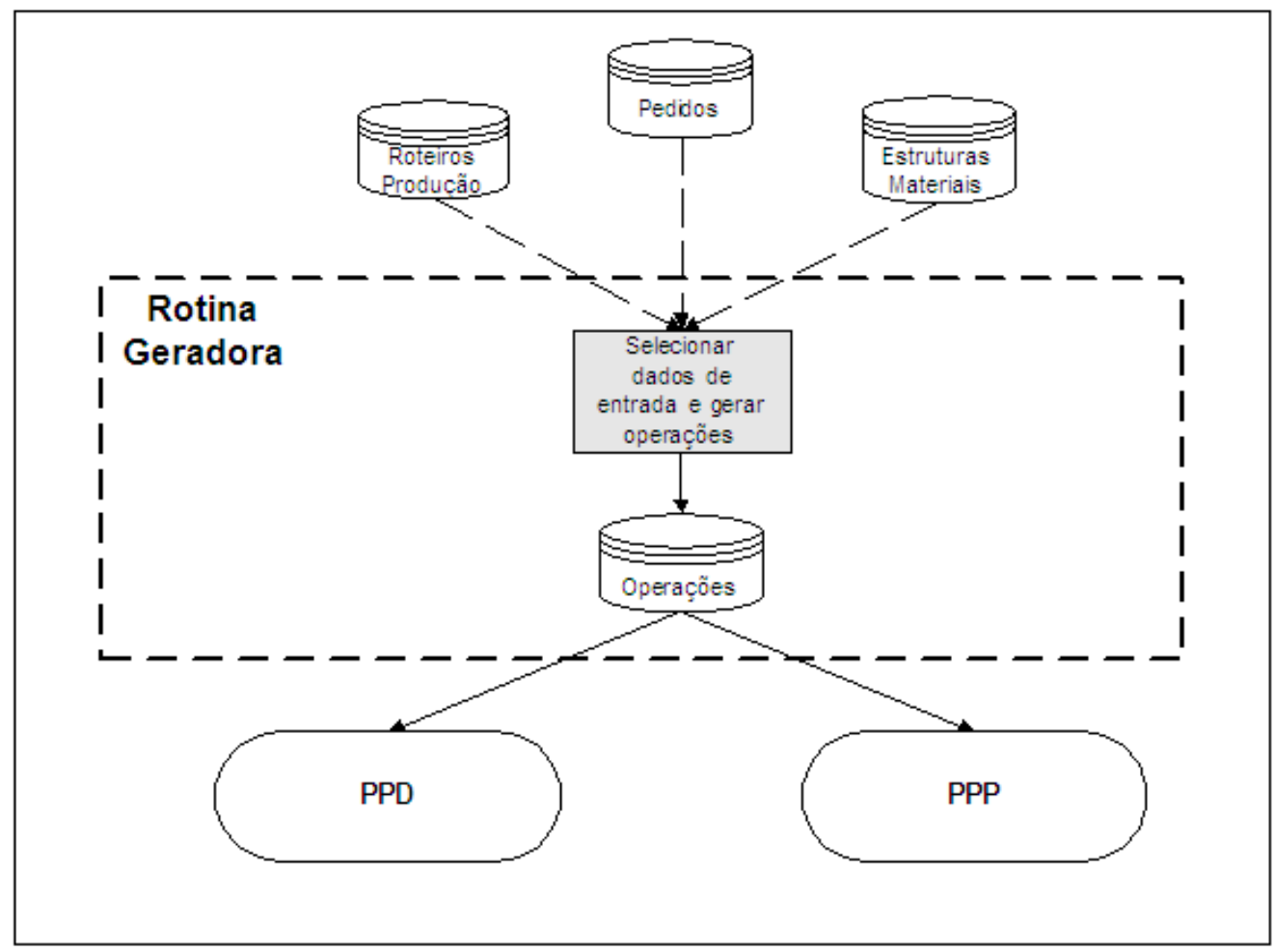

Figura 12 - Rotina geradora de operações. 


\subsection{Rotina backward de programação de operações}

A rotina backward é uma subestrutura algorítmica responsável por determinar as datas preliminares de término das operações. A razão fundamental por trás desta rotina é iniciar cada operação tanto mais tarde quanto possível, gerando um sistema de datas de entrega usado posteriormente pela rotina forward. A idéia por traz da utilização de um sistema de datas preliminares para nortear a programação forward foi inspirada em CONWAY; MAXWELL; MILLER (1967, p.243).

A data preliminar de término $\left(d_{i s}^{j}\right)$ é determinada com base na estrutura de precedência das operações através da fórmula

$$
d_{i s}^{j}=d_{j}-\sum_{i \in R_{n}^{*}(i, s, j)}\left(w_{i s}^{j}+p_{i s}^{j}\right)
$$

onde $p_{i s}^{j}$ é o tempo-padrão de processamento da operação $\boldsymbol{i}$ do item $s$ da ordem $\boldsymbol{j}$; $w_{i s}^{j}$ é a estimativa do tempo de fila; $d_{j}$ é a data de entrega da ordem $\boldsymbol{j} ; R_{n}^{*}(i, s, j)$ é o conjunto das operações da ramificação $R_{n}(j)$ da ordem $\boldsymbol{j}$ ainda não iniciadas, partindo-se da operação $i$ já concluída $\left(R_{n}^{*}(i, s, j) \in R_{n}(j)\right)$.

Os conjuntos $R_{n}(j)$ são gerados a partir das estruturas de precedência das operações criadas pela rotina geradora.

O exemplo a seguir ilustra o processo de determinação das datas preliminares de término das operações de duas montagens ( $\mathbf{A}$ e $\mathbf{B}$ ) que compartilham os mesmos recursos produtivos. As estruturas de ambas as montagens são apresentadas na Figura 13. Na figura, os blocos representam os itens e os círculos as operações dos respectivos roteiros de produção. Cada operação é identificada unicamente pelo número no interior do círculo. O tempo estimado de fila, o tempo-padrão de processamento, a máquina $\left(\mathrm{M}_{\mathrm{k}}\right)$ e centro de montagem $\left(\mathrm{CM}_{\mathrm{k}}\right)$ de cada operação são 
apresentados entre parênteses ao lado de cada círculo. A data de entrega de cada montagem é apresentada entre parênteses ao lado dos blocos A e $\mathbf{B}$.

A estrutura da montagem A possui duas ramificações de operações. Cada ramificação é definida pelo conjunto $R_{n}(A)$ de operações. A montagem A possui dois conjuntos, denotados por $R_{1}(A)$ e $R_{2}(A)$, com $R_{1}(A)=\{1,2,3\}$ e $R_{2}(A)=\{1,4,5,6\}$. Por sua vez, a montagem $\mathbf{B}$ possui os conjuntos $R_{1}(B)=\{7,8,9,10\}$ e $R_{2}(B)=\{7,11,12\}$.

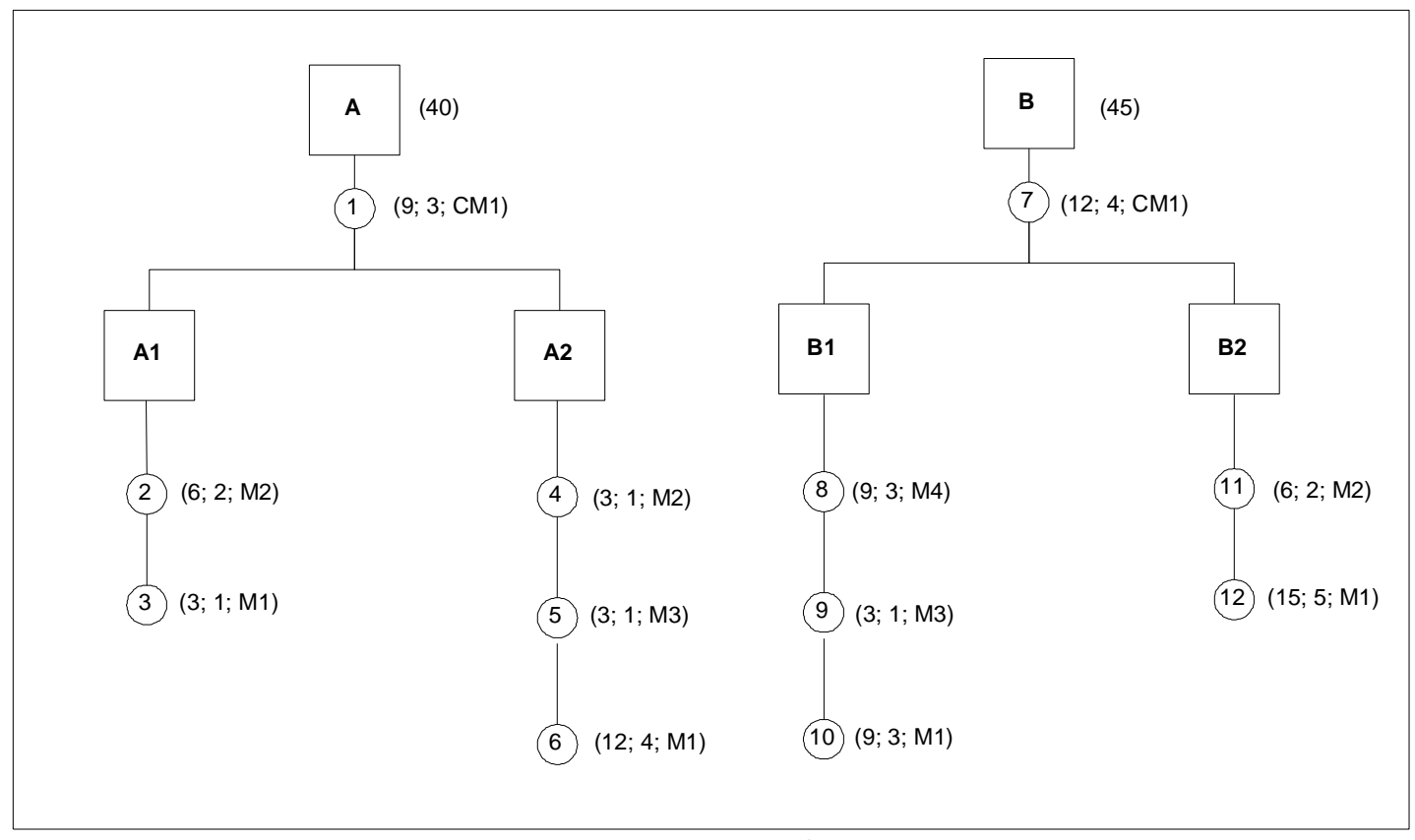

Figura 13 - Estrutura de materiais e operações do exemplo.

A partir do conjunto $R_{n}(j)$ são gerados os conjuntos $R_{n}^{*}(i, s, j)$ que agrupam operações ainda não executadas na ramificação partindo da operação $i$ já concluída. Portanto, a partir de $R_{1}(A)$ são gerados os subconjuntos $R_{1}^{*}(1, A, A)=\{\}$, $R_{1}^{*}(2, A 1, A)=\{1\}$ e $R_{1}^{*}(3, A 1, A)=\{1,2\}$. O mesmo procedimento é realizado para de $R_{2}(A)$. 
A partir do conjunto $R_{1}(B)$ são gerados os subconjuntos $R_{1}^{*}(7, B, B)=\{\}, R_{1}^{*}(8, B 1, B)=\{7\}, R_{1}^{*}(9, B 1, B)=\{7,8\}$ e $R_{1}^{*}(10, B 1, B)=\{7,8,9\}$. O procedimento análogo é realizado para $R_{2}(B)$.

Com base nos conjuntos $R_{n}^{*}(i, s, j)$, nos tempos padrões de processamento e de fila e na data de entrega de cada montagem, a rotina backward determina as datas preliminares de término de cada operação. Tomando-se, por exemplo, a operação $i=9$ da montagem $\mathbf{B}$, tem-se:

$$
d_{9, B 1}^{B}=d_{B}-\sum_{i \in R_{1}^{*}(9, B 1, B)}\left(w_{i, B 1}^{B}+p_{i, B 1}^{B}\right)=45-(16+12)=17
$$

Em outro exemplo, a data de término da operação $i=6$ da montagem $\mathbf{A}$ é determinada como:

$$
d_{6, A 2}^{A}=d_{A}-\sum_{i \in R_{2}^{*}(6, A 2, A)}\left(w_{i, A 2}^{A}+p_{i, A 2}^{A}\right)=40-(12+4+4)=20
$$

A Tabela 5.1 apresenta as datas preliminares de entrega dos roteiros das duas montagens.

É importante observar que as datas de término de $\mathbf{A} 1(\boldsymbol{i}=2)$ e $\mathbf{A} 2(\boldsymbol{i}=4)$ são coincidentes $\left(d_{i j}=28\right)$, assim como as datas de término de $\mathbf{B 1}(\boldsymbol{i}=8)$ e $\mathbf{B 2}(\boldsymbol{i}=11)$ também o são $\left(d_{i j}=31\right)$. A coincidência entre as datas de término dos componentes de uma mesma montagem pode ser dita como sendo o principal resultado do processo backward. Esta coincidência tem a pretensão de proporcionar uma melhor orientação à rotina forward durante a geração das datas programadas de início das operações, orientação esta que objetiva proporcionar a sincronização do término da execução das operações quando de suas implementações no chãode-fábrica e, consequentemente, a chegada simultânea dos componentes ao centro de montagem. 
Tabela 5.1 - Datas preliminares do exemplo.

\begin{tabular}{|c|c|c|}
\hline Item & Operação & $d_{i s}^{j}$ \\
\hline $\mathrm{A}$ & 1 & 40 \\
\hline $\mathrm{A} 1$ & 2 & 28 \\
\hline $\mathrm{A} 1$ & 3 & 20 \\
\hline $\mathrm{A} 2$ & 4 & 28 \\
\hline $\mathrm{A} 2$ & 5 & 24 \\
\hline $\mathrm{A} 2$ & 6 & 20 \\
\hline $\mathrm{B}$ & 7 & 45 \\
\hline $\mathrm{B} 1$ & 8 & 29 \\
\hline $\mathrm{B} 1$ & 9 & 17 \\
\hline $\mathrm{B} 1$ & 10 & 13 \\
\hline $\mathrm{B} 2$ & 11 & 29 \\
\hline $\mathrm{B} 2$ & 12 & 21 \\
\hline
\end{tabular}

Com base na data de término de cada operação é possível facilmente determinar a data de início, bastando para isto serem subtraídos destas os valores correspondentes dos tempos de fila e processamento da operação.

Ao aplicar o procedimento descrito acima para determinar as datas de início e término de cada operação, a rotina backward satisfaz completamente as datas de entrega dos pedidos. Porém, ela não considera explicitamente as limitações de capacidade dos recursos produtivos, permitindo a programação simultânea de mais de uma operação por recurso. Com a restrição de simultaneidade relaxada, a probabilidade de ser gerado um conjunto viável de operações é tanto mais baixa quanto forem ruins as estimativas de lead time dos itens. Isto, em termos práticos, significa dizer que se fosse feito deste conjunto de operações um programa de produção, a sua exequibilidade estaria vinculada a quão acuradas fossem as cadeias de lead times. A execução da rotina de programação forward conjuntamente com o processo iterativo backward-forward possibilita, supostamente, a criação de cadeias de lead times mais acuradas, devido à geração de melhores estimativas de tempo de fila. 
O procedimento de criação e manutenção do sistema de datas de preliminares é inspirada no procedimento denominado Lead Time Offsetting (LTO) descrito em HAX;CANDEA (1984, p.440), PLOSSL (1994, p.69) e VOLLMAN; BERRY; WHYBARK (1997, p.21). Porém, devido ao ciclo backward-forward, a rotina backward trabalha de maneira mais detalhada e tende a operar de forma mais acurada que o LTO.

\subsection{Rotina forward de programação de operações}

A rotina backward cria um sistema de datas (sugerido por CONWAY; MAXWELL; MILLER, 1967) onde uma data de início e outra de término são atribuídas a cada operação. A rotina forward utiliza este sistema de datas para construir um programa teoricamente viável que busca minimizar o atraso de atendimento.

A rotina forward é uma subestrutura algorítmica responsável por gerar efetivamente um programa de produção teoricamente viável, pois satisfaz a restrição de programar apenas uma operação por vez no recurso produtivo (restrição de simultaneidade). Esta rotina é por si uma heurística construtiva que gera programassem-espera ${ }^{1}$ utilizando 0 mecanismo-de-uma-só-passagem (single-pass procedure) para alocar as operações aos recursos. Através deste mecanismo, nenhum recurso é mantido ocioso se existirem operações disponíveis (na fila) para serem processadas. Através do mecanismo-de-uma-só-passagem, uma data de início e outra de término são permanentemente "fixadas" à operação no primeiro instante em que são atribuídas. Com isto, o programa completo pode ser gerado com uma única passagem pelo conjunto de operações. Este mecanismo difere do mecanismo-de-ajuste (backtracking) pelo qual novas datas de início e término podem ser atribuídas a qualquer operação já programada anteriormente após subsequentes operações já terem sido adicionadas ao programa (parcial) de produção. Para uma discussão detalhada de ambos os procedimentos de programação, vide BAKER (1974, p.187-188).

\footnotetext{
${ }^{1} \mathrm{O}$ conceito de programa-sem-espera é apresentado no Capítulo 3.
} 
A rotina forward percorre uma única ramificação da árvore de soluções à medida que monta o programa de produção. Dentro da árvore, o mecanismo-de-uma-sópassagem constrói um único caminho do nó inicial (programa "vazio") até algum nó final (última operação alocada), correspondendo a uma única solução completa (programa completo). Desta maneira, um único programa é construído em uma única passagem pela árvore de soluções. A seleção de uma e somente uma operação em cada nó é garantida pela utilização de uma regra de priorização. Desta forma, todas as vezes que a rotina identifica uma situação de conflito de alocação (mais do que uma operação elegível em um determinado nó), a regra de priorização é usada para forçar a escolha de uma e somente uma operação, resolvendo o conflito de alocação (simultaneidade) naquele nó (BAKER, 1974, p.195-196).

A rotina forward é executada tanto pelo PPD quanto pelo PPP. Entretanto, dentro do PPD, ela é executada diversas vezes (ciclo backward-forward), enquanto que dentro do PPP, a rotina é executada uma única vez.

A rotina forward executada dentro do PPD faz uso de um conjunto préestabelecido de regras de priorização orientadas por data de entrega. As datas preliminares de término das operações e entrega dos pedidos são usadas para nortear as regras de priorização. A rotina seleciona uma regra por vez e constrói um programa completo utilizando a regra escolhida. Para cada programa construído, o valor da função-objetivo é armazenado. A mesma regra de priorização é reexecutada várias vezes até que um critério de parada seja atendido. Uma vez atendido o critério de parada, a rotina seleciona outra regra do conjunto e realiza uma nova programação. Neste processo, a rotina forward trabalha iterativamente com a rotina backward. Após testar todas as regras disponíveis do conjunto de regras, o MIS compara os valores da função-objetivo obtidos em todas as iterações e para todas as regras, selecionando a regra que obteve o melhor (menor) valor. Esta regra é eleita vencedora. A regra vencedora é, então, passada para o PPP para ser usada em uma única execução da rotina forward, agora dentro de um contexto probabilístico. 
A Tabela 5.2 apresenta um exemplo de valores da função-objetivo (menor atraso médio) para um conjunto de 4 regras, nas respectivas iterações. A regra vencedora do exemplo é a ODD, pois obteve o menor valor (70) para a função-objetivo (FO) dentre todas as iterações.

O mecanismo iterativo backward-forward (executado pelo PPD) tem o objetivo de gerar melhores estimativas de tempo de fila para cada operação. Para cada regra utilizada, um número de iterações é realizado (vide Seção '5.6 - Rotina de avaliação da função-objetivo'). A pressuposição por trás do mecanismo iterativo backwardforward é a seguinte: as estimativas de tempo de fila geradas pela rotina forward na iteração atual serão ponderadas (suavizadas) e usadas pela rotina backward na próxima iteração para gerar datas preliminares de término de operações mais acuradas, o que, por sua vez, direcionará melhor o mecanismo-de-uma-sópassagem durante a resolução de conflitos de alocação de operações na próxima execução da rotina forward. A Seção 5.7 deste capítulo ('Atualização das estimativas de tempo de fila') descreve como é realizada a atualização (suavização) das estimativas de tempo de fila.

Tabela 5.2 - Valores da FO por regra.

\begin{tabular}{|c|c|c|}
\hline Regra & Iteração & Valor FO \\
\hline EDD & 1 & 90 \\
\hline EDD & 2 & 100 \\
\hline EDD & 3 & 80 \\
\hline ODD & 1 & 110 \\
\hline$\underline{\text { ODD }}$ & $\underline{\mathbf{2}}$ & $\underline{\mathbf{7 0}}$ \\
\hline ODD & 3 & 95 \\
\hline SOPN & 1 & 110 \\
\hline SOPN & 2 & 130 \\
\hline SOPN & 3 & 125 \\
\hline SLACK & 1 & 90 \\
\hline SLACK & 2 & 80 \\
\hline SLACK & 3 & 105 \\
\hline
\end{tabular}


A execução da rotina forward dentro do PPD difere daquela realizada dentro do PPP apenas pelo uso dos tempos de processamento (determinísticos e probabilísticos). O PPD usa tempos-padrões de processamento (determinísticos), enquanto que o PPP usa tempos de processamento probabilísticos selecionados de funções de distribuição de probabilidades vinculadas às operações dos roteiros de produção.

A seguir, é apresentado o algoritmo de programação inserido na rotina forward. Este algoritmo é uma variação do algoritmo heurístico de Baker (BAKER, 1974, p.196) para a geração de programas-sem-espera.

Para a descrição do algoritmo a seguinte notação é utilizada:

- $O$ : conjunto de todas as operações programadas pela rotina backward.

- $O R_{\tau}$ : conjunto das operações restantes na iteração $\tau$.

- $O P_{\tau}$ : conjunto das operações programáveis na iteração $\tau$.

- $P P_{\tau}$ : programa parcial, contendo todas as operações programadas na iteração $\tau$.

- $a_{i}$ : data-mais-cedo na qual a operação $i \in O P$ poderia ser iniciada ${ }^{1}$.

- $\theta_{k}$ : data de liberação do recurso $k$ na iteração.

- $\sigma_{i}=\left\{\begin{array}{l}\theta_{k}, \text { se } \theta_{k} \geq a_{i} \\ a_{i}, \text { se } \theta_{k}<a_{i}\end{array}\right.$

A variável $\sigma_{i}$ é a data potencial de início da operação $\boldsymbol{i}$ sendo determinada comparando-se a maior data de término dentre as operações predecessoras diretas de $\boldsymbol{i}\left(a_{i}\right)$ e a data de liberação da máquina $\boldsymbol{k}$ onde a operação deve ser processada $\left(\theta_{k}\right)$. A maior dentre estas duas datas é assumida por $\sigma_{i}$.

\footnotetext{
${ }^{1}$ Para maior clareza na apresentação, os índices da máquina $(k)$ e da ordem $(j)$ foram omitidos em $a_{i}$ e $\sigma_{i}$.
} 


\section{$>$ Algoritmo de programação forward}

Passo 1. Inicialização: $O R_{0}=O ; P P_{0}=\{\} ; O P_{0}=\{\}$.

Passo 2. Faça $\tau=1$. Remova as operações sem predecessoras de $O R_{0}$ e as insira em $O P_{1} ; O R_{1}=O R_{0}-O P_{1}$.

Passo 3. Determine $\sigma_{\tau}^{*}=\min _{i \in O P_{\tau}}\left\{\sigma_{i}^{\tau}\right\}=\min _{i \in O P_{\tau}}\left\{\max \left[a_{i}^{\tau} ; \theta_{k}^{\tau}\right]\right\}$ e o recurso $k^{*}$ no qual a operação $i$ que determinou $\sigma_{\tau}^{*}$ deve ser realizada.

Passo 4. Para cada operação $i \in O P_{\tau}$ que requer $k^{*}$ e para a qual $\sigma_{i}^{\tau}=\sigma_{\tau}^{*}$, calcule $\mathrm{o}$ índice de prioridade de acordo com a regra de priorização selecionada; em seguida, ache a operação $i^{*}$ com o menor índice; remova $i^{*}$ de $O P_{\tau}$ e insira-a em $P P_{\tau}$ com data de início $d_{i^{*}}^{\text {ini }}=\sigma_{\tau}^{*} \mathrm{e}$ data de término $d_{i^{*}}^{\text {term }}=d_{i^{*}}^{\text {ini }}+p_{i^{*}}$.

Passo 5. Atualize a data de liberação do recurso $k^{*}$ para $\theta_{k}^{\tau+1}=d_{i^{*}}^{\text {term }}$.

Passo 6. Atualize $a_{i}^{\tau+1}$ das operações sucessoras de $i^{*}$ fazendo $a_{i}^{\tau+1}=d_{i^{*}}^{\text {term }}$; em seguida, remova-as de $O R_{\tau}$ e insira-as em $O P_{\tau+1}$; $O R_{\tau+1}=O R_{\tau}-O P_{\tau+1}$

Passo 7. Se $O R_{\tau+1} \neq\{\}$ e $O P_{\tau+1} \neq\{\}$, faça $\tau \leftarrow \tau+1$, retorne ao Passo 3 e inicie uma nova iteração. Caso contrário $\left(O R_{\tau+1}=\{\}\right.$ e $\left.O P_{\tau+1}=\{\}\right)$, finalize o método para a regra de priorização atual.

Passo 8. Para todas as operações de $P P_{\tau}$, calcule os tempos de fila pela expressão $Q_{i}=d_{i^{*}}^{\text {ini }}-a_{i}^{\tau}$.

Passo 9. Remova as operações programadas de $O$.

Ao final do processo de programação, já com o programa de produção completamente gerado, as estimativas de tempo de fila $Q_{i}$ são selecionadas do conjunto $P P$ e atualizadas no conjunto $O$ para serem usadas: 1) pela rotina backward na determinação de novas datas preliminares de término no próximo ciclo 
iterativo backward-forward do PPD ou 2) pela rotina forward, inserida no PPP, para calcular os tempos médios de fila dos recursos produtivos que, por sua vez, serão usados como estimativas iniciais em um novo ciclo iterativo determinísticoprobabilístico.

O exemplo a seguir descreve o funcionamento da rotina forward na programação das operações das montagens da Figura 13. O exemplo também faz uso dos dados da Tabela 5.1. A regra de priorização escolhida para resolver as situações de conflito de alocação é a ODD-SPT que seleciona a operação com a data de término $\left(d_{i s}^{j}\right)$ mais próxima do instante de programação, usando o menor tempo de processamento da operação $\left(p_{i s}^{j}\right)$ com regra de desempate. Duas iterações do algoritmo são apresentadas.

\section{Iteração 1 - Passo 1}

$\mathrm{Na}$ inicialização da rotina forward, $O R_{0}=\{1,2,3,4,5,6,7,8,9,10,11,12\}$ e $P P_{0}=O P_{0}=\{\}$. Todas as máquinas estão disponíveis para alocação, ou seja, estão ociosas aguardando serem alocadas.

\section{Iteração 1 - Passo 2}

O processo de programação inicia no instante $\mathbf{t}=10$, com a seleção do primeiro subconjunto de operações programáveis para compor $O P_{\tau}$, onde $\tau$ é o índice da iteração. Para a primeira interação $(\tau=1), O P_{1}=\{3,6,10,12\}$ e $O R_{1}=\{1,2,4,5,7$, $8,9,11\}$

\section{Iteração 1 - Passo 3}

Para $O P_{1}, a_{i k}^{\tau}=\left\{a_{31}^{1}, a_{61}^{1}, a_{10,1}^{1}, a_{12,1}^{1}\right\}=\{10,10,10,10\}, \theta_{k}^{\tau}=\left\{\theta_{1}^{1}\right\}=\{0\} ; \operatorname{logo}$ $\sigma_{i k}^{\tau}=\left\{\sigma_{31}^{1}, \sigma_{61}^{1}, \sigma_{10,1}^{1}, \sigma_{12,1}^{1}\right\}=\{10 ; 10 ; 10 ; 10\}$ e $\sigma_{\tau}^{*}=\sigma_{1}^{*}=\{10\}$. 
Como todas as operações de $O P_{1}$ requerem a máquina $\mathrm{M} 1$, a regra ODD deve ser utilizada para resolver o conflito de alocação. A aplicação da regra seleciona a operação B1-10 com $d_{10 ; B 1}^{B}=13$. A operação B1-10 é retirada de $O P_{1}$ e inserida em $P P_{1}$. Logo, $O P_{1}=\{3,6,12\}$ e $P P_{1}=\{10\}$. A data de início de B1-10 é $d_{10}^{\text {ini }}=10$ e a data de término é $d_{10}^{\text {term }}=13$.

\section{$>$ Iteração 1 - Passo 5}

A data de liberação da máquina M1 é $\theta_{1}^{2}=13$.

\section{Iteração 1 - Passo 6}

Uma vez B1-10 programada, a operação sucessora B1-9 é liberada para ser programada. A data-mais-cedo de B1-9 (a ser usada na próxima iteração) é $a_{93}^{2}=13$. Os conjuntos $O P$ e $O R$ atualizados para a próxima iteração ficam $O P_{2}=\{3,6,9$, $12\}$ e $O R_{2}=\{1,2,4,5,7,8,11\}$

\section{Iteração 1 - Passo 7}

Como os conjuntos $\mathrm{OP}_{2}$ e $\mathrm{OR}_{2}$ ainda possuem operações para programar, a segunda iteração deve ser realizada.

\section{Iteração 2 - Passo 3}

Para $O P_{2}, a_{i k}^{\tau}=\left\{a_{31}^{2}, a_{61}^{2}, a_{93}^{2}, a_{12,1}^{2}\right\}=\{10,10,13,10\}, \theta_{k}^{\tau}=\left\{\theta_{1}^{2}, \theta_{3}^{2}\right\}=\{13,0\} ;$ logo $\sigma_{i k}^{\tau}=\left\{\sigma_{31}^{2}, \sigma_{61}^{2}, \sigma_{93}^{2}, \sigma_{12,1}^{2}\right\}=\{13 ; 13 ; 13 ; 13\}$ e $\sigma_{\tau}^{*}=\sigma_{2}^{*}=\{13\}$. 
Para $\sigma_{2}^{*}=\{13\}$, três operações requerem a máquina $\mathrm{M} 1$ e uma requer M3. A regra ODD-SPT deve ser utilizada para resolver o conflito de alocação apenas para M1. A aplicação da regra ODD seleciona duas operações, a saber: A1-3 com $d_{3 ; A 1}^{A}=$ 20 e A2-6 também com $d_{6 ; A 2}^{A}=20$. Neste caso, a regra SPT deve ser acionada. A operação escolhida para ser programada é A1-3 com $p_{3 ; A 1}^{A}=1$. A operação B1-9 também é escolhida. As operações A1-3 e B1-9 são retiradas de $O P_{2}$ e inserida em $P P_{2}$. Logo, $O P_{2}=\{6,12\}$ e $P P_{2}=\{3,9,10\}$. A data de início de A1-3 é $d_{3}^{\text {ini }}=13$ e de término é $d_{3}^{\text {term }}=14$. A data de início de B1-9 é $d_{9}^{\text {ini }}=13$ e de término é $d_{9}^{\text {term }}=$ 14.

\section{Iteração 2 - Passo 5}

A data deliberação da máquina $\mathrm{M} 1$ é $\theta_{1}^{3}=14$. A data de liberação da máquina M3 é $\theta_{3}^{3}=14$.

\section{Iteração 2 - Passo 6}

Uma vez A1-3 e B1-9 programadas, as operações sucessoras B1-8 e A1-2 são liberadas para serem programadas. A data-mais-cedo de B1-8 (a ser usada na próxima iteração) é $a_{84}^{3}=14$. A data-mais-cedo de A1-2 (a ser usada na próxima iteração) é $a_{22}^{3}=14$. Os conjuntos $O P$ e $O R$ atualizados para a próxima iteração ficam $O P_{3}=\{2,6,8,12\}$ e $O R_{3}=\{1,4,5,7,11\}$

\section{Iteração 2 - Passo 7}

Como os conjuntos $\mathrm{OP}_{3}$ e $\mathrm{OR}_{3}$ ainda possuem operações para programar, a terceira iteração deve ser realizada. 


\subsection{Regras de priorização usadas pela rotina forward}

Uma regra de priorização é um procedimento heurístico concebido para usar determinadas informações contextuais do sistema de produção e selecionar uma e somente uma operação do conjunto de operações elegíveis e concorrentes para ser executada no recurso produtivo em um determinado instante do processo de programação. A regra de priorização define um índice de prioridade que é associado a cada operação. As operações são então programadas (ou executadas) no recurso em ordem crescente ou decrescente dos valores do índice de prioridade. Os métodos que fazem uso de regras de priorização sempre solucionam aproximadamente o problema, ou seja, estabelecem programas viáveis, mas não necessariamente ótimos. Alguns autores também utilizam os termos regra de sequenciamento, regra de urgência, disciplina de fila e disciplina de seleção. Nesta dissertação, o termo adotado é regra de priorização.

Como o principal objetivo do método é buscar atender o mais eficientemente possível as datas de entrega dos pedidos (com a melhor sincronização das operações de montagem), regras de priorização orientadas por data de entrega são preferíveis às demais. Mas cabe observar que o método proposto foi concebido para executar qualquer conjunto de regras de priorização selecionado pelo programador ou tomador de decisão.

Nesta pesquisa, cinco regras orientadas por data de entrega foram selecionadas para análise: ODD-SPT (data-mais-cedo de conclusão da operação - tempo de processamento mais curto), EDD-SPT (data-mais-cedo de entrega do pedido tempo de processamento mais curto), SOPN (menor folga média por operação remanescente), SLACK (folga mínima da operação) e CR (razão crítica da operação).

A regra EDD foi selecionada por ser considerada uma regra clássica, por ter formulação matemática simples, por ser um importante parâmetro norteador de atendimento e por ter alcançado bom desempenho em estudos anteriores realizados em sistemas assembly shop estocásticos para o critério de atraso médio de 
atendimento ((ADAM et al., 1993); (FRY et al., 1989); (REEJA; RAJENDRAN, 2000); (HICKS; PONGCHAROEN, 2006); MOHANASUNDARAM et al., 2002))

As regras ODD, SLACK, SOPN e CR foram selecionadas por serem consideradas regras clássicas, sendo costumeiramente utilizadas em estudos de análise de desempenho de sistemas job shops clássicos e assembly shops para o critério de atraso médio de atendimento ((KUTANOGLU; SABUNCUOGLU, 1999); (FRY et al., 1989)). Nesta pesquisa, estas regras foram modificadas para considerarem, explícita ou implicitamente, as datas preliminares de término das operações e as estimativas dos tempos de fila da operação. MORTON; PENTICO (1993) trazem as formulações e descrições detalhadas das versões originais.

A seguir, são apresentadas a descrição e a formulação matemática de cada uma delas.

A regra EDD (data-mais-cedo de entrega do pedido) seleciona a operação cujo pedido tem a menor data de entrega, sendo formulada como:

$$
\min d_{j}
$$

A regra ODD (data-mais-cedo de conclusão da operação) seleciona a operação com menor data de término. Esta regra utiliza, explicitamente, as datas preliminares de término e implicitamente as estimativas de tempo de fila de cada operação geradas pelo ciclo iterativo backward-forward. Ela é formulada como:

$$
\min d_{i s}^{j}=d_{j}-\sum_{i \in R_{n}^{*}(i, s, j)}\left(w_{i s}^{j}+p_{i s}^{j}\right)
$$

onde $R_{n}^{*}(i, s, j)$ é o conjunto das operações da ramificação $R_{n}(j)$ da ordem $j$ ainda não iniciadas, partindo-se da operação $i$ já concluída $\left(R_{n}^{*}(i, s, j) \in R_{n}(j)\right)$.

A regra SPT (menor tempo de processamento da operação) é usada como regra de desempate conjuntamente com as regras EDD e ODD, sendo acionada nos 
casos onde as regras EDD e ODD não conseguem resolver o conflito de concorrência. Esta regra seleciona a operação de menor tempo-padrão de processamento, sendo formulada como:

$$
\min p_{i s}^{j}
$$

A regra SLACK (folga mínima da operação) seleciona a operação com o menor valor de folga total na ramificação, ou seja, é a diferença entre tempo restante de processamento das operações da ramificação (calculado a partir da operação $i$ a ser executada) e 0 instante $\boldsymbol{t}$ atual. Esta regra utiliza, explicitamente, as datas preliminares de término geradas pela rotina backward e, implicitamente, as estimativas de tempo de fila geradas pelo ciclo iterativo backward-forward. Ela é formulada como:

$$
\min \left(d_{i s}^{j}-w_{i s}^{j}-p_{i s}^{j}-t\right)
$$

A regra SOPN (menor folga média por operação remanescente) seleciona a operação com o menor valor de folga média, sendo a folga média calculada pela razão entre o valor da folga total na ramificação e o número de operações faltantes na ramificação, incluindo-se aí a operação a ser programada. Esta regra utiliza, explicitamente, as datas preliminares de término geradas pela rotina backward e, implicitamente, as estimativas de tempo de fila geradas pelo ciclo iterativo backwardforward. Ela é formulada como:

$$
\min \frac{\left(d_{i s}^{j}-w_{i s}^{j}-p_{i s}^{j}-t\right)}{N\left(R_{n}(i, s, j)\right)}
$$

onde $N\left(R_{n}(i, s, j)\right)$ é o número de operações do conjunto $R_{n}(i, s, j)$, o qual inclui a operação $i$ ainda não executada.

A regra CR (razão crítica) seleciona a operação com menor valor do índice calculado pela razão entre o tempo restante até entrega (partindo-se do instante $\boldsymbol{t}$ 
atual) e o tempo restante de processamento das operações da ramificação, calculado a partir da operação $\boldsymbol{i}$ a ser executada. Esta regra utiliza, explicitamente, as estimativas de tempo de fila geradas pelo ciclo iterativo backward-forward. Ela é formulada como:

$$
\min \frac{\left(d_{j}-t\right)}{\sum_{i \in R_{n}(i, s, j)}\left(w_{i s}^{j}+p_{i s}^{j}\right)}
$$

Durante a fase experimental, além das 5 regras baseadas em data de entrega (EDD, ODD, SLACK, SOPN e CR), a regra RANDOM (aleatória) foi usada com o objetivo de tentar caracterizar o pior caso ou cenário de programação. Neste cenário, as operações foram selecionadas aleatoriamente, portanto, sem a avaliação de nenhuma informação contextual da ordem ou do sistema. Obviamente, esta regra não fez parte do conjunto (biblioteca) de regras aplicáveis do MIS.

\subsection{Rotina de avaliação da função-objetivo}

Dentro do ciclo backward-forward PPD, o método heurístico executa, iteração a iteração, a rotina de avaliação da melhoria incremental do valor da função-objetivo. Em linhas gerais, esta rotina é responsável por:

a. Calcular a melhoria incremental da função-objetivo.

b. Comparar a melhoria com um critério de parada.

c. Finalizar o método para a regra atual se o critério de parada for atendido.

A rotina trabalha com dois critérios de parada, um principal e outro complementar.

A avaliação da melhoria é realizada comparando-se o valor obtido na funçãoobjetivo ( $F$ ) na iteração atual com aquele obtido na iteração anterior. Como o objetivo global a ser alcançado pelo método é a minimização de $F$, uma melhoria 
ocorre quando $F(l)<F(l-1)$, ou seja, se o valor da função-objetivo na iteração atual $(l)$ for menor que o valor obtido na iteração anterior $(l-1)$.

Ao final de cada iteração, havendo melhoria, esta é confrontada com o critério de parada principal. Se o critério de parada é atendido, o método é finalizado para a regra atual. Caso não ocorra melhoria em $F$, ou se esta não atende ao critério de parada principal, o critério de parada complementar é avaliado. Se este último for atendido, o método é finalizado, senão, prossegue executando novas iterações, procurando melhorar a função-objetivo.

A medida de desempenho (função-objetivo) usada pela rotina de avaliação da melhoria é o atraso médio de atendimento de pedidos $\left(\bar{T}_{H}\right)$, calculado dentro do horizonte de programação $(H)$ e formulado como

$$
\begin{gathered}
\min T_{H}^{--}=\frac{\sum_{j=1}^{N_{H}} T_{j}}{N_{H}} \\
T_{j}=\max \left\{0, C_{j}-d_{j}\right\}
\end{gathered}
$$

onde $N_{H}$ é o número de ordens atrasadas dentro do horizonte de programação $\mathbf{H}$.

Os critérios de parada usados pela rotina são o percentual mínimo de melhoria (critério principal) e o número máximo de iterações (critério complementar).

Através do percentual mínimo de melhoria, a rotina compara o percentual de melhoria $\varepsilon_{l}$ na iteração atual, calculado pela expressão $\varepsilon_{l}=\frac{|F(l)-F(l-1)|}{F(l-1)}$, com o percentual mínimo $\varepsilon_{\min }$. O valor $\varepsilon_{l}$ é calculado sempre que $F(\imath)<F(l-1)$. Se $\varepsilon_{l} \leq \varepsilon_{\text {min }}$ em um número limite $n_{\text {lim }}$ de iterações consecutivas $n_{\text {consec }}$, o método é finalizado. Caso $F(\imath)>F(l-1)$ em alguma iteração, $n_{\text {consec }}=0$. 
Através do número máximo de iterações, a rotina compara o número de iterações ocorridas até o momento $(l)$ com um parâmetro limitador $\left(n_{\max }\right)$. Se $\imath=n_{\max }$, o método é finalizado para a regra atual.

O algoritmo da rotina de verificação da melhoria incremental é apresentado a seguir.

$>$ Algoritmo de verificação da melhoria incremental

Passo 1. Se $F(\imath) \geq F(l-1)$, faça $n_{\text {consec }}=0$ e vá para o passo 3. Caso contrário $(F(\imath)<F(l-1))$, vá para o passo 2.

Passo 2. Calcule $\varepsilon_{l}=\frac{|F(l)-F(l-1)|}{F(l-1)}$. Se $\varepsilon_{l} \leq \varepsilon_{\text {min }}$, então $n_{\text {consec }} \leftarrow n_{\text {consec }}+1$. Se $n_{\text {consec }}=n_{\text {lim }}$, finalize o método para a regra de priorização atual. Caso contrário $\left(n_{\text {consec }}<n_{\text {lim }}\right)$, vá para o passo 3.

Passo 3. Se $\imath<n_{\max }$, faça $\imath \leftarrow \imath+1$ e reinicie o método para a regra atual. Caso contrário ( $\iota=n_{\max }$ ), finalize o método para a regra atual.

O algoritmo de verificação da melhoria incremental foi inspirado no procedimento similar descrito em PIRLOT (1996) para a metaheurística Simulated Annealing.

\subsection{Atualização das estimativas de tempo de fila}

A rotina forward executada pelo PPD atualiza (suaviza) os tempos de fila das operações utilizando a seguinte fórmula:

$$
w_{i s}^{j, l+1}=\alpha \times w_{i s}^{j, l}+(1-\alpha) \times Q_{i s}^{j, l}
$$


onde $w_{i s}^{j, t+1}$ é a estimativa do tempo de fila para a próxima iteração ; $w_{i s}^{j, l}$ é a estimativa do tempo de fila determinada para a iteração anterior; $Q_{i s}^{j, l}$ é a estimativa obtida ao final da execução da rotina forward na iteração atual; $\alpha$ é fator de suavização, com $0<\alpha<1$.

O método de suavização dos tempos de fila foi baseado no método proposto por KUTANOGLU; SABUNCUOGLU (2001) para suavização de tempos de fila.

O processo de suavização dos tempos de fila tem o objetivo de prevenir contra mudanças drásticas no valor das estimativas, as quais podem gerar fortes oscilações da função-objetivo, com risco de não convergência de seu valor (KUTANOGLU; SABUNCUOGLU, 2001).

A rotina forward executada pelo PPP calcula os tempos médios de fila do recurso produtivo utilizando a seguinte fórmula:

$$
w_{k}^{\tau+1}=\frac{1}{n_{k}^{\tau}} \sum_{1}^{n_{k}^{\tau}} Q_{i k}^{\tau}
$$

onde $Q_{i k}^{\tau}$ é a estimativa de tempo de fila da operação $\boldsymbol{i}$ no recurso $\boldsymbol{k}$ ao final da iteração $\tau$ do ciclo determinístico-probabilístico ; $n_{k}^{\tau}$ é o número total de operações programadas no recurso $\boldsymbol{k}$ na iteração $\tau$.

\subsection{Parâmetros de execução do método}

Os principais parâmetros de execução do método são dados na Tabela 5.3. Estes parâmetros são selecionados na inicialização do método e permanecem fixos até a sua finalização. 
Tabela 5.3 - Parâmetros de execução do método.

\begin{tabular}{|l|c|l|}
\hline \multicolumn{1}{|c|}{ Parâmetro } & Símbolo & \multicolumn{1}{c|}{ Descrição } \\
\hline $\begin{array}{l}\text { Número máximo de } \\
\text { iterações backward- } \\
\text { forward }\end{array}$ & $n_{\max }$ & $\begin{array}{l}\text { Define o número máximo de iterações } \\
\text { backward-forward. Quando o número de } \\
\text { iterações atinge este limite o PPD troca a } \\
\text { regra de priorização. }\end{array}$ \\
\hline $\begin{array}{l}\text { Número limite de } \\
\text { iterações consecutivas } \\
\text { backward-forward }\end{array}$ & $n_{\text {lim }}$ & $\begin{array}{l}\text { Define o número limite de iterações } \\
\text { backward-forward consecutivas para } \\
\text { uma mesma regra de priorização. }\end{array}$ \\
\hline $\begin{array}{l}\text { Número de iterações do } \\
\text { ciclo determinístico- } \\
\text { probabilístico }\end{array}$ & $\tau_{\text {lim }}$ & $\begin{array}{l}\text { Define o número limite de iterações entre } \\
\text { o PPD e o PPP. }\end{array}$ \\
\hline $\begin{array}{l}\text { Percentual mínimo de } \\
\text { melhoria }\end{array}$ & $\varepsilon_{\min }$ & $\begin{array}{l}\text { Define o percentual mínimo de melhoria } \\
\text { da função objetivo entre iterações para o } \\
\text { cômputo do } n_{\text {consec }} \text {. }\end{array}$ \\
\hline Fator de suavização & $\alpha$ & $\begin{array}{l}\text { Percentual de suavização para } \\
\text { atualização dos tempos de fila da próxima } \\
\text { iteração do PPD. }\end{array}$ \\
\hline $\begin{array}{l}\text { Horizonte de } \\
\text { programação }\end{array}$ & $\mathrm{T}$ & $\begin{array}{l}\text { Determina o intervalo de programação } \\
\text { determinística, dentro do qual o processo } \\
\text { de programação determinística ocorre. }\end{array}$ \\
\hline $\begin{array}{l}\text { Determina o intervalo de programação } \\
\text { probabilística, dentro do qual o processo } \\
\text { de programação probabilística ocorre. }\end{array}$ \\
\hline
\end{tabular}

\subsection{Sistema de programação baseado em simulação iterativa}

No contexto dos sistemas de planejamento e controle da produção, o método proposto nesta pesquisa poderia estar inserido em um sistema de apoio à decisão baseado no mecanismo iterativo de simulação da programação e execução da produção. A Figura 14, adaptada de KUTANOGLU; SABUNCUOGLU (2001), apresenta uma possível estrutura funcional do modelo de um sistema de informações dentro do qual o MIS operaria. 
Na Figura 14, os módulos Gerador de Ordens e Operações (GO), Selecionador de Parâmetros de Execução (SPE) e o Mecanismo de Iterativo de Simulação (MIS) pertencem ao Sistema de Programação da Produção o qual é responsável pela programação detalhada da produção, ou seja, pela geração e liberação do programa de produção e das ordens de produção (e todas as informações a eles relacionadas, tais como os roteiros de produção e estruturas de precedência).

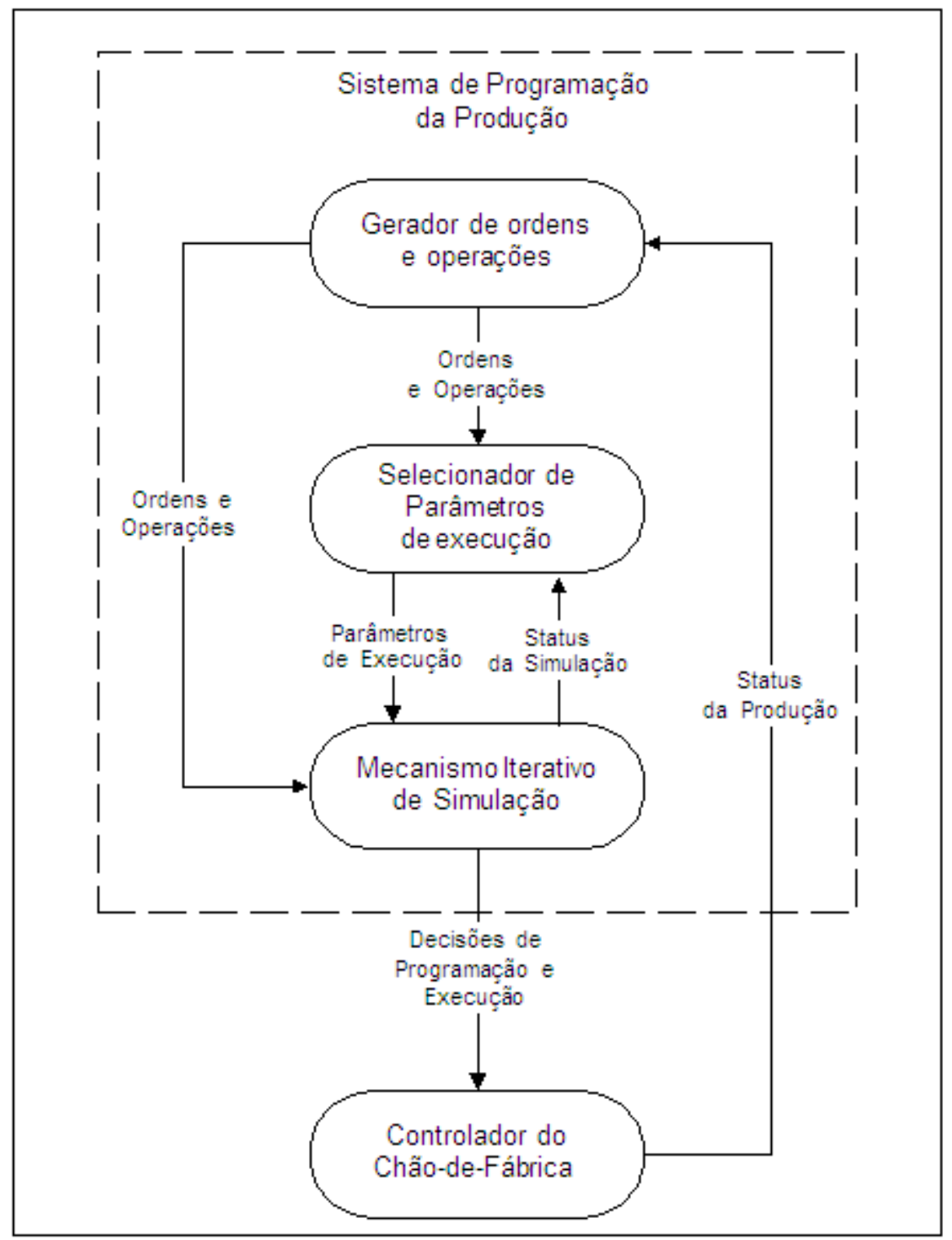

Figura 14 - Modelo do sistema de programação iterativa.

O módulo GO é responsável pela execução da rotina geradora de operações. Cabe a ele também excluir do programa de produção as operações já executadas no 
chão-de-fábrica. Esta atividade é realizada com base nas informações de status da produção passadas a ele pelo módulo Controlador do Chão-de-Fábrica pertencente ao Sistema de Execução e Controle da Produção. Diferente do modelo implementado nesta pesquisa, neste modelo a rotina geradora opera fora do MIS.

O módulo SPE é responsável pela calibração dinâmica dos parâmetros de execução do método de programação e pela atualização também dinâmica da biblioteca de regras de priorização. Estas atividades são realizadas com base no status da simulação passado ao SPE pelo MIS. Parâmetros, tais como, o fator de suavização $(\alpha)$, o número limite de iterações consecutivas backward-forward $\left(n_{\lim }\right)$ e o número máximo de iterações backward-forward $\left(n_{\max }\right)$ poderiam ser alterados dinamicamente com base na evolução do processo de simulação. Por exemplo, a não convergência do valor da função-objetivo durante a programação, usando uma determinada regra de priorização que apresentasse um histórico de convergência (programações anteriores convergentes), poderia fazer com que o SPE alterasse automaticamente o valor do fator de suavização (aumentando-o ou diminuindo-o) e aumentasse o número máximo de iterações para que o MIS "buscasse" a convergência. Um exemplo de alteração da biblioteca de regras estaria relacionado à escolha, por parte do programador, da função-objetivo a ser otimizada. Funçõesobjetivo relacionadas à data de entrega (por ex.: o atraso médio de atendimento e o percentual de ordens atrasadas) liberariam para execução regras relacionadas à data de entrega (ex.: EDD, ODD, SLACK), retendo outras não relacionadas diretamente a este critério (ex.: TWK e TWKR). Cabe observar que, nesta pesquisa, os parâmetros de execução do método foram mantidos fixos ao longo de toda a simulação.

O módulo MIS é responsável pela geração do programa de produção por meio do mecanismo iterativo de simulação implementado pelas rotinas backward e forward. As decisões de programação e execução correspondem ao programa de produção atualizado, as ordens liberadas, as regras de priorização escolhidas para a execução efetiva das operações no chão-de-fábrica e outras informações relevantes, tais como o cancelamento de ordens, ordens rush e o uso de roteiros alternativos. 
O Sistema de Programação da Produção faz parte de um sistema maior denominado Sistema de Planejamento e Programação da Produção. Este último, por sua vez, faz parte de outro sistema denominado Sistema de Gestão da Produção. A Figura 15, baseada em VOLLMAN; BERRY; WHYBARK (1997, p.15 e p.166), apresenta uma possível estrutura funcional e o relacionamento deste sistema com outros sistemas de gestão e controle da empresa mostrado através de alguns fluxos relevantes de informações. Na figura, os subsistemas possuem seus próprios bancos de dados transacionais (BD), os quais, em conjunto, compõem o banco de dados corporativo.

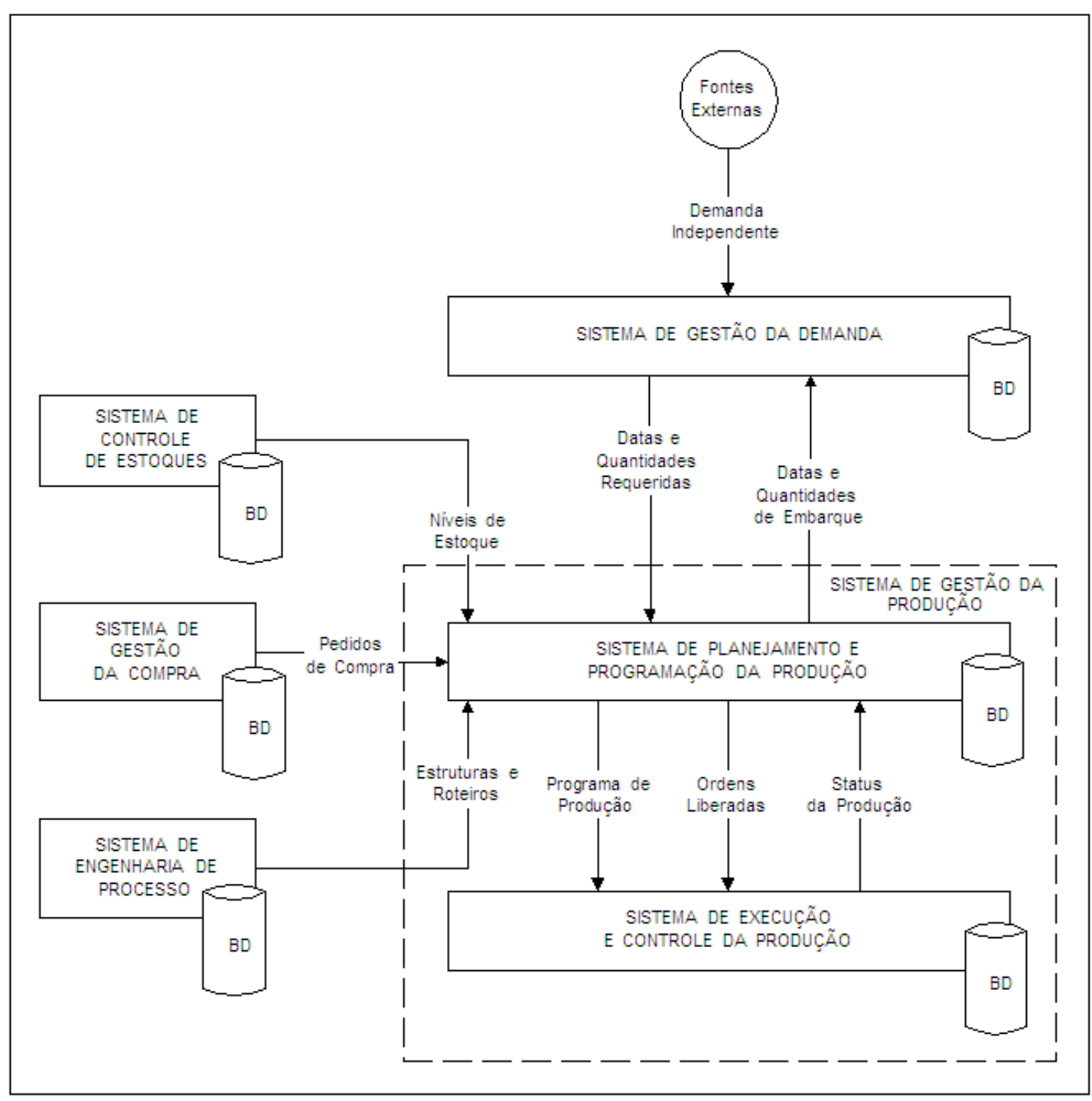

Figura 15 - Modelo do sistema integrado de gestão da produção. 


\section{Projeto Experimental}

Sendo a avaliação do método heurístico proposto um dos objetivos desta pesquisa, dois conjuntos de experimentos foram conduzidos para tal fim. O procedimento experimental baseou-se na execução de um modelo de simulação computacional de um sistema assembly shop onde regras e métodos de programação foram estatisticamente avaliados. A escolha desta abordagem foi influenciada pelos estudos levantados durante a pesquisa bibliográfica, os quais, em sua totalidade, utilizaram a simulação, notadamente estocástica, como veículo de investigação experimental.

O procedimento experimental completo foi dividido em seis fases:

Fase 1. Elaboração do projeto experimental;

Fase 2. Construção do modelo de simulação computacional (software simulador);

Fase 3. Geração das instâncias (ou replicações) do problema;

Fase 4. Simulação do sistema assembly shop e coleta das medidas de desempenho;

Fase 5. Análise estatística dos resultados;

Fase 6. Conclusões e proposições.

A primeira fase do procedimento é descrita neste capítulo; as fases dois, três, quatro e cinco são descritas no Capítulo 7. A última fase é descrita no Capítulo 8.

O projeto experimental baseou-se nas diretrizes estabelecidas em MONTGOMERY (2001, p.13) e RARDIN; UZSOY (2001) e tratou da elaboração do procedimento experimental e da concepção do modelo de simulação do sistema de produção, sendo dividido em quatro subfases:

1. Escolha dos parâmetros experimentais (fatores, níveis e variável de resposta);

2. Seleção dos parâmetros de execução do método; 
3. Configuração do sistema de produção simulado;

4. Especificação dos modelos de geração dos dados de entrada das instâncias do problema.

Cada uma destas subfases é detalhada a seguir.

\subsection{Parâmetros experimentais}

O projeto experimental foi concebido com o objetivo de investigar o impacto de três fatores experimentais no desempenho do sistema, a saber:

1. O tipo de estrutura de materiais (Fator 1 ).

2. O método de programação (Fator 2).

3. A regra de priorização (Fator 3).

Para o Fator 1, estrutura de materiais, foram escolhidos dois níveis experimentais:

1. Estrutura simples, correspondendo a estruturas de um só nível (Nível 1).

2. Estrutura complexa, correspondendo a estruturas de dois ou três níveis (Nível 2).

Para $\circ$ Fator 2, método de programação, foram escolhidos dois níveis experimentais:

1. Executar o MIS permitindo que o método utilize iterativamente todas as regras de priorização do conjunto durante toda a simulação (Nível 1).

2. Programar as operações de forma não iterativa, fixando a regra de priorização do início ao fim do experimento (single-pass procedure). Ou seja, as operações são programadas usando apenas uma regra de priorização por vez, fixada do início ao fim da simulação (Nível 2).

Para o Fator 3, regra de priorização, foram escolhidos cinco níveis experimentais:

1. Regra CR (Nível 1). 

2. Regra EDD-SPT (Nível 2).
3. Regra ODD-SPT (Nível 3).
4. Regra SLACK (Nível 4).
5. Regra SOPN (Nível 5).

A variável de resposta escolhida para medir o desempenho estatístico do sistema foi, obviamente, o atraso médio de atendimento de pedidos.

A Tabela 6.1 apresenta os fatores experimentais e seus níveis.

Tabela 6.1 - Fatores e níveis experimentais.

\begin{tabular}{|c|c|c|}
\hline Fator $\mathbf{1}$ (Estrutura) & Fator $\mathbf{2}$ (Método) & Fator $\mathbf{3}$ (Regra) \\
\hline \multirow{4}{*}{ Simples } & $\begin{array}{c}\text { Programar } \\
\text { executando o MIS }\end{array}$ & TODAS \\
\cline { 2 - 3 } Complexa & $\begin{array}{c}\text { Programar } \\
\text { fixando a regra de }\end{array}$ & CRD \\
& EDDP \\
& Oriorização (procedimento & SLACK \\
& de única passagem) & SOPN \\
\hline
\end{tabular}

Para estudar estes três fatores, dois conjuntos de experimentos foram conduzidos. O primeiro objetivou avaliar o efeito das estruturas simples sobre a eficiência das cinco regras e dos dois métodos. O segundo objetivou avaliar o efeito das estruturas complexas sobre eficiência das mesmas regras e métodos.

Um tratamento constitui-se da combinação de todos os níveis experimentais dos três fatores. No total, doze tratamentos foram criados usando os dois tipos de estrutura, os dois métodos de programação e as cinco regras de priorização.

Para cada tratamento, cinco replicações (instâncias) foram geradas, totalizando 60 replicações. O número de replicações por tratamento foi arbitrado em cinco devido ao longo tempo de execução de cada replicação no computador. Das 60 replicações geradas, 30 corresponderam ao primeiro conjunto de experimentos 
(estruturas simples) e 30 corresponderam ao segundo conjunto de experimentos (estruturas complexas).

A análise estatística dos resultados foi realizada utilizando as técnicas de Análise de Variância (MONTGOMERY, 2001, p.70), Teste de Tukey (MONTGOMERY, 2001, p.96) e Teste de Múltiplos Intervalos de Duncan (MONTGOMERY, 2001, p.100). Estas três técnicas foram selecionadas com base nos artigos pesquisados. Os testes foram aplicados separadamente nos dois conjuntos de experimentos.

A Tabela 6.2 apresenta o resumo do plano experimental.

Tabela 6.2 - Plano experimental.

\begin{tabular}{|c|c|c|}
\hline Método/Regra (1) & Tipo de Estrutura (2) & $\begin{array}{c}\text { Número de } \\
\text { Replicações por } \\
\text { Tratamento (3) }\end{array}$ \\
\hline 6 & 2 & 5 \\
\hline \multicolumn{2}{|c|}{ Número Total de Tratamentos (1 x 2) } \\
\hline \multicolumn{2}{|c|}{ Número Total de Replicações (1 x 2 x 3) } \\
\hline \multicolumn{2}{|c|}{60} \\
\hline
\end{tabular}

\subsection{Parâmetros de execução do MIS}

A Tabela 6.3 apresenta os valores dos parâmetros de execução do MIS. Os parâmetros de execução foram selecionados no início do processo de simulação e foram mantidos fixos para todas as replicações simuladas. Seus valores foram definidos com base em uma série de execuções-piloto do modelo de simulação. 
Tabela 6.3 - Valores dos parâmetros de execução.

\begin{tabular}{|l|c|}
\hline Parâmetro de simulação & Valor \\
\hline Número máximo de iterações do ciclo backward-forward $-n_{\max }$ & 10 \\
\hline $\begin{array}{l}\text { Número limite de iterações consecutivas } \\
\text { (ciclo backward-forward) }-n_{\lim }\end{array}$ & 3 \\
\hline Percentual mínimo de melhoria (ciclo backward-forward) $-\varepsilon_{\min }$ & $2 \%$ \\
\hline Número de iterações do ciclo determinístico-probabilístico $-\tau_{\lim }$ & 1 \\
\hline Fator de suavização - $\alpha$ & 0,2 \\
\hline Horizonte de Programação - H & 10 dias \\
\hline Período de Programação - T & 1 dia \\
\hline Período de Simulação - PS & 150 dias \\
\hline
\end{tabular}

\subsection{Configuração do sistema de produção simulado}

O sistema de produção assembly shop modelado computacionalmente, consistiu de:

1. Três centros de montagem contendo um montador cada.

2. Quatro centros de fabricação contendo uma máquina cada.

Os quatro centros de fabricação serviram à produção dos componentes individuais que foram posteriormente montados. Os três centros de montagem serviram à produção das submontagens e montagens finais.

O esquema do sistema de produção é apresentado na Figura 16.

O sistema de produção operou sob as seguintes restrições:

a. O padrão de liberação de ordens no chão-de-fábrica era determinístico.

b. Os únicos recursos limitados eram a máquina e o montador.

c. Cada recurso pôde realizar apenas uma operação por vez.

d. O recurso estava continuamente disponível para alocação. 
e. Os roteiros de produção eram predefinidos (fixos).

f. Não existiam recursos alternativos (intercambiáveis); cada operação podia ser executada somente no recurso predefinido no roteiro do item.

g. Os tempos de processamento das operações eram estocásticos.

h. Os tempos de movimentação de materiais, preparação (setup), quebra, manutenção e limpeza de máquinas foram incluídos nos tempos de processamento como variações estocásticas.

i. Uma vez iniciada, a operação não podia ser interrompida.

j. A sobreposição de operações não era permitida.

k. A recirculação de ordens nos centros de produção era permitida.

I. Os itens eram produzidos para atender exatamente as quantidades dos pedidos; nenhum estoque era mantido.

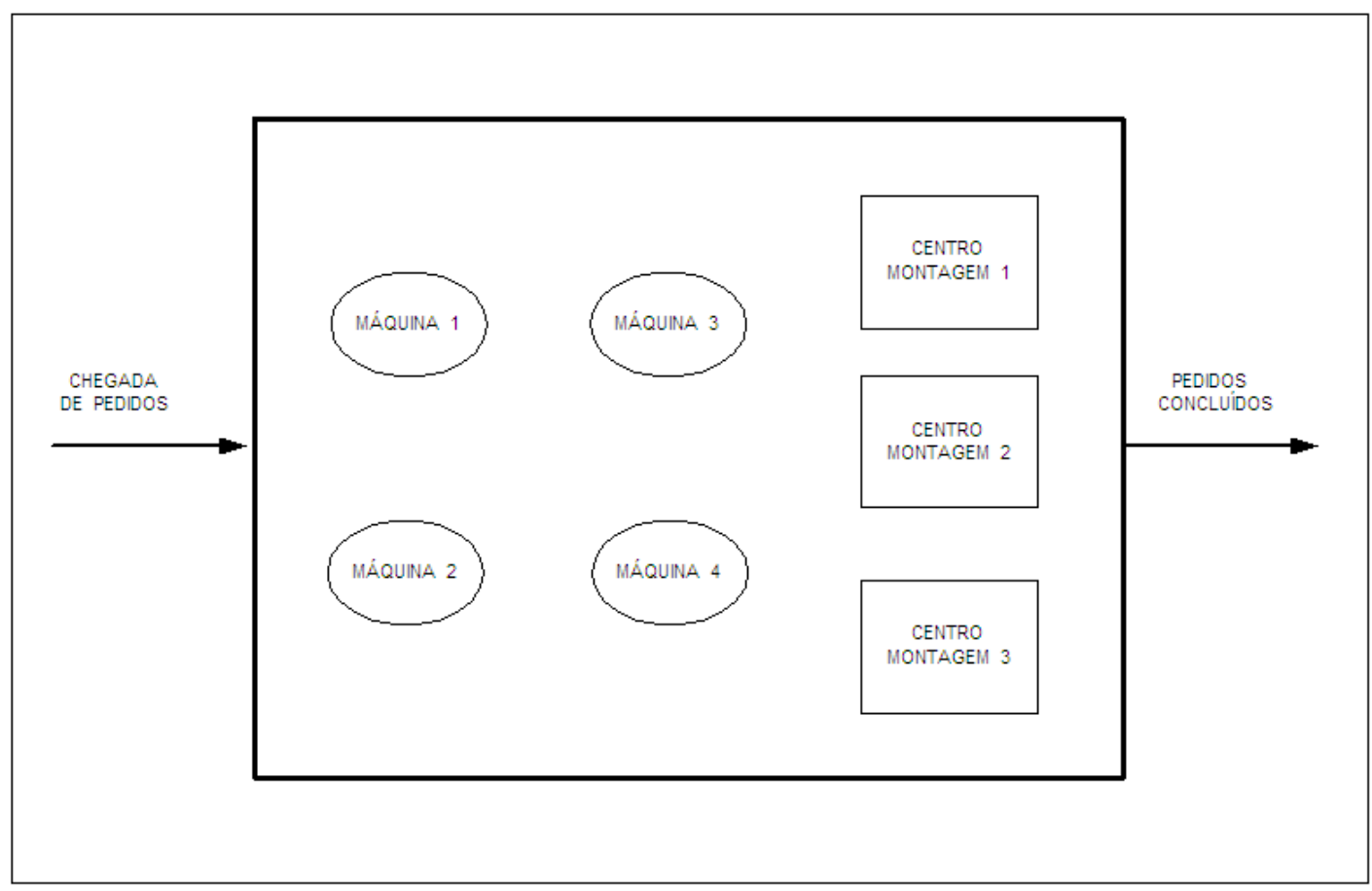

Figura 16 - O sistema de produção assembly-shop simulado 


\subsection{Especificação dos modelos de geração das instâncias}

$\mathrm{Na}$ fase de geração das instâncias (replicações) do problema, as seguintes entidades de dados foram criadas:

i. Estruturas de materiais.

ii. Roteiros de produção.

iii. Pedidos de venda.

A massa de dados para as três entidades foi gerada a partir de modelos de simulação estocástica construídos no software ARENA (Rockwell Software, Inc.).

A descrição de cada modelo gerador de dados é feita a seguir.

\subsubsection{Modelo de geração de estruturas de materiais}

Dois tipos de estrutura de materiais foram simulados:

1. Simples, correspondendo a estruturas de um só nível.

2. Complexo, correspondendo a estruturas de dois ou três níveis.

Foram geradas cinco estruturas de materiais simples e dez estruturas de materiais complexas com base nas funções de geração descritas a seguir.

\section{Estruturas simples}

As estruturas simples foram formadas por componentes individuais e a montagem final. O número de componentes individuais de cada estrutura foi selecionado com igual probabilidade de ocorrência de uma distribuição discreta de valores iguais a $\{2,3\}$.

\section{$>$ Estruturas complexas de dois níveis}


As estruturas complexas de dois níveis foram formadas por componentes individuais, submontagens e montagem final. $\mathrm{O}$ número de submontagens distintas para cada montagem final foi selecionado com igual probabilidade de ocorrência de uma distribuição discreta de valores iguais a $\{1,2\}$. $O$ número de componentes individuais distintos para cada submontagem foi selecionado com igual probabilidade de ocorrência de uma distribuição discreta de valores iguais a $\{2,3\}$.

Um componente individual foi vinculado diretamente à montagem final nos casos onde apenas uma submontagem tenha sido vinculada.

\section{$>$ Estruturas complexas de três níveis}

As estruturas complexas de três níveis foram formadas por componentes individuais, sub-submontagens, submontagens e montagem final. O número de submontagens por montagem final foi selecionado com igual probabilidade de ocorrência de uma distribuição discreta de valores iguais a $\{1,2\}$. O número de subsubmontagens por submontagem também foi selecionado com igual probabilidade de ocorrência de uma distribuição discreta de valores iguais a $\{1,2\}$.

O número de componentes individuais por sub-submontagem e por submontagem foi selecionado com igual probabilidade de ocorrência de uma distribuição discreta de valores iguais a $\{2,3\}$.

Um componente individual foi vinculado diretamente à submontagem nos casos onde apenas uma sub-submontagem tenha sido vinculada. Um componente individual foi vinculado diretamente à montagem final nos casos onde apenas uma submontagem tenha sido vinculada.

\section{Quantidades-padrões por componente}

As quantidades-padrões de componentes individuais por sub-submontagem e submontagem foram selecionadas com igual probabilidade de ocorrência de uma distribuição discreta de valores iguais a $\{1,2,3\}$. 
As quantidades-padrões de sub-submontagens por submontagem e de submontagens por montagem final foram fixadas em uma unidade.

\subsubsection{Modelo de geração de roteiros de produção}

O número de operações por roteiro de um componente individual foi selecionado com igual probabilidade de ocorrência a partir de uma distribuição discreta de valores iguais a $\{1,2,3\}$.

Apenas uma única operação foi vinculada aos roteiros das sub-submontagens, submontagens e montagens finais.

Os centros de fabricação (máquinas) foram selecionados com igual probabilidade de ocorrência a partir de uma distribuição discreta de valores iguais a $\{1,2,3,4\}$ e associados a cada operação de fabricação.

Os centros de montagem (montadores) foram selecionados com igual probabilidade de ocorrência a partir de uma distribuição discreta de valores iguais a $\{1,2,3\}$ e associados a cada operação de montagem.

Os tempos-padrões de ciclo de fabricação (em minutos) foram selecionados de uma distribuição uniforme de intervalo $[5,10]$.

Os tempos-padrões de ciclo de montagem (em minutos) foram selecionados de uma distribuição uniforme de intervalo [20, 30].

\subsubsection{Modelo de geração de pedidos de venda}

Quatro parâmetros foram usados na geração das instâncias dos pedidos de venda: 
1. O intervalo entre chegadas de pedidos.

2. O número de pedidos por evento de chegada.

3. A Montagem final (produto).

4. A quantidade do produto por pedido.

O intervalo entre chegadas foi fixado em 1 dia.

Dois conjuntos (carteiras) de pedidos foram simulados separadamente, a saber: o primeiro contendo apenas montagens simples e o segundo contendo apenas montagens complexas.

O número de pedidos por evento de chegada foi selecionado de uma distribuição Normal $(5,1)$.

Para estruturas complexas, a quantidade requerida do produto por pedido foi selecionada de uma distribuição Normal $(10,1)$. Para estruturas simples, a quantidade requerida foi selecionada de uma distribuição Normal $(20,2)$.

A Tabela 6.4 apresenta o resumo das funções-geradoras de dados de instâncias descritas nesta seção.

Tabela 6.4 - Funções de geração dos dados das instâncias

\begin{tabular}{|l|c|}
\hline Parâmetro de simulação & Função Geradora \\
\hline $\begin{array}{l}\text { Número de componentes individuais distintos por } \\
\text { montagem final em estruturas simples }\end{array}$ & Discreta $\{2,3\}$ \\
\hline $\begin{array}{l}\text { Número de submontagens distintas por montagem final } \\
\text { em estruturas complexas de dois níveis }\end{array}$ & Discreta $\{1,2\}$ \\
\hline $\begin{array}{l}\text { Número de componentes individuais distintos por } \\
\text { submontagem em estruturas complexas de dois níveis }\end{array}$ & Discreta $\{2,3\}$ \\
\hline $\begin{array}{l}\text { Número de submontagens distintas por montagem final } \\
\text { em estruturas complexas de três níveis }\end{array}$ & Discreta $\{1,2\}$ \\
\hline $\begin{array}{l}\text { Número de sub-submontagens distintas por } \\
\text { submontagem em estruturas complexas de três níveis }\end{array}$ & Discreta $\{1,2\}$ \\
\hline
\end{tabular}




\begin{tabular}{|c|c|}
\hline Parâmetro de simulação & Função Geradora \\
\hline $\begin{array}{l}\text { Número de componentes distintos por sub-submontagem } \\
\text { e submontagem em estruturas complexas de três níveis }\end{array}$ & Discreta $\{2,3\}$ \\
\hline $\begin{array}{l}\text { Quantidade-padrão do componente individual por sub- } \\
\text { submontagem ou submontagem }\end{array}$ & Discreta $\{1,2,3\}$ \\
\hline $\begin{array}{l}\text { Quantidade-padrão da sub-submontagem por } \\
\text { submontagem }\end{array}$ & Constante $=1$ \\
\hline Quantidade-padrão da submontagem por montagem final & Constante $=1$ \\
\hline $\begin{array}{l}\text { Número de operações distintas por componente } \\
\text { individual }\end{array}$ & Discreta $\{1,2,3\}$ \\
\hline $\begin{array}{l}\text { Número de operações distintas por sub-submontagem, } \\
\text { submontagem e montagem final }\end{array}$ & Constante $=1$ \\
\hline Centros de montagem & Discreta $\{1,2,3\}$ \\
\hline Máquinas & Discreta $\{1,2,3,4\}$ \\
\hline $\begin{array}{l}\text { Tempo-padrão de fabricação dos componentes } \\
\text { individuais }\end{array}$ & Uniforme $[5,10]$ \\
\hline $\begin{array}{l}\text { Tempo-padrão de montagem das sub-submontagens, } \\
\text { submontagens e montagens finais }\end{array}$ & Uniforme $[20,30]$ \\
\hline Intervalo entre chegadas de pedidos de venda & Constante $=1$ \\
\hline Número de pedidos simultâneos por evento de chegada & Normal $(5,1)$ \\
\hline Qdte do produto por pedido (estruturas complexas) & Normal $(10,1)$ \\
\hline Qdte do produto por pedido (estruturas simples) & Normal $(20,2)$ \\
\hline
\end{tabular}




\section{Simulação e Análise dos Resultados}

Este capítulo descreve as seguintes fases do procedimento experimental:

Fase 2. Construção do modelo de simulação computacional (simulador).

Fase 3. Geração das instâncias (ou replicações) do problema.

Fase 4. Simulação do sistema assembly shop e coleta das medidas de desempenho.

Fase 5. Análise estatística dos resultados.

A primeira fase do procedimento experimental é descrita no Capítulo 6 .

As fases 2 a 5 são descritas a seguir.

\subsection{Modelo de simulação computacional}

O modelo de simulação desenvolvido nesta pesquisa pode ser classificado como (KELTON; SADOWSKI; SADOWSKI, 2002):

a. Dinâmico. O sistema evolui com o passar do tempo; várias entidades (pedidos) chegam ao sistema para atendimento a cada evento de chegada e outras (operações processadas) deixam o sistema a cada evento de saída;

b. Discreto. O sistema evolui em períodos discretos de tempo (controlados pelo relógio de simulação) dentro dos quais o sistema é avaliado;

c. Estocástico. Alguns dos parâmetros de entrada do modelo, tais como as datas de chegada dos pedidos no sistema, as quantidades dos produtos por pedido, os códigos de produto por pedido, as estruturas de materiais e os roteiros de produção, foram previamente gerados de maneira probabilística, 
ou seja, seus valores foram gerados por funções de distribuição de probabilidades devidamente selecionadas (vide Tabela 6.4 no Capítulo 6). Os tempos de processamento das operações usados pelo procedimento de programação probabilística (PPP) foram calculados com base em valores de variações estocásticas de tempo de processamento nos recursos, variações estas selecionadas de uma distribuição uniforme de probabilidades durante a simulação.

O modelo de simulação computacional foi desenvolvido em linguagem Visual Basic 6.0 utilizando para sua construção a ferramenta de gestão de ambiente de desenvolvimento Visual Studio. As estruturas de dados foram definidas e mantidas através da ferramenta Microsoft Access.

As instâncias do problema foram executadas em dois computadores PC Intel Pentium-4 de 2,80 GHs. Cada instância de estrutura simples levou em média dois dias para ser executada. Cada instância de estrutura complexa levou em média oito dias para ser executada.

O funcionamento do modelo é descrito resumidamente a seguir.

\subsubsection{Modus Operandi}

O modelo de simulação foi construído para imitar a operação diária de um sistema de apoio à decisão para a programação e execução de operações em um ambiente de produção assembly shop. Neste contexto, as seguintes atividades principais eram realizadas:

1. Processamento de pedidos;

2. Cálculo das necessidades de materiais;

3. Geração do conjunto de operações a programar;

4. Programação determinística da produção (apenas o MIS);

5. Programação probabilística da produção (MIS e procedimento não-iterativo);

6. Execução das operações no chão-de-fábrica. 
O processamento de pedidos constituiu-se da recepção diária dos pedidos e da atividade de promising (definição da data de entrega).

O cálculo de necessidades de materiais constituiu-se da determinação diária das quantidades a produzir das montagens finais e de seus componentes (baseadas nas estruturas de materiais).

A geração das operações constituiu-se da criação ou atualização diária do conjunto de todas as operações a programar (baseada nos roteiros de produção) e na criação ou atualização da estrutura de precedência das operações (baseada nas estruturas de materiais e nos roteiros de produção).

A programação determinística constituiu-se da execução diária do PPD para as operações novas ou aquelas ainda não executadas, dentro do horizonte de programação (decendial), usando as seis regras de priorização avaliadas.

A programação probabilística constituiu-se da execução do PPP para todas as operações novas ou aquelas ainda não executadas, dentro do período de programação (diário), usando a regra de priorização vencedora.

A execução das operações no chão-de-fábrica constituiu-se da implementação "exata" do programa final gerado pelo PPP para o período de programação, ou seja, as datas de término das operações programadas pelo PPP foram assumidas como sendo as datas "efetivas" de término das operações no chão-de-fábrica dentro do período de programação.

O modelo de simulação foi executado para cada instância (replicação) do problema durante um período de simulação de 150 dias. Durante este período, o MIS foi executado uma vez por dia, totalizando 150 execuções.

A Figura 17 ilustra esquematicamente a rolagem dos períodos durante a execução da simulação. 


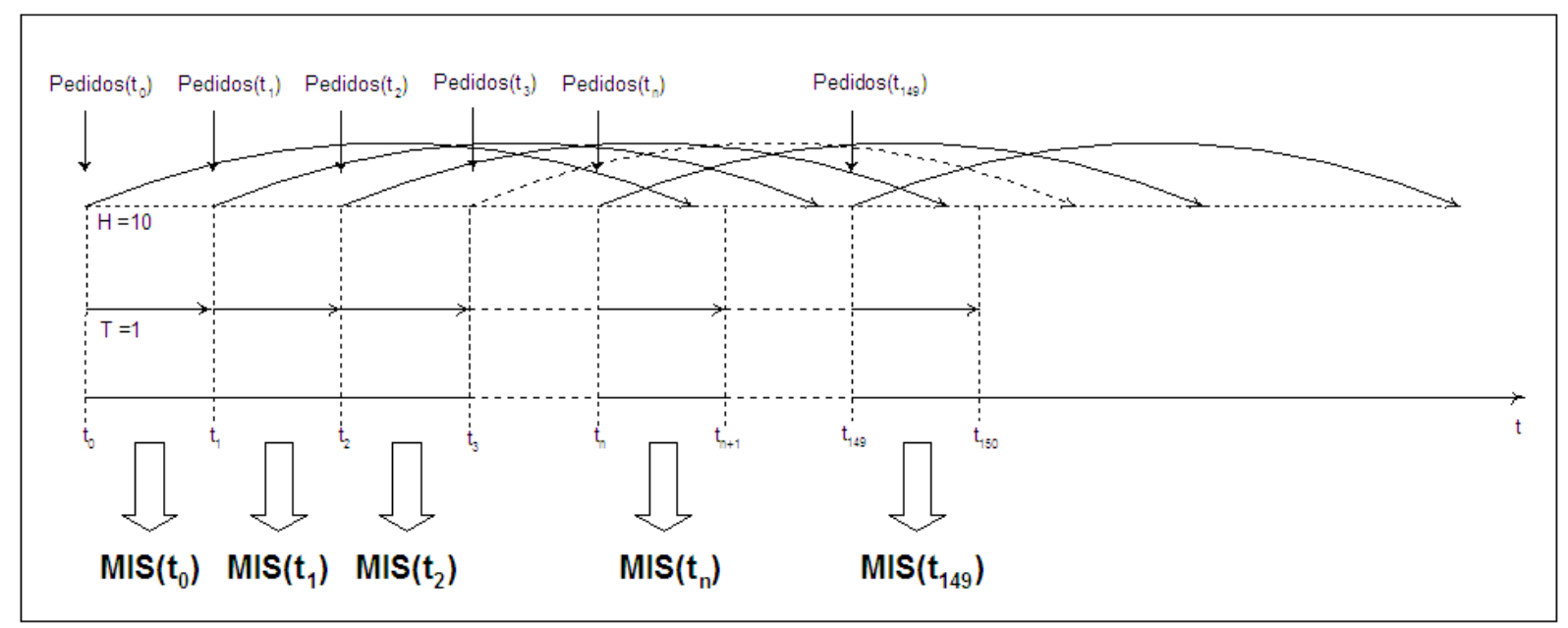

Figura 17 - Execuções do MIS no período de simulação.

Diariamente, as estatísticas de desempenho do sistema eram coletadas para posterior análise.

A Tabela 7.1 apresenta os principais parâmetros complementares da simulação.

Tabela 7.1 - Parâmetros complementares da simulação.

\begin{tabular}{|l|c|}
\hline Parâmetro de simulação & Valor \\
\hline Período de simulação & 150 dias \\
\hline Período de aquecimento (warm-up) & 10 dias \\
\hline Duração do dia de simulação & 24 horas \\
\hline Intervalo entre chegadas de pedidos & 1 dia (cte) \\
\hline Fator de permissão $(\lambda)$ - estruturas simples & 1 (fixo) \\
\hline Fator de permissão $(\lambda)$ - estruturas complexas & 2 (fixo) \\
\hline Variação estocástica do tempo de processamento $\left(\delta_{k}\right)$ & $\mathrm{U}[-0,2 ; 1]$ \\
\hline
\end{tabular}

A Figura 18 apresenta o modelo de simulação computacional do sistema. Em um dado instante $t_{n}$, o simulador é executado, captando os pedidos existentes neste instante, executando o MIS para o horizonte $H_{n}$ e o período de programação $T_{n}$, gerando o programa de produção, executando as operações no chão-de-fábrica, calculando o desempenho do sistema e determinando os tempos médios e o status 
da produção, necessários à execução do MIS do período seguinte $\left(t_{n+1}\right)$. Cabe observar que o fluxo de dados do ciclo determinístico-probabilístico foi modificado para atender ao modelo de simulação.

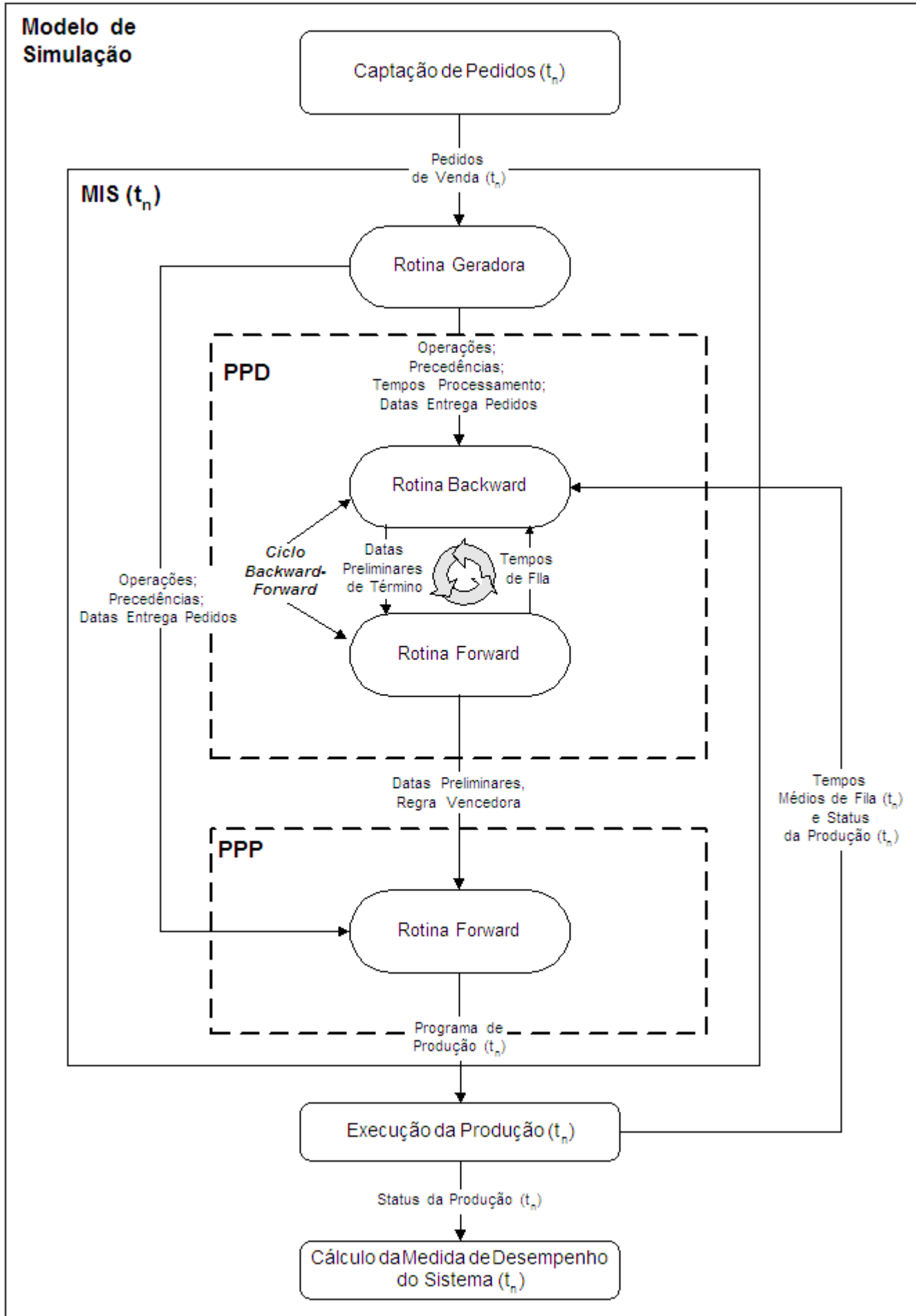

Figura 18 - Modelo de simulação computacional do sistema. 
A Figura 19 apresenta o fluxograma simplificado do modelo de simulação. Nela são destacados as três rotinas e os dois procedimentos principais do MIS.

\subsubsection{Descrição das principais características do modelo de simulação}

A seguir, são descritos resumidamente os principais elementos constituintes do modelo de simulação.

Estado inicial. O sistema partiu do estado vazio e ocioso.

Warm-up. O período de aquecimento do sistema (warm-up) foi de 10 dias. A partir do décimo primeiro dia, todas as saídas do sistema foram consideradas na análise experimental.

Duração do dia de simulação. O sistema operou ininterruptamente 24 horas por dia ao longo de todo o período de simulação.

Período de Simulação. O sistema foi simulado por um período de 150 dias ininterruptamente, totalizando 3.600 horas de simulação.

Mecanismo de atualização do relógio de simulação. Durante a simulação, o relógio de simulação foi avançado a intervalos discretos de acordo com os eventos constantes na lista de eventos (mecanismo de avanço de tempo baseado em evento).

Entidade. A principal entidade do sistema foi a operação; seus principais atributos foram a data de liberação no sistema, o tempo de processamento (determinístico e probabilístico), o tempo de fila no recurso produtivo e as datas de início e término. 
Variáveis de estado. As principais variáveis de estado do sistema foram:

i. O número de operações concluídas diariamente.

ii. O atraso de atendimento individual de cada ordem.

iii. O atraso médio de atendimento diário.

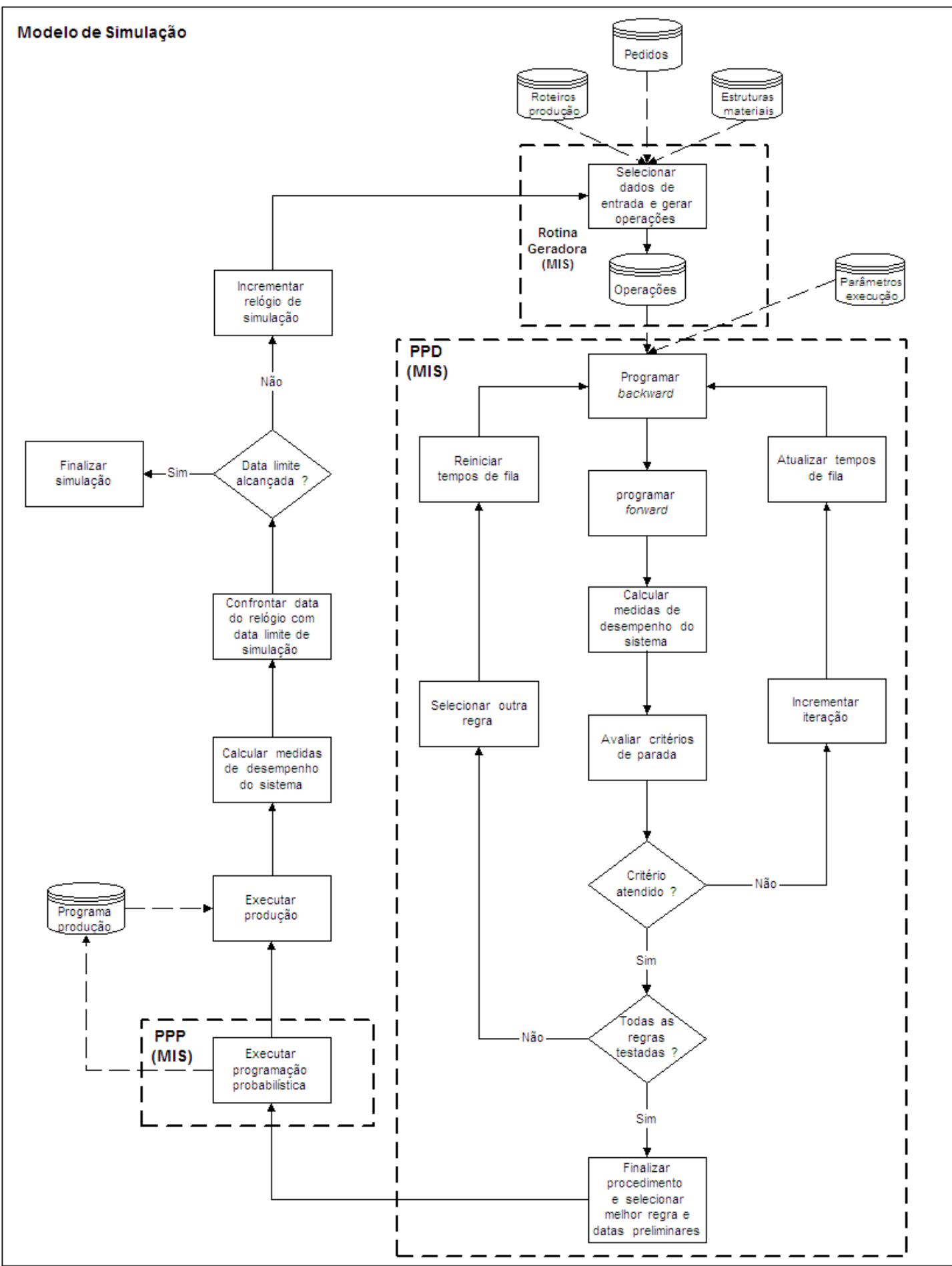

Figura 19 - Fluxograma simplificado do modelo de simulação. 
Principais eventos. Os principais eventos do sistema foram:

a. Chegada de novos pedidos de venda ao sistema.

b. Alocação da operação ao recurso produtivo.

c. Conclusão da operação no recurso.

d. Saída das ordens concluídas do sistema.

Nível de utilização dos recursos. O nível de utilização de cada recurso (individualmente coletado) variou de $50 \%$ a $100 \%$ ao longo da simulação.

Nível de utilização do sistema. O nível de utilização do sistema alcançou a média de $70 \%$ ao longo da simulação.

Sobrecarga operacional do sistema. A parametrização de execução da simulação foi escolhida de forma a levar o sistema rapidamente à situação de sobrecarga, com as filas nos recursos em contínuo aumento durante a simulação, fato este perceptível pela contínua ascendência das curvas de atraso médio de atendimento diário (vide os gráficos da Seção 7.2). Esta abordagem foi adotada objetivando avaliar de forma mais efetiva o desempenho de cada regra de priorização.

Regra de dimensionamento dos lotes de produção. Os tamanhos dos lotes de produção foram determinados utilizando a técnica denominada 'lote-a-lote'.

Regra RANDOM. Além das 5 regras baseadas em data de entrega (EDD, ODD, SLACK, SOPN e CR), a regra RANDOM (aleatória) foi escolhida com o objetivo de tentar caracterizar o pior caso ou cenário de programação, cenário este onde as operações eram selecionadas aleatoriamente, portanto, sem a avaliação de nenhuma informação contextual da ordem ou do sistema. O algoritmo de aleatorização e seleção de operações da regra RANDOM baseou-se: 1) na utilização de números pseudo-aleatórios como índices de priorização, gerados por uma função de geração de números pseudo-aleatórios (Rnd) da linguagem Visual Basic (cujo algoritmo é desconhecido) e 2) em uma rotina de ordenação de valores. 


\subsubsection{Principais variáveis descritivas do modelo de simulação}

Data de entrega $\left(d_{j}\right)$. A data de entrega de cada pedido que ingressava no sistema era calculada pela fórmula

$$
d_{j}=r_{j}+\lambda \times \sum_{i \in C P(j)} p_{i s}^{j}
$$

onde $\lambda$ é o fator de permissão (allowance factor) usado para aumentar o tempo total de processamento com o objetivo de incluir indiretamente os tempos de fila; $p_{i s}^{j}$ é o tempo-padrão de processamento da operação; $C P(j)$ é o conjunto de todas as operações que formam o caminho crítico da montagem final da ordem $j$. O valor de $\lambda$ foi fixado em 1 para estruturas simples e 2 para estruturas complexas durante toda a simulação.

Tempo de fila da operação $\left(w_{i s}^{j, t+1}\right)$. A estimativa de tempo de fila usada pela rotina backward dentro do ciclo backward-forward era calculada pela fórmula

$$
w_{i s}^{j, l+1}=\alpha \times w_{i s}^{j, l}+(1-\alpha) \times Q_{i s}^{j, l}
$$

onde $Q_{i s}^{j, l}$ é o tempo de fila da operação na iteração atual.

Cabe observar que na primeira execução do MIS, no primeiro dia de simulação de todas as instâncias, os tempos de fila das operações foram assumidos com iguais a zero. A partir da segunda iteração (ainda no primeiro dia), os tempos de fila das operações passaram a ser calculados pela fórmula acima.

Tempo médio de fila no recurso produtivo $\left(w_{k}^{t+1}\right)$. Ao final da execução do MIS no dia $\mathbf{t}$, as estimativas do tempo médio de fila de cada recurso $\boldsymbol{k}$ eram calculadas para compor, no início do dia seguinte $(\mathbf{t + 1})$, os tempos estimados de fluxo $\left(f_{i s}^{j}\right)$, 
tanto para novas operações quanto para as operações de pedidos anteriores ainda não executadas. Os tempos eram calculados pela fórmula

$$
w_{k}^{t+1}=\frac{1}{n_{k}^{t}} \sum_{1}^{n_{k}^{t}} Q_{i k}^{t}
$$

onde $Q_{i k}^{t}$ é a estimativa de tempo de fila da operação $\boldsymbol{i}$ no recurso $\boldsymbol{k}$ ao final do dia $\boldsymbol{t} ; n_{k}^{t}$ é o número total de operações programadas ou executadas no recurso $\boldsymbol{k}$ no dia $t$.

Tempo determinístico de fluxo da operação $\left(f_{i s}^{j}\right)$. A estimativa de tempo de fluxo usada pela rotina backward era calculada pela fórmula

$$
f_{i s}^{j}=q_{s}^{j} \times s t_{i s}+w_{i s}^{j}=p_{i s}^{j}+w_{i s}^{j}
$$

onde $s t_{i s}$ é o tempo-padrão de ciclo da operação $i$ do item $\boldsymbol{s}$ e $q_{s}^{j}$ é a necessidade líquida do item $\boldsymbol{s}$ na ordem $\boldsymbol{j}$.

Tempo probabilístico de processamento da operação $\left(\pi_{i s}^{j}\right)$. O tempo probabilístico de processamento usado pela rotina forward do PPP era calculado pela fórmula

$$
\pi_{i s}^{j}=\left(q_{s}^{j} \times s t_{i s}\right) \times\left(1+\delta_{k}\right)=p_{i s}^{j} \times\left(1+\delta_{k}\right)
$$

onde $\delta_{k}$ é a variação estocástica sobre o tempo-padrão de processamento da operação $p_{i s}$ no recurso $\boldsymbol{k}$, com $\delta_{k}$ sendo selecionada de uma distribuição uniforme de probabilidades com intervalo $[-0,2 ; 1]$. 
Tempo probabilístico de fluxo da operação $\left(\phi_{i s}^{j}\right)$. O tempo probabilístico de fluxo resultante da execução da programação probabilística (PPP) das operações era calculado pela fórmula

$$
\phi_{i s}^{j}=\pi_{i s}^{j}+Q_{i s}^{j}
$$

Atraso médio de atendimento. $\mathrm{O}$ atraso médio de atendimento era calculado de duas maneiras:

1. Diariamente, ao final da programação determinística das operações, o PPD calculava o atraso médio de atendimento, objetivando escolher a melhor regra de priorização, usando as fórmulas

$$
\begin{gathered}
\bar{T}_{H}=\frac{1}{N_{H}} \sum_{j=1}^{N_{H}} T_{j} \\
T_{j}=\max \left\{0, C_{j}-d_{j}\right\}
\end{gathered}
$$

2. Diariamente, ao final da execução das operações, o simulador calculava o atraso médio de atendimento, objetivando avaliar o desempenho do sistema no dia, usando as fórmulas

$$
\begin{gathered}
\bar{T}_{t_{f}}=\frac{1}{N_{t_{f}}} \sum_{j=1}^{N_{t_{f}}} T_{t_{f}}^{j} \\
T_{t_{f}}^{j}=\left\{\begin{array}{l}
0, \text { se } C_{j} \leq d_{j} \\
t_{f}-d_{j}, \text { se } t_{f}>d_{j} \text { e } C_{j}>t_{f} \\
C_{j}-d_{j}, \text { se } C_{j}>d_{j} \text { e } C_{j} \leq t_{f}
\end{array}\right.
\end{gathered}
$$

onde $\bar{T}_{t_{f}}$ é o atraso médio de atendimento calculado ao final do dia de simulação $t_{f} ; T_{t_{f}}^{j}$ é o atraso de atendimento da ordem $\boldsymbol{j}$ computado ao final do 
dia de simulação; $N_{t_{f}}$ é o número de ordens atrasadas no dia. Esta formulação estabelece que:

i. Somente haverá atraso se a data de conclusão da ordem for superior a data de entrega do pedido $\left(C_{j}>d_{j}\right)$; caso contrário $\left(C_{j} \leq d_{j}\right)$, não haverá cômputo do atraso;

ii. O atraso parcial da ordem será computado ao final de cada dia de simulação $\left(t_{f}-d_{j}\right)$ até que a ordem seja concluída;

iii. No dia da conclusão da ordem será computado o atraso total da ordem $\left(C_{j}-d_{j}\right)$.

\subsection{Resultados coletados}

A Tabela 7.2 apresenta os resultados de cada replicação do primeiro conjunto de experimentos, o qual objetivou avaliar o efeito das estruturas simples sobre a eficiência das seis regras e dos dois métodos. $\mathrm{O}$ atraso médio total (em dias) é igual à soma dos atrasos médios diários para todo o período de simulação.

Tabela 7.2 - Atraso médio total (dias) - estruturas simples.

\begin{tabular}{|c|c|c|c|c|c|}
\hline \multirow{2}{*}{$\begin{array}{c}\text { Método/ } \\
\text { Regra }\end{array}$} & \multicolumn{5}{|c|}{ Replicação } \\
\cline { 2 - 6 } & № 1 & № 2 & № 3 & № 4 & № 5 \\
\hline CR & 3834 & 3649 & 3643 & 3733 & 3528 \\
\hline EDD-SPT & 3513 & 3315 & 3384 & 3380 & 3282 \\
\hline ODD-SPT & 3521 & 3361 & 3381 & 3404 & 3326 \\
\hline RANDOM & 4253 & 4172 & 4171 & 4206 & 3941 \\
\hline SLACK & 3540 & 3315 & 3404 & 3390 & 3264 \\
\hline SOPN & 3762 & 3608 & 3624 & 3681 & 3530 \\
\hline MIS & 3510 & 3304 & 3376 & 3371 & 3261 \\
\hline
\end{tabular}


Os gráficos 1 ao 5 apresentam a evolução diária do atraso médio de atendimento de cada replicação para estruturas simples.

A Tabela 7.3 apresenta os resultados de cada replicação do segundo conjunto de experimentos, o qual objetivou avaliar o efeito das estruturas complexas sobre a eficiência das seis regras e dos dois métodos. $O$ atraso médio total (em dias) é igual à soma dos atrasos médios diários para todo o período de simulação.

Os gráficos 6 a 10 apresentam a evolução diária do atraso médio de atendimento de cada replicação para estruturas complexas.

Tabela 7.3 - Atraso médio total (dias) - estruturas complexas.

\begin{tabular}{|c|c|c|c|c|c|}
\hline \multirow{2}{*}{$\begin{array}{c}\text { Método/ } \\
\text { Regra }\end{array}$} & \multicolumn{5}{|c|}{ Replicação } \\
\cline { 2 - 6 } & № 1 & № 2 & № 3 & № 4 & № 5 \\
\hline CR & 3598 & 3056 & 3363 & 3588 & 3392 \\
\hline EDD-SPT & 3467 & 2900 & 3228 & 3389 & 3215 \\
\hline ODD-SPT & 3494 & 2907 & 3229 & 3399 & 3222 \\
\hline RANDOM & 4902 & 4430 & 4649 & 4868 & 4662 \\
\hline SLACK & 3496 & 2922 & 3218 & 3414 & 3233 \\
\hline SOPN & 3567 & 2997 & 3346 & 3461 & 3323 \\
\hline MIS & 3465 & 2892 & 3209 & 3383 & 3206 \\
\hline
\end{tabular}

A Tabela 7.4 apresenta, por replicação, o número de vezes em que cada regra de priorização foi selecionada durante execução do MIS para estruturas simples.

Tabela 7.4 - Regras usadas no MIS - estruturas simples.

\begin{tabular}{|c|c|c|c|c|c|}
\hline \multirow{2}{*}{ Regra } & \multicolumn{5}{|c|}{ Replicação } \\
\cline { 2 - 6 } & № 1 & № 2 & № 3 & № 4 & № 5 \\
\hline CR & 3 & 4 & 7 & 4 & 13 \\
\hline EDD-SPT & 113 & 71 & 63 & 81 & 27 \\
\hline ODD-SPT & 31 & 7 & 70 & 23 & 0 \\
\hline
\end{tabular}




\begin{tabular}{|c|c|c|c|c|c|}
\hline \multirow{2}{*}{ Regra } & \multicolumn{5}{|c|}{ Replicação } \\
\cline { 2 - 6 } & № 1 & № 2 & № 3 & № 4 & № 5 \\
\hline SLACK & 3 & 68 & 7 & 41 & 107 \\
\hline SOPN & 0 & 0 & 3 & 1 & 3 \\
\hline
\end{tabular}

A Tabela 7.5 apresenta, por replicação, o número de vezes em que cada regra de priorização foi selecionada durante execução do MIS para estruturas complexas.

Tabela 7.5 - Regras usadas no MIS - estruturas complexas.

\begin{tabular}{|c|c|c|c|c|c|}
\hline \multirow{2}{*}{ Regra } & \multicolumn{5}{|c|}{ Replicação } \\
\cline { 2 - 6 } & № 1 & № 2 & № 3 & № 4 & № 5 \\
\hline CR & 4 & 10 & 16 & 5 & 9 \\
\hline EDD-SPT & 121 & 79 & 35 & 90 & 68 \\
\hline ODD-SPT & 11 & 52 & 18 & 39 & 51 \\
\hline SLACK & 5 & 2 & 76 & 1 & 14 \\
\hline SOPN & 9 & 7 & 5 & 15 & 8 \\
\hline
\end{tabular}




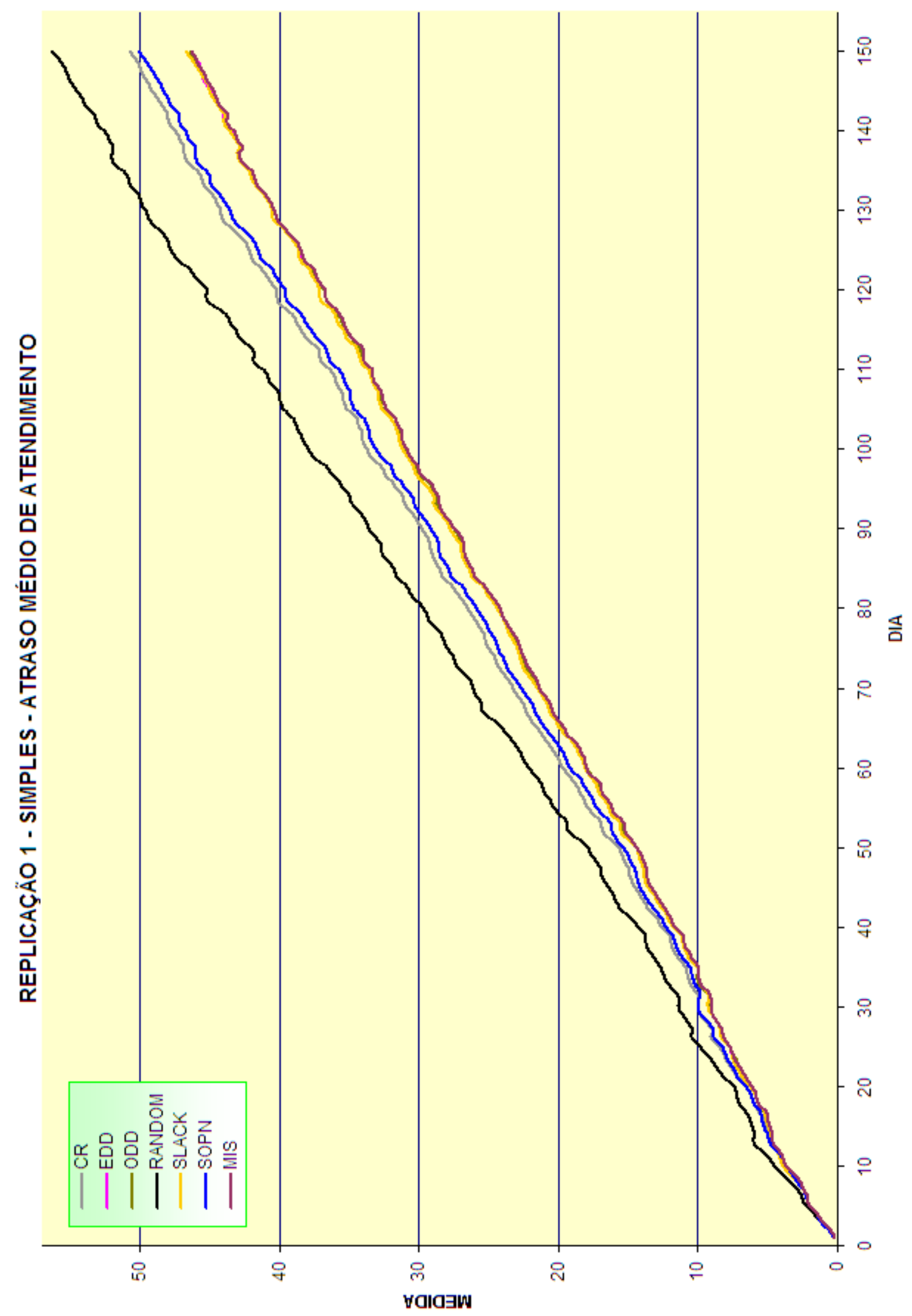

Gráfico 1 - Estrutura Simples - Replicação № 1. 


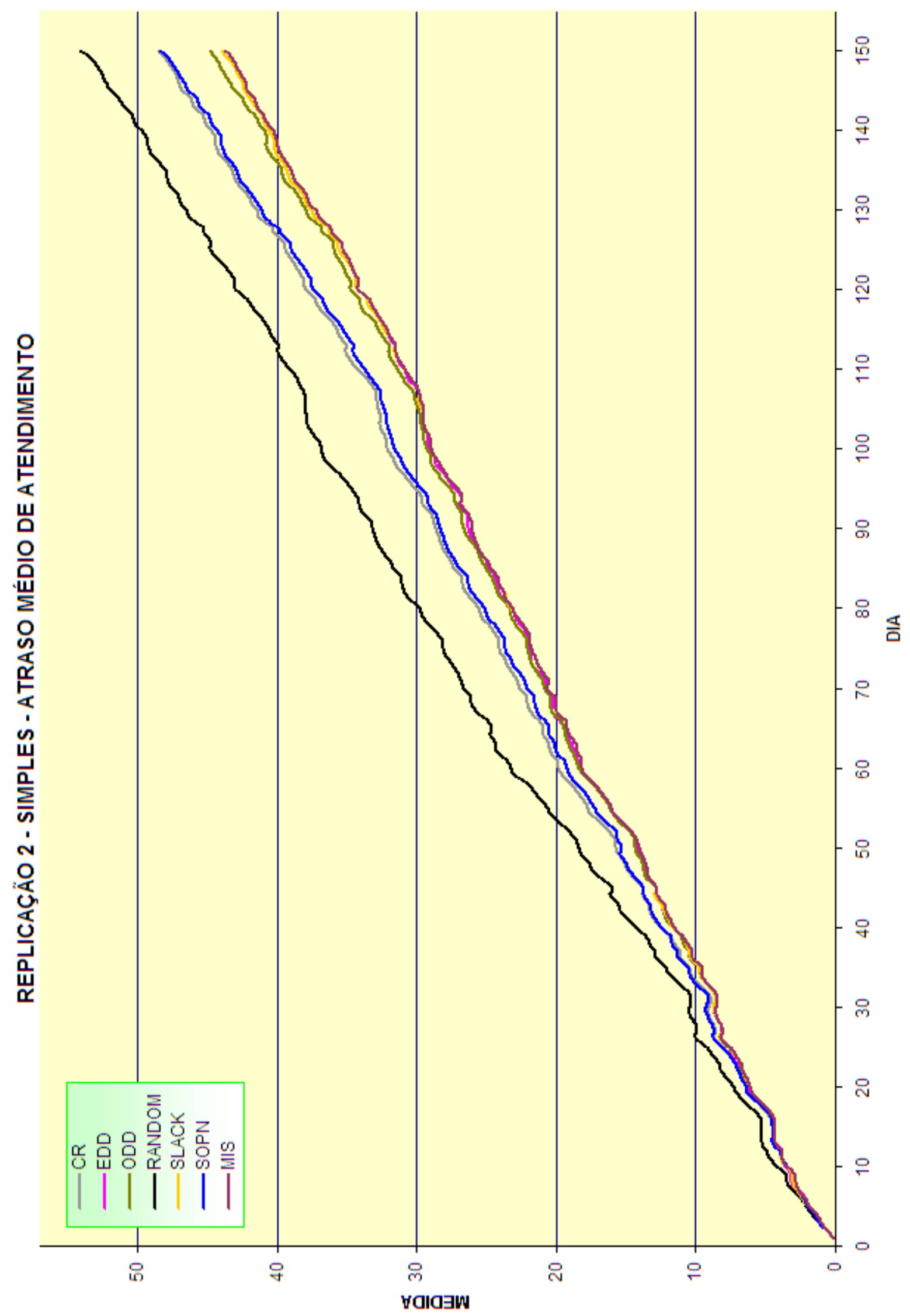

Gráfico 2 - Estrutura Simples - Replicação № 2. 


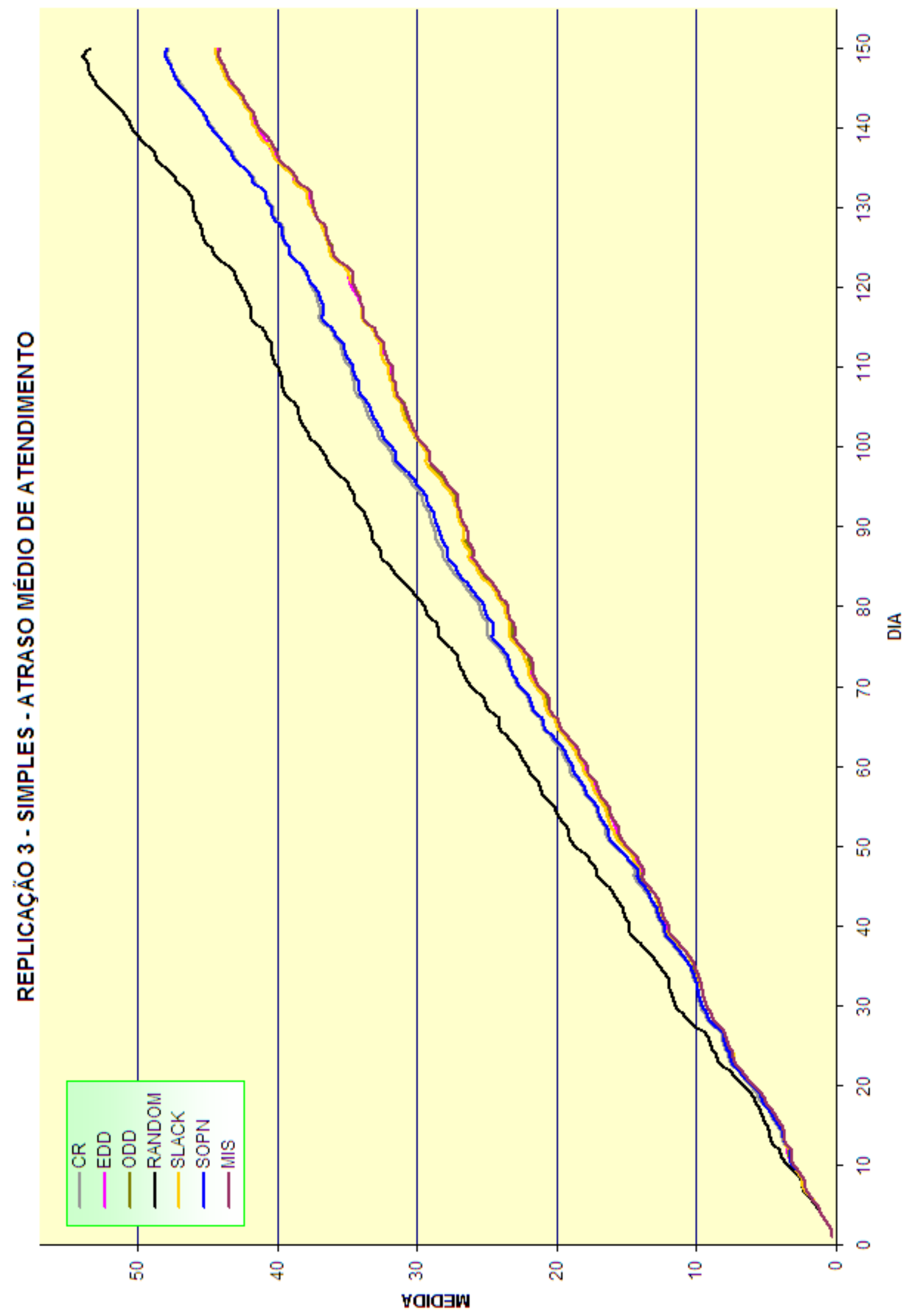

Gráfico 3 - Estrutura Simples - Replicação № 3. 


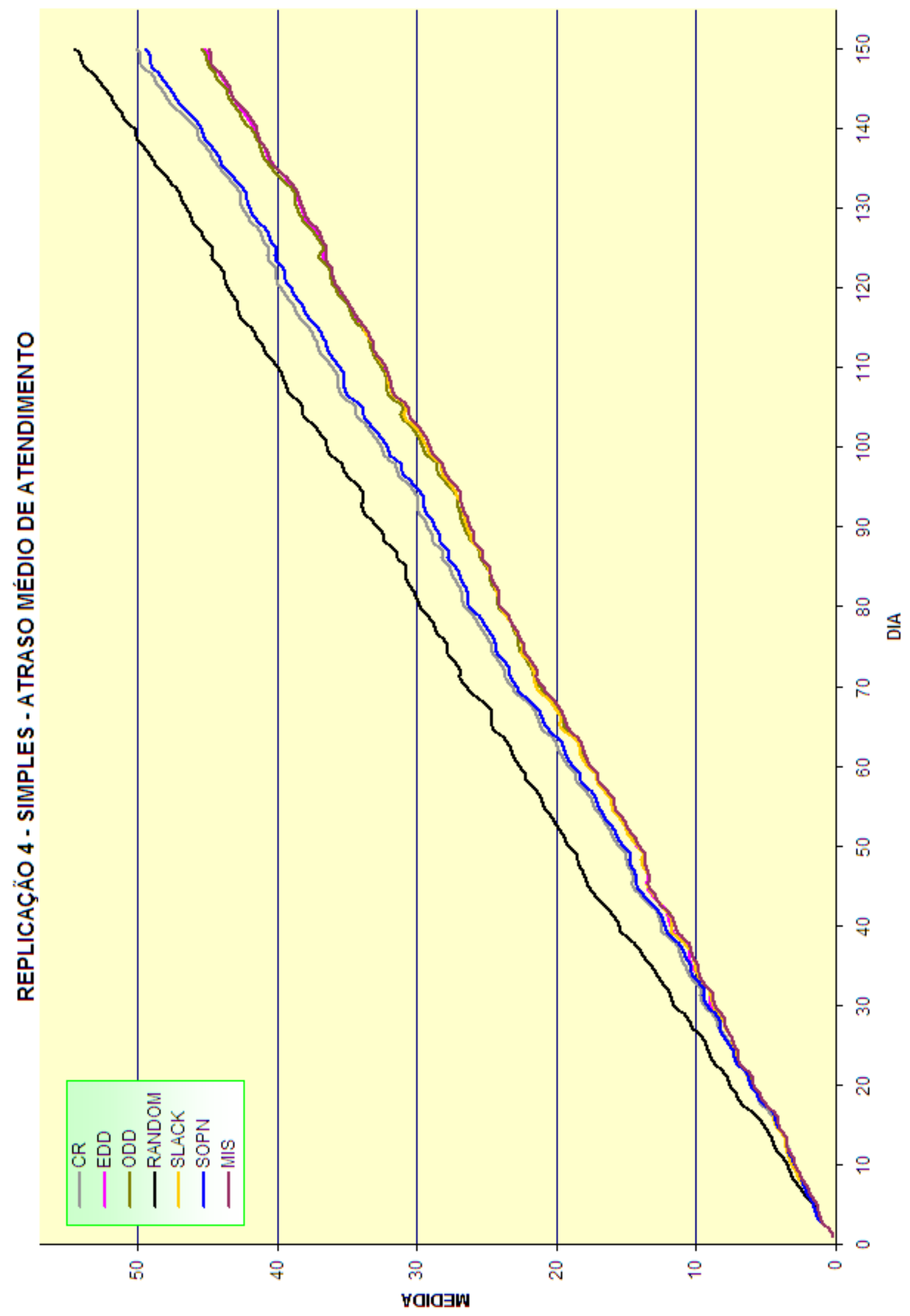

Gráfico 4 - Estrutura Simples - Replicação № 4. 


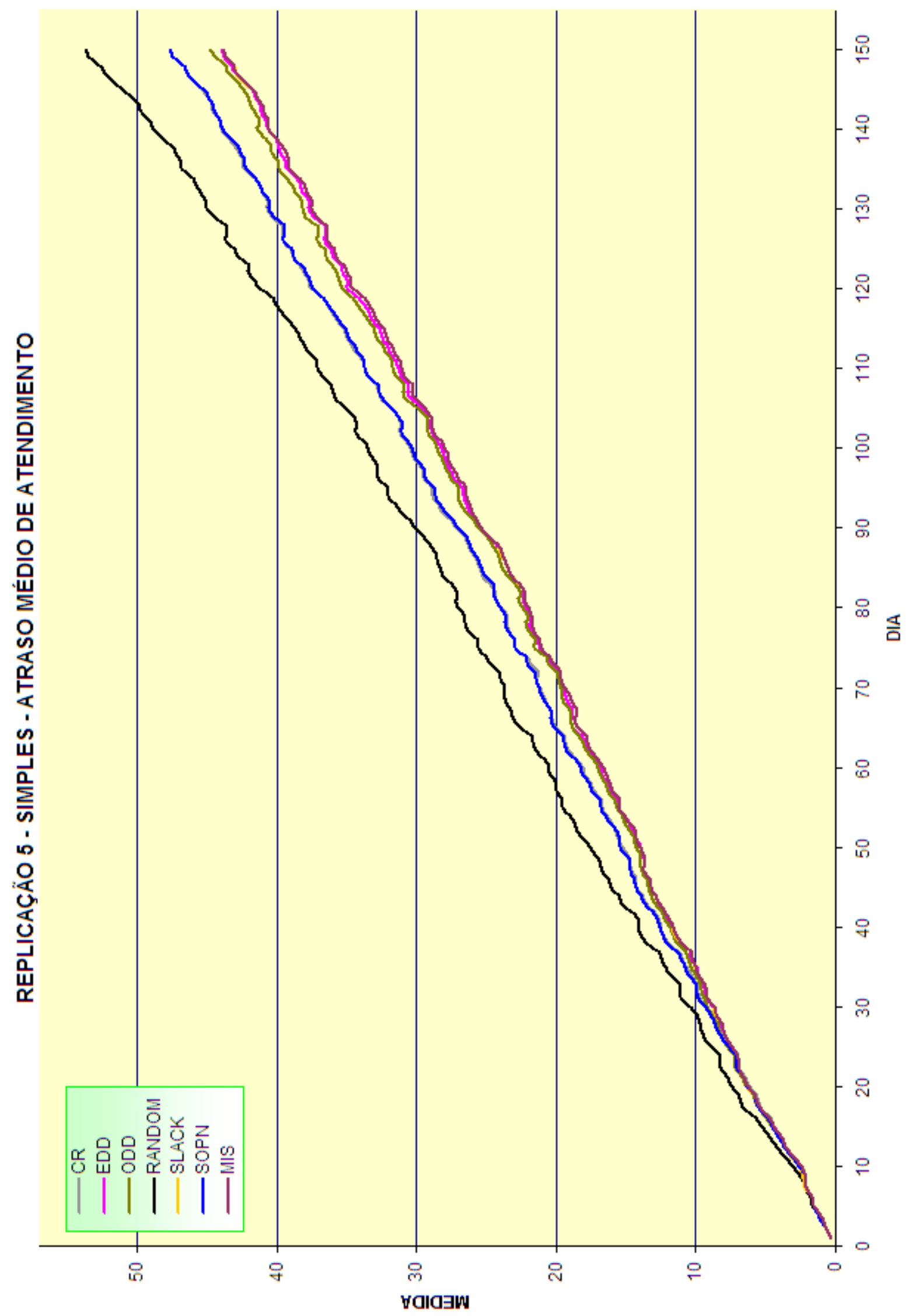

Gráfico 5 - Estrutura Simples - Replicação № 5. 


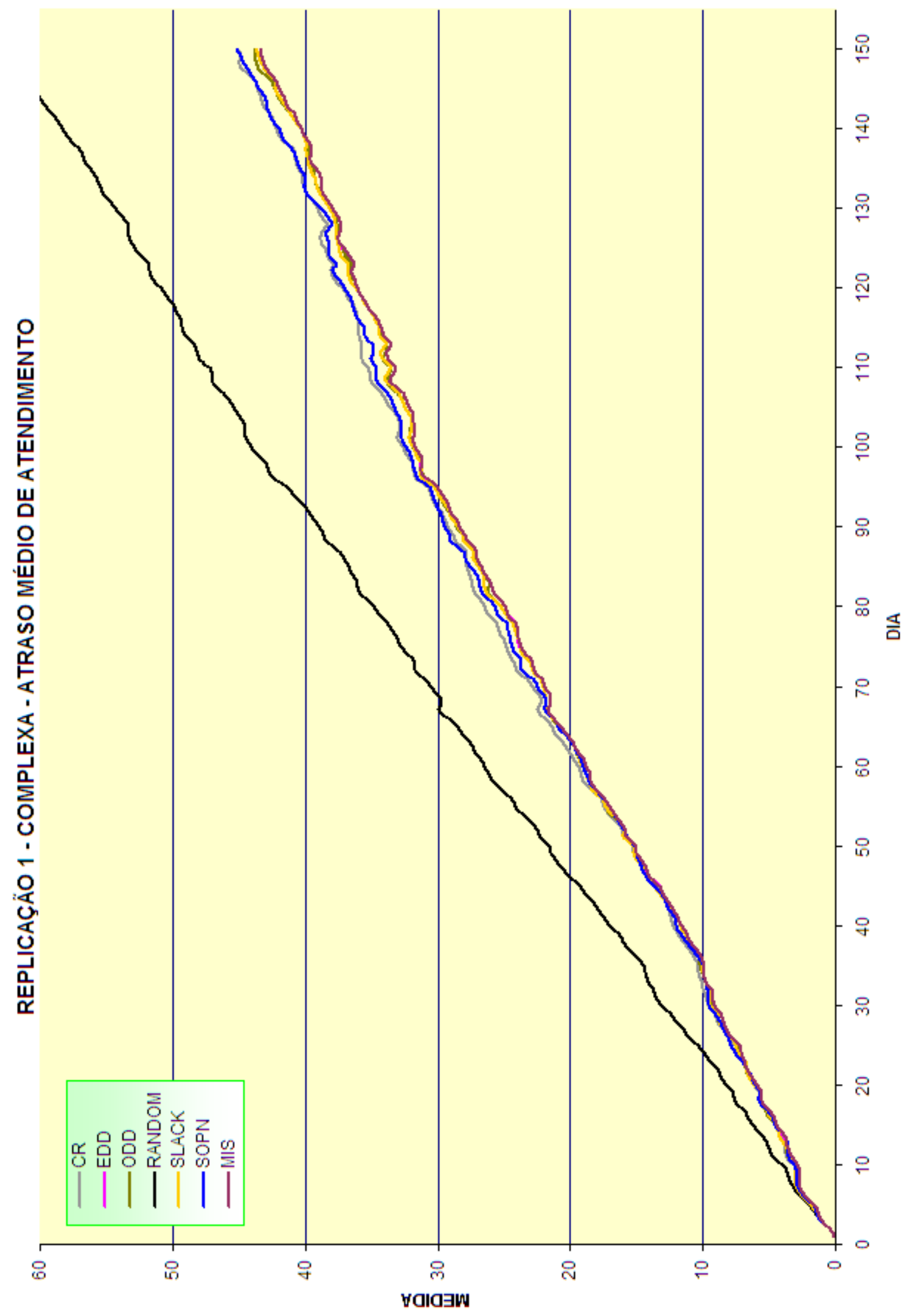

Gráfico 6 - Estrutura Complexa - Replicação № 1. 


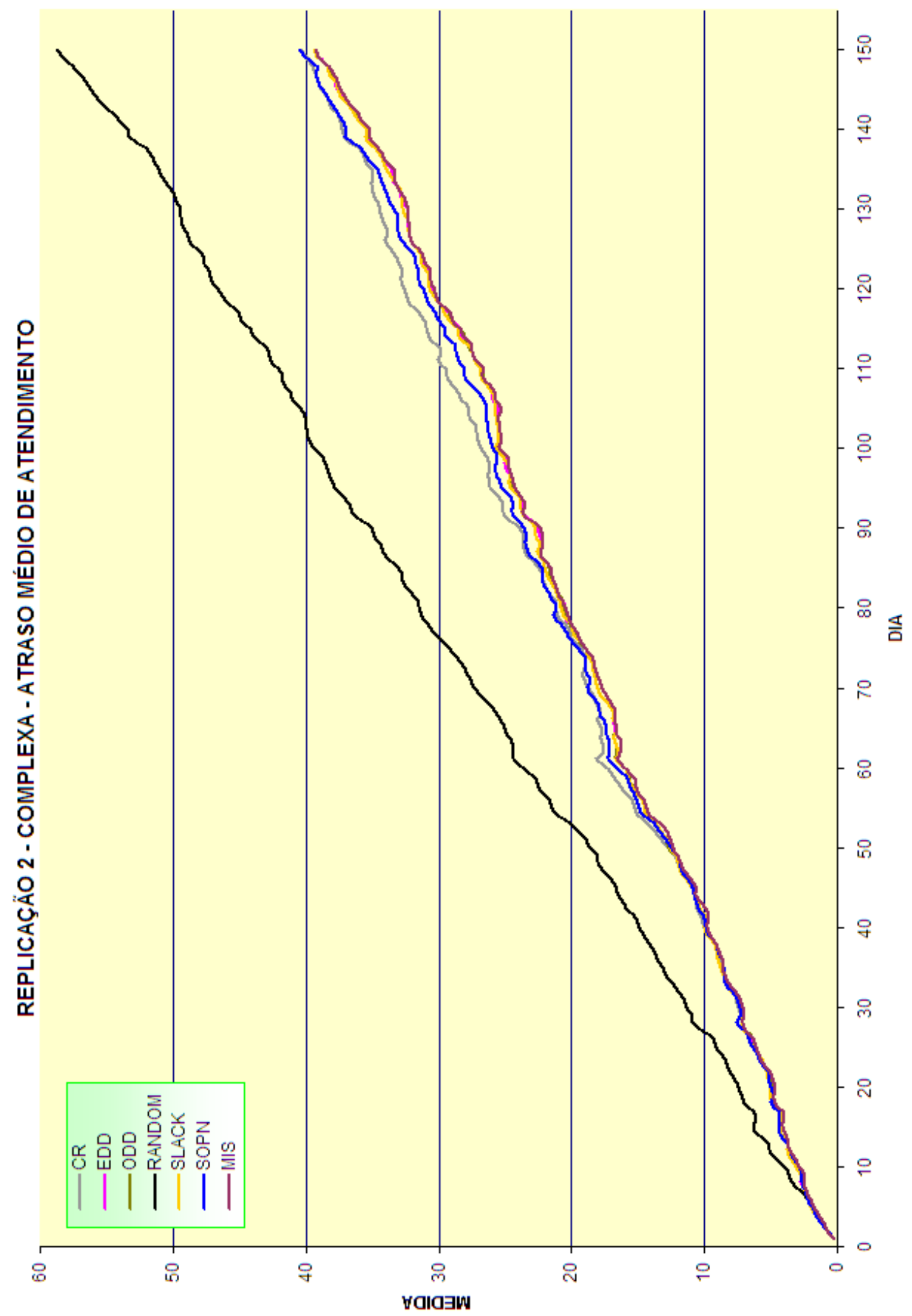

Gráfico 7 - Estrutura Complexa - Replicação № 2. 


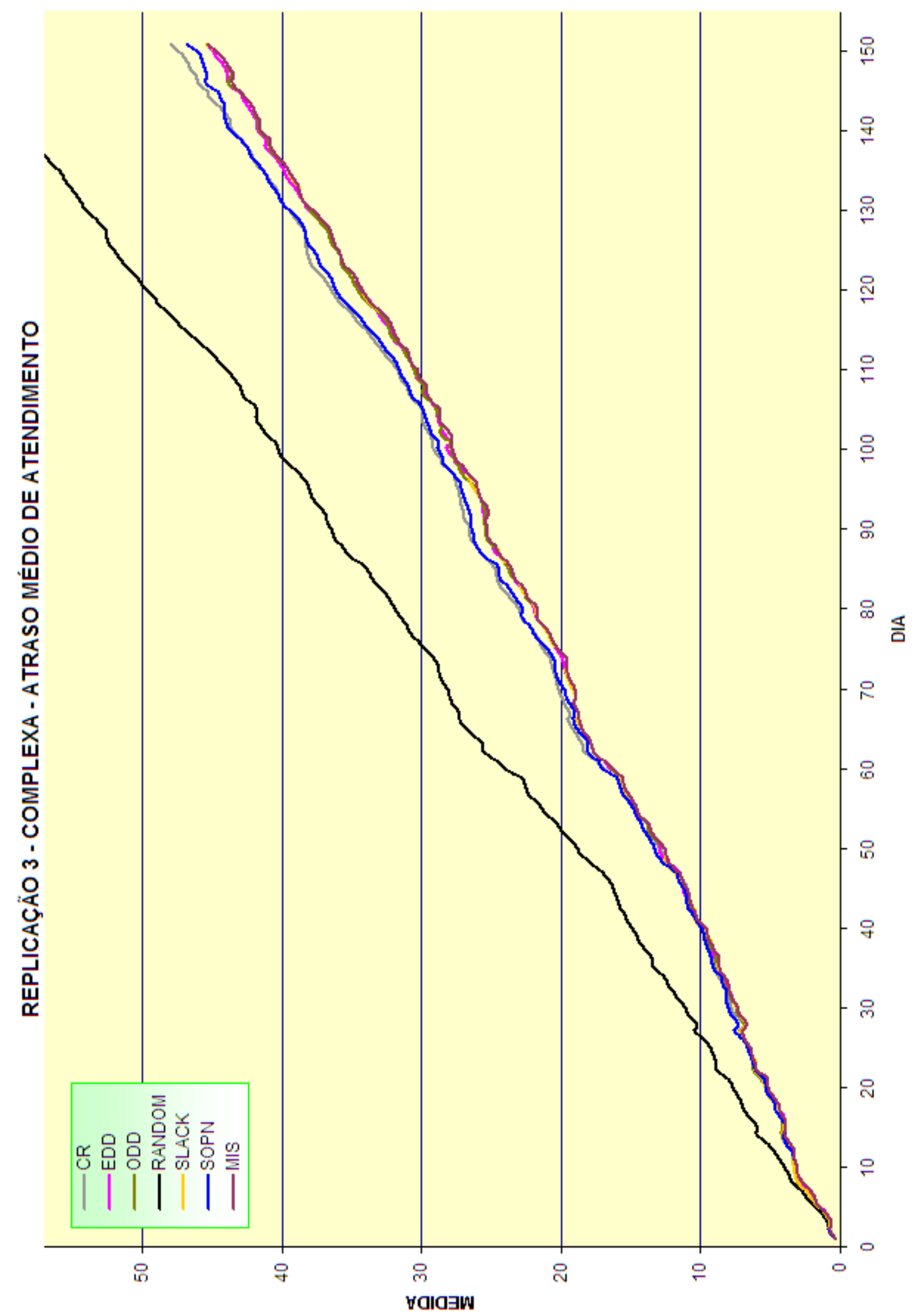

Gráfico 8 - Estrutura Complexa - Replicação № 3. 


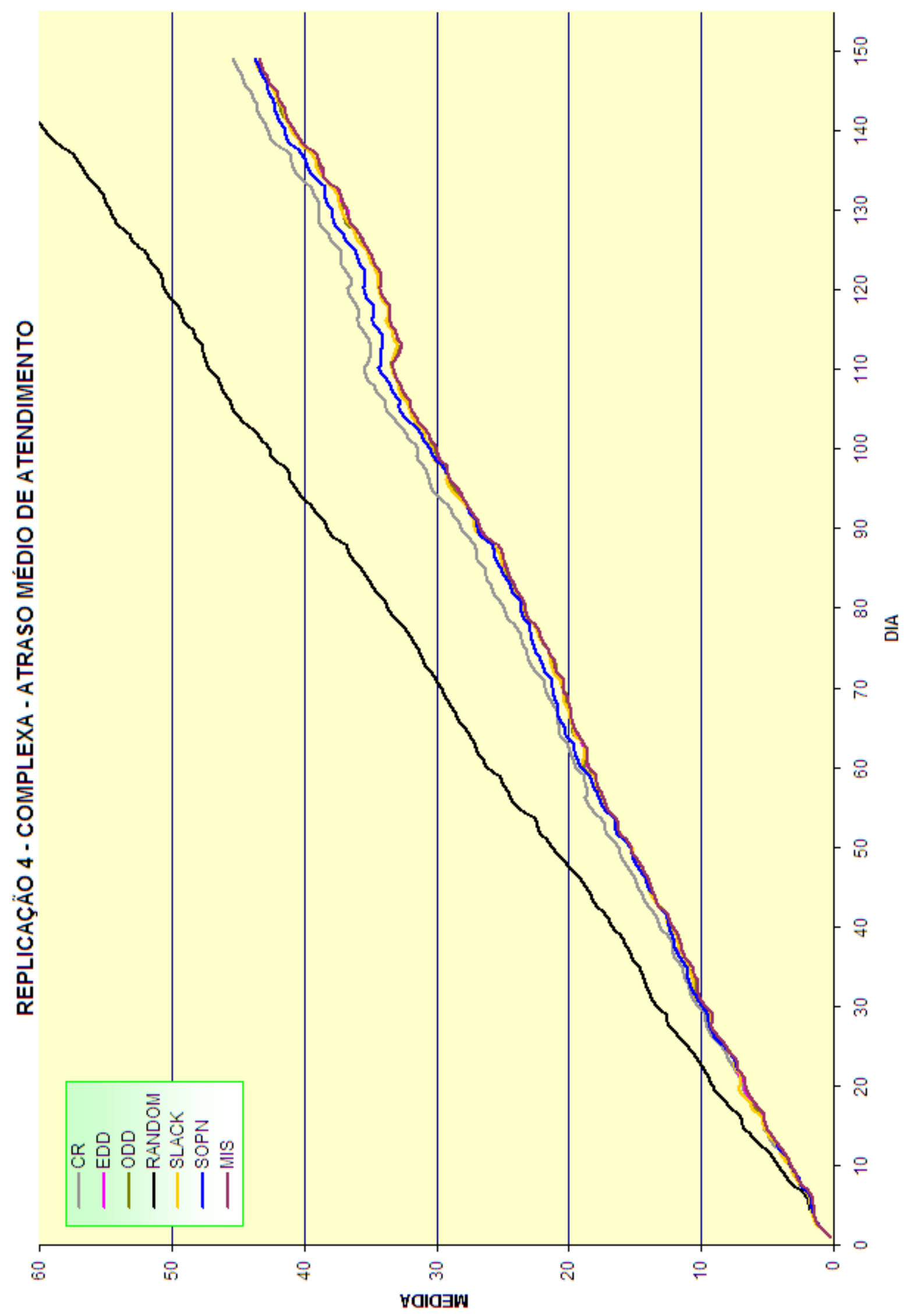

Gráfico 9 - Estrutura Complexa - Replicação № 4. 


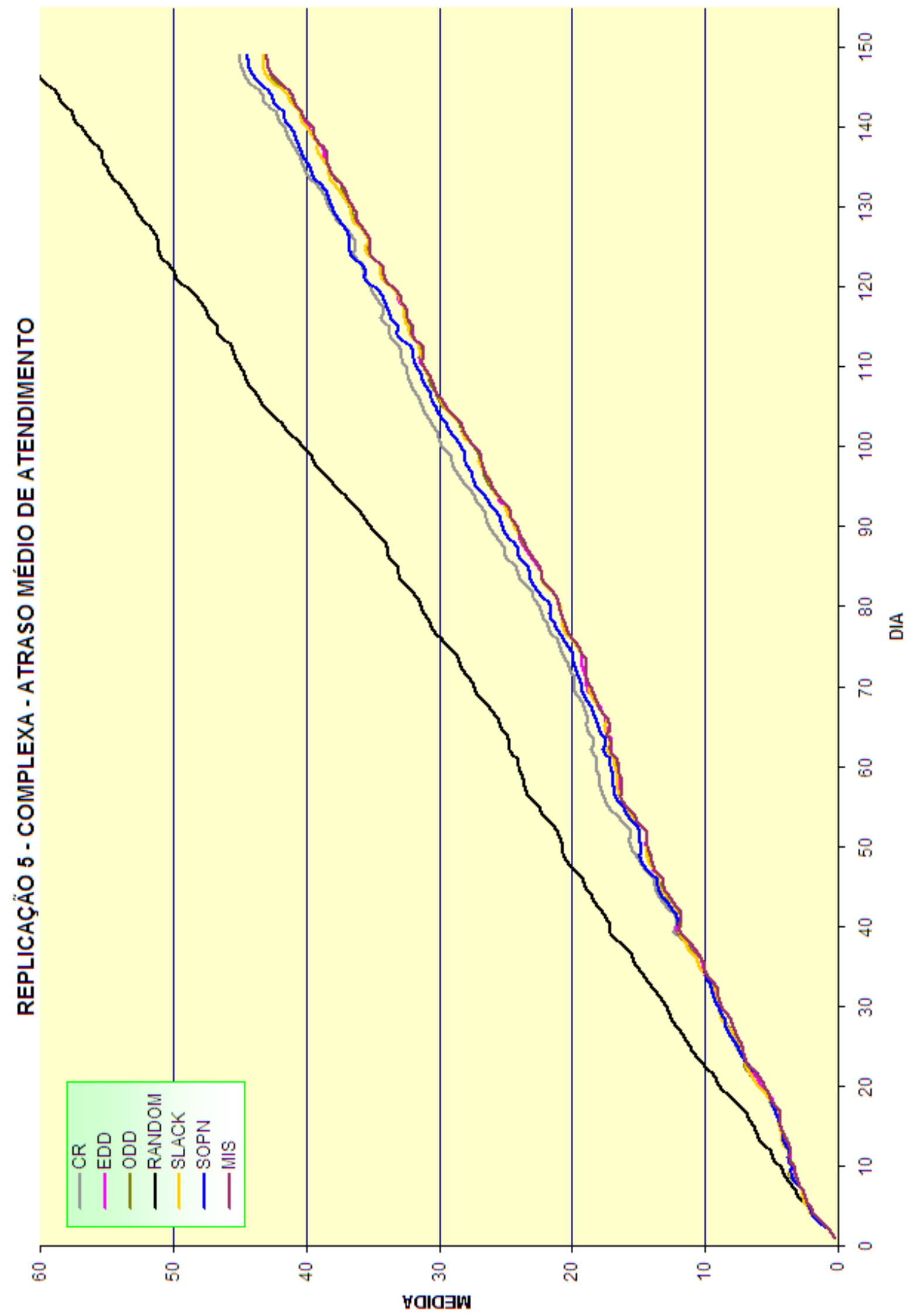

Gráfico 10 - Estrutura Complexa - Replicação № 5. 


\subsection{Análise estatística dos resultados}

Esta seção apresenta os resultados da aplicação de três técnicas estatísticas para o teste de hipótese $H_{0}: \mu_{i}=\mu_{j} / H_{1}: \mu_{i} \neq \mu_{j}, \forall i \neq j$, a saber: 1) Análise de Variância, 2) Teste de Tukey e 3) Teste dos Múltiplos Intervalos de Duncan.

Cabe observar que os resultados gerados pela regra RANDOM foram excluídos da análise estatística devido à irrelevância desta regra para a análise e ao risco de distorção do resultado.

\subsubsection{Estatísticas básicas}

A Tabela 7.6 apresenta a média simples (MS), o desvio padrão (DP) e o coeficiente de variação $(\mathrm{CV})$ dos resultados apresentados na Tabela 7.2, excluindose a regra RANDOM.

Tabela 7.6 - Estatísticas básicas - estruturas simples.

\begin{tabular}{|c|c|c|c|}
\hline \multirow{2}{*}{ Regra } & \multicolumn{3}{|c|}{ Estatística } \\
\cline { 2 - 4 } & MS & DP & CV(\%) \\
\hline CR & 3677 & 114 & 3,1 \\
\hline EDD & 3375 & 89 & 2,6 \\
\hline ODD & 3399 & 74 & 2,2 \\
\hline SLACK & 3383 & 105 & 3,1 \\
\hline SOPN & 3641 & 87 & 2,4 \\
\hline MIS & 3364 & 94 & 2,8 \\
\hline
\end{tabular}


A Tabela 7.7 apresenta a média simples (MS), o desvio padrão (DP) e o coeficiente de variação (CV) dos dados apresentados na Tabela 7.3, excluindo-se a regra RANDOM.

Tabela 7.7 - Estatísticas básicas - estruturas complexas.

\begin{tabular}{|c|c|c|c|}
\hline \multirow{2}{*}{ Regra } & \multicolumn{3}{|c|}{ Estatística } \\
\cline { 2 - 4 } & MS & DP & CV(\%) \\
\hline CR & 3399 & 220 & 6,5 \\
\hline EDD & 3240 & 218 & 6,7 \\
\hline ODD & 3250 & 224 & 6,9 \\
\hline SLACK & 3257 & 221 & 6,8 \\
\hline SOPN & 3339 & 215 & 6,4 \\
\hline MIS & 3231 & 220 & 6,8 \\
\hline
\end{tabular}

\subsubsection{Análise de Variância}

Esta seção é baseada em MONTGOMERY (2001, p.70).

A Tabela 7.8 apresenta o resultado da Análise de Variância para os dados apresentados na Tabela 7.2 (estruturas simples), excluindo-se a regra RANDOM.

Para um nível de significância $\alpha=0,05$, a Tabela IV de MONTGOMERY (2001, p.644) apresenta $F_{\alpha ; \nu_{1} ; \nu_{2}}=F_{0,05 ; 5 ; 24}=2,62$.

Para as estruturas simples, $F_{0}>F_{0,05 ; 5 ; 24}$, portanto, rejeita-se a hipótese $H_{0}: \mu_{i}=\mu_{j}(\forall i \neq j)$ e conclui-se que as médias dos experimentos diferem, ou seja, $H_{1}: \mu_{i} \neq \mu_{j}$ para pelo menos um par $(i, j)$ de médias. Isto significa dizer que os diferentes métodos de programação e regras de priorização afetaram significativamente a variável de resposta para estruturas de materiais simples, 
considerando-se o conjunto de parâmetros de execução do simulador e para a configuração do sistema de produção adotados no procedimento experimental. A comparação mais detalhada dos métodos e regras é feita através dos testes de Tukey e Duncan.

Tabela 7.8 - Análise de Variância - estruturas simples.

\begin{tabular}{|l|c|c|c|c|}
\hline \multicolumn{1}{|c|}{$\begin{array}{c}\text { Fonte de } \\
\text { Variação }\end{array}$} & $\begin{array}{c}\text { Soma dos } \\
\text { Quadrados }\end{array}$ & $\begin{array}{c}\text { Graus de } \\
\text { Liberdade }\end{array}$ & Variâncias & $\boldsymbol{F}_{0}$ \\
\hline $\begin{array}{l}\text { Entre } \\
\text { Experimentos }\end{array}$ & 525.740 & 5 & 105.148 & \multirow{2}{*}{11,74} \\
\cline { 1 - 4 } $\begin{array}{l}\text { Dentro dos } \\
\text { Experimentos }\end{array}$ & 214.909 & 24 & 8.955 (MSE) & \\
\cline { 1 - 4 } Total & 740.649 & 29 & & \\
\hline
\end{tabular}

A Tabela 7.9 apresenta o resultado da Análise de Variância para os dados apresentados na Tabela 7.3 (estruturas complexas), excluindo-se a regra RANDOM.

Tabela 7.9 - Análise de Variância - estruturas complexas.

\begin{tabular}{|l|c|c|c|c|}
\hline \multicolumn{1}{|c|}{$\begin{array}{c}\text { Fonte de } \\
\text { Variação }\end{array}$} & $\begin{array}{c}\text { Soma dos } \\
\text { Quadrados }\end{array}$ & $\begin{array}{c}\text { Graus de } \\
\text { Liberdade }\end{array}$ & Variâncias & $\boldsymbol{F}_{0}$ \\
\hline $\begin{array}{l}\text { Entre } \\
\text { Experimentos }\end{array}$ & 114.764 & 5 & 22.953 & \multirow{2}{*}{0,48} \\
\cline { 1 - 4 } $\begin{array}{l}\text { Dentro dos } \\
\text { Experimentos }\end{array}$ & 1.159 .143 & 24 & 48.298 (MSE) & \\
\hline Total & 1.273 .907 & 29 & & \\
\hline
\end{tabular}

Para as estruturas complexas, $F_{0}<F_{0,05 ; 5 ; 24}$, portanto, aceita-se a hipótese $H_{0}: \mu_{i}=\mu_{j}(\forall i \neq j)$ e conclui-se que as médias dos experimentos não diferem. Isto significa dizer que os diferentes métodos de programação e regras de priorização não afetaram significativamente a variável de resposta para estruturas de materiais complexas, considerando-se o conjunto de parâmetros de execução do simulador e para a configuração do sistema de produção adotados no procedimento 
experimental. Esta conclusão é reforçada pelos resultados dos testes de Tukey e Duncan.

\subsubsection{Teste de Tukey}

Esta seção é baseada em MONTGOMERY (2001, p.96).

A Tabela 7.10 apresenta o resultado do Teste de Tukey para as médias simples apresentadas na Tabela 7.6 (estruturas simples), excluindo-se a regra RANDOM. A coluna $\bar{y}_{i}-\bar{y}_{j}$ mostra os valores de média a serem subtraídos para cada par método-regra. A coluna 'Resultado' mostra o valor final.

Para um nível de significância $\alpha=0,05$, A Tabela VIII de MONTGOMERY (2001, p.657) apresenta $q_{\alpha}(p, f)=q_{0,05}(5 ; 24)=4,17$.

Para estruturas simples:

$$
T_{\alpha}=q_{\alpha}(a ; f) \times \sqrt{\frac{\mathrm{MSE}}{n}} \rightarrow T_{0,05}=4,17 \times \sqrt{\frac{8.955}{5}} \approx 176
$$

Logo, qualquer diferença absoluta calculada para cada par de médias dos experimentos que seja maior que $T_{0,05}=176$ implica na diferença significativa entre os pares método-regra, para o conjunto de parâmetros de execução do simulador e para a configuração do sistema de produção adotados no procedimento experimental.

Os valores marcados com asterisco na Tabela 7.10 indicam pares de médias (método-regra) que diferem significativamente. 
A Tabela 7.11 apresenta o resultado do Teste de Tukey para as médias simples apresentadas na Tabela 7.7 (estruturas complexas), excluindo-se a regra RANDOM. A coluna ' $\bar{y}_{i}-\bar{y}_{j}$ ' mostra os valores de média a serem subtraídos para cada par método-regra. A coluna 'Resultado' mostra o valor final.

Tabela 7.10 - Teste de Tukey - estruturas simples.

\begin{tabular}{|c|c|c|}
\hline \multicolumn{3}{|c|}{ Diferença Entre Médias } \\
\hline Método/Regra & $\left(\bar{y}_{i}-\bar{y}_{j}\right)$ & Resultado \\
\hline CR vs. EDD & $3677-3375$ & $302^{*}$ \\
\hline CR vs. ODD & $3677-3399$ & $278^{*}$ \\
\hline CR vs. SLACK & $3677-3383$ & $294^{*}$ \\
\hline CR vs. SOPN & $3677-3641$ & 36 \\
\hline CR vs. MIS & $3677-3364$ & $313^{*}$ \\
\hline EDD vs. ODD & $3375-3399$ & -24 \\
\hline EDD vs. SLACK & $3375-3383$ & -8 \\
\hline EDD vs. SOPN & $3375-3641$ & $-266^{\star}$ \\
\hline EDD vs. MIS & $3375-3364$ & 11 \\
\hline ODD vs. SLACK & $3399-3383$ & 16 \\
\hline ODD vs. SOPN & $3399-3641$ & $-242^{*}$ \\
\hline ODD vs. MIS & $3399-3364$ & 35 \\
\hline SLACK vs. SOPN & $3383-3641$ & $-258^{\star}$ \\
\hline SLACK vs. MIS & $3383-3364$ & 19 \\
\hline SOPN vs. MIS & $3641-3364$ & $277^{*}$ \\
\hline
\end{tabular}

Para estruturas complexas:

$$
T_{\alpha}=q_{\alpha}(a ; f) \times \sqrt{\frac{\mathrm{MSE}}{n}} \rightarrow T_{0,05}=4,17 \times \sqrt{\frac{48.298}{5}} \approx 410
$$

Logo, qualquer diferença absoluta calculada para cada par de médias dos experimentos que seja maior que $T_{0,05}=410$ implica na diferença significativa entre os pares método-regra, para o conjunto de parâmetros de execução do simulador e para a configuração do sistema de produção adotados no procedimento experimental. 
Para estruturas complexas, nenhum par método-regra difere significativamente.

Tabela 7.11 - Teste de Tukey - estruturas complexas.

\begin{tabular}{|c|c|c|}
\hline \multicolumn{3}{|c|}{ Diferença Entre Médias } \\
\hline Método/Regra & $\left(\bar{y}_{i}-\bar{y}_{j}\right)$ & Resultado \\
\hline CR vs. EDD & $3399-3240$ & 159 \\
\hline CR vs. ODD & $3399-3250$ & 149 \\
\hline CR vs. SLACK & $3399-3257$ & 142 \\
\hline CR vs. SOPN & $3399-3339$ & 60 \\
\hline CR vs. MIS & $3399-3231$ & 168 \\
\hline EDD vs. ODD & $3240-3250$ & -10 \\
\hline EDD vs. SLACK & $3240-3257$ & -17 \\
\hline EDD vs. SOPN & $3240-3339$ & -99 \\
\hline EDD vs. MIS & $3240-3231$ & 9 \\
\hline ODD vs. SLACK & $3250-3257$ & -7 \\
\hline ODD vs. SOPN & $3250-3339$ & -89 \\
\hline ODD vs. MIS & $3250-3231$ & 19 \\
\hline SLACK vs. SOPN & $3257-3339$ & -82 \\
\hline SLACK vs. MIS & $3257-3231$ & 26 \\
\hline SOPN vs. MIS & $3339-3231$ & 108 \\
\hline
\end{tabular}

\subsubsection{Teste dos Múltiplos Intervalos de Duncan}

Esta seção é baseada em MONTGOMERY (2001, p.100).

A Tabela 7.12 apresenta o resultado do Teste Duncan para as médias simples apresentadas na Tabela 7.6 (estruturas simples), excluindo-se a regra RANDOM. A coluna ' $\bar{y}_{i}-\bar{y}_{j}$ ' mostra os valores de média a serem subtraídos para cada par método-regra. A coluna 'Resultado' mostra o valor final.

Para um nível de significância $\alpha=0,05$, A Tabela VII de MONTGOMERY (2001, p.655) apresenta os seguintes valores aproximados para $r_{\alpha}(p, f)=r_{0,05}(p, 24)$ : 


$$
\begin{aligned}
& r_{0,05}(2 ; 24)=2,93 ; \quad r_{0,05}(3 ; 24)=3,08 ; \quad r_{0,05}(4 ; 24)=3,16 ; \quad r_{0,05}(5 ; 24)=3,23 ; \\
& r_{0,05}(6 ; 24)=3,28
\end{aligned}
$$

Para estruturas simples, os intervalos $R_{p}=r_{\alpha}(p, f) \times \sqrt{\frac{M S E}{n}}$ são:

$$
\begin{aligned}
& \text { i. } R_{2}=2,93 \times \sqrt{\frac{8.955}{5}} \approx 124 \\
& \text { ii. } R_{3}=3,08 \times \sqrt{\frac{8.955}{5}} \approx 130 \\
& \text { iii. } R_{4}=3,16 \times \sqrt{\frac{8.955}{5}} \approx 134 \\
& \text { iv. } R_{5}=3,23 \times \sqrt{\frac{8.955}{5}} \approx 137 \\
& \text { v. } R_{6}=3,28 \times \sqrt{\frac{8.955}{5}} \approx 139
\end{aligned}
$$

Logo, qualquer diferença absoluta calculada para cada par de médias dos experimentos que seja maior que $\circ R_{p}$ correspondente implica na diferença significativa entre os pares método-regra, para o conjunto de parâmetros de execução do simulador e para a configuração do sistema de produção adotados no procedimento experimental.

Os valores marcados com asterisco na Tabela 7.12 indicam pares de médias (método-regra) que diferem significativamente.

A Tabela 7.13 apresenta o resultado do Teste Duncan para as médias simples apresentadas na Tabela 7.7 (estruturas complexas), excluindo-se a regra RANDOM. A coluna ' $\bar{y}_{i}-\bar{y}_{j}$ ' mostra os valores de média a serem subtraídos para cada par método-regra. A coluna 'Resultado' mostra o valor final. 
Para estruturas complexas, os intervalos $R_{p}=r_{\alpha}(p, f) \times \sqrt{\frac{M S E}{n}}$ são:

i. $\quad R_{2}=2,93 \times \sqrt{\frac{48.298}{5}} \approx 288$

ii. $R_{3}=3,08 \times \sqrt{\frac{48.298}{5}} \approx 303$

iii. $R_{4}=3,16 \times \sqrt{\frac{48.298}{5}} \approx 311$

iv. $R_{5}=3,23 \times \sqrt{\frac{48.298}{5}} \approx 317$

v. $R_{6}=3,28 \times \sqrt{\frac{48.298}{5}} \approx 322$

Para estruturas complexas, nenhum par método-regra difere significativamente.

Tabela 7.12 - Teste de Duncan - estruturas simples.

\begin{tabular}{|c|c|c|c|}
\hline \multicolumn{4}{|c|}{ Diferença Entre Médias } \\
\hline Método/Regra & $\boldsymbol{R}_{\boldsymbol{p}}$ & $\left(\bar{y}_{i}-\bar{y}_{j}\right)$ & Resultado \\
\hline CR vs. MIS & 139 & $3677-3364$ & $313^{*}$ \\
\hline CR vs. EDD & 137 & $3677-3375$ & $302^{*}$ \\
\hline CR vs. SLACK & 134 & $3677-3383$ & $294^{*}$ \\
\hline CR vs. ODD & 130 & $3677-3399$ & $278^{*}$ \\
\hline CR vs. SOPN & 124 & $3677-3641$ & 36 \\
\hline SOPN vs. MIS & 137 & $3641-3364$ & $277^{*}$ \\
\hline SOPN vs. EDD & 134 & $3641-3375$ & $266^{*}$ \\
\hline SOPN vs. SLACK & 130 & $3641-3383$ & $258^{*}$ \\
\hline SOPN vs. ODD & 124 & $3641-3399$ & $242^{*}$ \\
\hline ODD vs. MIS & 134 & $3399-3364$ & 35 \\
\hline ODD vs. EDD & 130 & $3399-3375$ & 24 \\
\hline ODD vs. SLACK & 124 & $3399-3383$ & 16 \\
\hline SLACK vs. MIS & 130 & $3383-3364$ & 19 \\
\hline SLACK vs. EDD & 124 & $3383-3375$ & 8 \\
\hline EDD vs. MIS & 124 & $3375-3364$ & 11 \\
\hline
\end{tabular}


Tabela 7.13 - Teste de Duncan - estruturas complexas.

\begin{tabular}{|c|c|c|c|}
\hline \multicolumn{4}{|c|}{ Diferença Entre Médias } \\
\hline Método/Regra & $\boldsymbol{R}_{\boldsymbol{p}}$ & $\left(\bar{y}_{i}-\bar{y}_{j}\right)$ & Resultado \\
\hline CR vs. MIS & 322 & $3399-3231$ & 168 \\
\hline CR vs. EDD & 317 & $3399-3240$ & 159 \\
\hline CR vs. ODD & 311 & $3399-3250$ & 149 \\
\hline CR vs. SLACK & 303 & $3399-3257$ & 142 \\
\hline CR vs. SOPN & 288 & $3399-3339$ & 60 \\
\hline SOPN vs. MIS & 317 & $3339-3231$ & 108 \\
\hline SOPN vs. EDD & 311 & $3339-3240$ & 99 \\
\hline SOPN vs. ODD & 303 & $3339-3250$ & 89 \\
\hline SOPN vs. SLACK & 288 & $3339-3257$ & 82 \\
\hline SLACK vs. MIS & 311 & $3257-3231$ & 26 \\
\hline SLACK vs. EDD & 303 & $3257-3240$ & 17 \\
\hline SLACK vs. ODD & 288 & $3257-3250$ & 7 \\
\hline ODD vs. MIS & 303 & $3250-3231$ & 19 \\
\hline ODD vs. EDD & 288 & $3250-3240$ & 10 \\
\hline EDD vs. MIS & 288 & $3240-3231$ & 9 \\
\hline
\end{tabular}

A análise estatística dos resultados dos experimentos demonstrou que:

1. Para estruturas simples, apesar do método proposto (MIS) ter obtido em média melhores resultados para todas as instâncias, a análise estatística experimental demonstrou que, para o conjunto de parâmetros de execução do simulador e para a configuração do sistema de produção adotados no procedimento experimental, o método proposto apresentou melhores resultados (significativamente diferentes) apenas quando comparado com a programação não-iterativa usando as regras CR e SOPN.

2. Para estruturas simples, o método não-iterativo apresentou resultados significativamente melhores para a regra EDD quando comparada com as regras CR e SOPN.

3. Para estruturas simples, o método não-iterativo apresentou resultados significativamente melhores para a regra SLACK quando comparada com as regras CR e SOPN.

4. Para estruturas simples, o método não-iterativo apresentou resultados significativamente melhores para a regra ODD quando comparada com as regras CR e SOPN. 
5. Para estruturas complexas, apesar do método proposto (MIS) ter obtido em média melhores resultados para todas as instâncias, a análise estatística experimental demonstrou que, para o conjunto de parâmetros de execução do simulador e para a configuração do sistema de produção adotados no procedimento experimental, nenhum par método-regra apresentou resultado significativamente melhor. 


\section{Conclusão e Proposições}

Esta dissertação estudou o problema da programação de operações em sistemas job shop de manufatura onde itens com estruturas de materiais são produzidos a partir de componentes fabricados e montados. Tais sistemas são denominados assembly shops.

Um novo método heurístico para a programação de operações em sistemas assembly shop foi proposto. O método implementa dois algoritmos ou rotinas de programação: uma rotina backward que satisfaz completamente as datas de entrega e outra forward que satisfaz completamente a restrição de capacidade de máquina. Ambas trabalham iterativamente dentro de dois modelos de simulação do sistema de produção - um determinístico e outro probabilístico - na busca pela melhoria da sincronização das operações e no atendimento das datas de entrega.

Um modelo de simulação computacional de um sistema assembly shop (simulador) foi desenvolvido para avaliar o método.

O método foi avaliado através de um conjunto de experimentos executados no simulador. Os experimentos buscaram avaliar o efeito simultâneo de três fatores sobre a programação, a saber: a estrutura de materiais (simples e complexa), o método de programação (MIS vs. programação não-iterativa) e a regra de priorização (CR, SOPN, EDD-SPT, ODD-SPT, SLACK). A variável de resposta utilizada no estudo foi o atraso médio de atendimento.

Os resultados mostraram que o método proposto (MIS) obteve em média melhor desempenho que o método não-iterativo para todas as regras de priorização e tipos de estrutura de materiais. Porém, a análise estatística experimental apontou o desempenho significativamente melhor do MIS apenas quando comparado com as programações não-iterativas das regras CR e SOPN para estruturas simples. Para 
estruturas complexas, a análise estatística experimental não apontou diferenças significativas entre os métodos e regras.

Tais resultados poderiam levar a conclusão que o uso do método proposto não compensaria o esforço computacional quando comparado com métodos nãoiterativos (single-pass procedures) os quais certamente exigem menos esforço computacional. O autor considera, no entanto, que mais investigação necessita ser feita antes que se conclua sobre a superioridade de um ou de outro método.

Pode-se conjecturar que apesar do MIS ter provado ser efetivo para o conjunto de parâmetros utilizados, seu desempenho geral poderia ter sido melhor se a natureza estocástica do sistema fosse melhor capturada pelo processo de programação através de alterações dinâmicas dos parâmetros norteadores do método ao longo da simulação, parâmetros estes que foram mantidos fixos durante todo o tempo.

Como proposições relevantes para detalhamento do estudo e futuras pesquisas, têm-se:

i. Testar o método, alterando dinamicamente os valores dos parâmetros de execução do método (vide Tabela 5.3 e Tabela 6.3).

ii. Testar o método, variando os parâmetros complementares de simulação (vide Tabela 7.1).

iii. Realizar experimentos complementares utilizando outras instâncias, criadas a partir de outras funções de geração de dados (vide Tabela 6.4).

iv. Avaliar outras regras de priorização especializadas, desenvolvidas com o propósito de minimizar o atraso de atendimento, tais como, ATC (Apparent Tardness Cost), BD (Bottleneck Dynamics) e COVERT (Cost over Time).

v. Avaliar o método através de outros critérios de desempenho relevantes para o contexto dos sistemas assembly shop, tais como, a espera média de montagem, o desvio-padrão de atendimento e o desvio-padrão da espera de montagem. 


\section{Referências Bibliográficas}

ADAM, N. R.; BERTRAND, J. W. M.; SURKIS, J. Priority assignment procedures in multi-level assembly job shops. IIE Transactions, v.19, p.317-328, 1987.

ADAM, N. R. et al. Due date assignment procedures with dynamic updated coefficients for multi-level assembly job shops. European Journal of Operational Research, v.68, p.212-227, 1993.

BAKER, K. R. Introduction to Sequencing and Scheduling. New York: John Wiley \& Sons, 1974.

BAKER, K. R. Requirements planning. In: Logistics of Production and Inventory. Amsterdam: Elsevier Science Publishers, cap.11, p.571-627, 1993.

BANKS, J.; CARSON II, J. S.; NELSON, B. L. Discrete-event System Simulation. New Jersey: Prentice Hall, 2. ed., 1996.

BERRY, W. L.; RAO, V. Critical ratio scheduling: an experimental analysis. Management Science, v.22, n.2, p.192-201, 1975.

BIGGS, J. R. Priority rules for shop floor control in a material requirements planning system under various levels of capacity. International Journal of Production Research, v.23, p.33-46, 1985.

BROOKS, G. H.; WHITE, C. R. An algorithm for finding optimal or near-optimal solutions to the production scheduling problem. Journal of Industrial Engineering, v.16, n.1, p.34-40,1965. 
BUFFA, E.; SARIN, R. K. Modern Production/Operations Management. New York: John Wiley \& Sons, 8. ed., 1987.

CHENG, T. C. E.; GUPTA, M. C. Survey of scheduling research involving due date determination decisions. European Journal of Operational Research, v.38, p.156166, 1989.

CONWAY, R. W.; MAXWELL, W. L.; MILLER, L. W. Theory of Scheduling. Massachusetts: Addison-Wesley Publishing, 1967.

FISHER, M. L; RINNOOY KAN, A. H. G. The design, analysis and implementation of heuristics. Management Science, v.34, n.3, p.263-265, 1988.

FRY, T. D.; PHILIPOOM, P. R.; MARKLAND, R. E. Due date assignment in a multistage job shop. IIE Transactions, v.21, p.153-161, 1989.

FRY, T. D. et al. The effects of product structure and sequencing rule on assembly shop performance. International Journal of Production Research, v.27, p.671-686, 1989.

FOULDS, L. R. The heuristic problem-solving approach. Journal of Operational Research Society, v.34, n.10, p.927-934, 1983.

GLIFFER, B., THOMPSON, G. L. Algorithms for solving production scheduling problems. Operations Research, v.8, n.4, p.487-503, 1960.

GLOVER, F.; GREENBERG, H. J. New approaches for heuristic search: a bilateral linkage with artificial intelligence. European Journal of Operational Research, v.39, p.119-130, 1989.

GOODWIN, J. S.; GODDWIN, J. C. Operating policies for scheduling assembled products. Decision Sciences, v.13, p.585-603, 1982. 
GOODWIN, J. S.; WEEKS, J. K. Evaluating scheduling policies in a multi-level assembly system. International Journal of Production Research, v.24, p.247-257, 1986.

GROOVER, M. P. Automation, Production Systems, and Computer-Integrated Manufacturing. New Jersey: Prentice Hall, 2. ed., 2001.

HAX, A. C.; CANDEA, D. Production and Inventory Management. New Jersey: Prentice Hall, 1984.

HICKS, C.; PONGCHAROEN, P. Dispatching rules for production scheduling in the capital goods industry. International Journal of Production Economics, v.104, p.154-163, 2006.

HUANG, P. Y. Comparative study of priority dispatching rules in a hybrid assembly/job shop. International Journal of Production Research, v.22, p.375-387, 1984.

JAIN, A. S.; MEERAN, S. A state-of-art review of job-shop scheduling techniques. Dundee: Department of Applied Physics, Electronic and Mechanical Engineering, University of Dundee, 1998.

JOHNSON, L. A.; MONTGOMERY, D. C. Operations Research in Production Planning, Scheduling, and Inventory Control. New York: John Wiley \& Sons, 1974.

KARP, R. M. Reducibility among combinatorial problems. In: Complexity of Computer Computations, New York: Plenum Press, 1972.

KELTON, W. D.; SADOWSKI, R. P.; SADOWSKI, D. A. Simulation with Arena. New York: McGraw-Hill, 2. ed., 2002.

KUTANOGLU, E.; SABUNCUOGLU, I. An analysis of heuristics in a dynamic job shop with weighted tardiness objectives. International Journal of Production Research, v.37, n.1, p.165-187, 1999. 
KUTANOGLU, E.; SABUNCUOGLU, I. Experimental investigation of iterative simulation-based scheduling in a dynamic and stochastic job shop. Journal of Manufacturing Systems, v.20, n.4, p.264-279, 2001.

LAGEWEG et al. Computer aided complexity classification of combinatorial problems. Communications of the ACM, v.25, n.11, p.817-822, 1982.

LAGEWEG et al. Computer aided complexity classification of deterministic scheduling problems. Amsterdam: Center of Mathematics and Computer Science, 1981. (Technical Report BW 138).

LAWLER et al. Sequencing and Scheduling: Algorithms and Complexity. In: Logistics of Production and Inventory. Amsterdam: Elsevier Science Publishers, cap.9, p.445-522, 1993.

MAROS, I.; KHALIQ, M. H. Advances in design and implementation of optimization software. European Journal of Operational Research, v.140, p.322-337, 2002.

MAXWELL, W. L. Priority dispatching and assembly operations in a job shop. Santa Monica: Rand Corporation, 1965. (Technical Report RM-5370-PR).

MAXWELL, W. L.; MEHRA, M. Multiple-factor rules for sequencing with assembly constraints. Naval Research Logistics Quarterly, v.15, p.241-254, 1968.

MILLER, L. W.; GINSBERG, A. S.; MAXWELL, W. L. An experimental investigation of priority dispatching in a simple assembly shop. In: Logistics, North Holland, p.161-184, 1975.

MOHANASUNDARAM, K. M. et al. Scheduling rules for dynamic shops that manufacture multi-level jobs. Computers and Industrial Engineering, v.44, p.119131, 2002.

MONTGOMERY, D. C. Design and Analysis of Experiments. New York: John Wiley \& Sons, 5. ed., 2001. 
MORTON, T. E.; PENTICO, D. W. Heuristic Scheduling Systems. New York: John Wiley \& Sons, 1993.

MÜLLER-MERBACH, H. Heuristics and their design: a survey. European Journal of Operational Research, v.8, p.1-23, 1981.

PAI, A. R.; McROBERTS, K. L. Simulation research in interchangeable parts manufacturing. Management Science, v.17, p.B732-B743, 1971.

PAPADIMITRIOU, C. H., STEIGLITZ, K. Combinatorial Optimization: Algorithms and Complexity. Mineola: Dover Publications, 1998.

PARKER, R. G.; RARDIN, R. L. An overview of complexity theory in discrete optimizations: part II. Results and Implications. IIE Transactions, v.14, n.2, p.83-89, 1982.

PARKER, R. G.; RARDIN, R. L. An overview of complexity theory in discrete optimizations: part I. Concepts. IIE Transactions, v.14, n.1, p.3-10, 1982.

PHILIPOOM, P. P.; MARKLAND, R. E.; FRY, T. D. Sequencing rules, progress milestones and product structures in a multistage job shop. Journal of Operations Management, v.8, p.209-229, 1989.

PHILIPOOM, P. R.; RUSSELL, R. S.; FRY, T. D. A preliminary investigation of multiple-attribute based sequencing rules for assembly shops. International Journal of Production Research, v.32, p.739-753, 1991.

PINEDO, M. Scheduling: Theory, Algorithms, and Systems. New Jersey: Prentice Hall, 2. ed., 2002.

PINSON, E. The job shop scheduling problem: a concise survey and some recent developments. In: Scheduling Theory and its Applications. New York: John Wiley and Sons, 1995. 
PIRLOT, M. General Local Search Methods. European Journal of Operational Research, v.92, p.493-511, 1996.

PLOSSL, G. W. Orlicky's Material Requirements Planning. New York: McGrowHill, 2. ed., 1994.

RARDIN, R. L.; UZSOY, R. An experimental evaluation of heuristic optimization algorithms: a tutorial. Journal of Heuristics, v.7, n.3, p.261-304, 2001.

REEJA, M. K.; RAJENDRAN, C. Dispatching rules for scheduling in assembly job shops - Part II. International Journal of Production Research, v.38, n.10, p.20512066, 2000b.

REEJA, M. K.; RAJENDRAN, C. Dispatching rules for scheduling in assembly job shops - Part I. International Journal of Production Research, v.38, n.9, p.20512066, 2000a.

ROCHETTE, R.; SADOWSKI, R. P. A statistical comparison of the performance of simple dispatching rules for a particular set of job shops. International Journal of Production Research, v.14, p.63-75, 1976.

ROMAN, D. B.; DEL VALLE, A. G. Dynamic assignation of due-dates in an assembly shop based in simulation. International Journal of Production Research, v.34, p.1539-1554, 1996.

RUSSELL, R. S.; TAYLOR III, B. W. An evaluation of sequencing rules in an assembly shop. Decision Sciences, v.16, p.196-212, 1985a.

RUSSELL, R. S.; TAYLOR III, B. W. An evaluation of scheduling policies in a dual resource constrained assembly shop. IIE Transactions, v.17, p.219-232, 1985b.

SALVADOR, M. S. Scheduling and sequencing. In: Handbook of Operations Research: Models and Applications. New York: Van Nostrand Reinhold, 1978. 
SCULLI, D. Priority dispatching rules in job shops with assembly operations and random delays. OMEGA, v.8, p.227-234, 1980.

SILVER, E.A. An overview of heuristics solution methods. Journal of the Operational Research Society, v.55, n.9, p.936-956, 2004.

SMITH, C. H.; MINOR, E. D.; WEN, H. J. Regression-based due date assignment for improved assembly shop performance. International Journal of Production Research, v.33, p.2375-2385, 1995.

THIAGARAJAN, S.; RAJENDRAN, C. Scheduling in dynamic assembly job-shops with jobs having different holding and tardiness costs. International Journal of Production Research, v.41, n.18, p.4453-4486, 2003.

VEPSALAINEN, A. P.J.; MORTON, T. Priority rules for job shops with weighted tardiness costs. Management Science, v.33, n.8, p.1035-1047, 1987.

VOLLMAN, T. E.; BERRY, W. L.; WHYBARK, D. C. Manufacturing Planning and Control Systems. Boston: McGraw-Hill, 4. ed., 1997.

WINSTON, W. L. Operations Research - Applications and Algorithms. Toronto: Brooks Cole - Thompson Learning, 4. ed., 2004. 


\section{Apêndice A - Complexidade Computacional}

A experiência prática leva à conclusão que alguns problemas computacionais são mais difíceis de serem resolvidos do que outros. A Teoria da Complexidade Computacional provê um arcabouço matemático com 0 qual problemas computacionalmente estruturados podem ser estudados de maneira a serem classificados como de fácil solução ou de difícil solução. O conhecimento desta classificação pode direcionar melhor os esforços intelectuais na elaboração de algoritmos de solução mais eficientes sem que ao mesmo tempo tenham a pretensão de proverem a solução exata (ótimo global). A seguir, são apresentados resumidamente alguns dos principais conceitos desta importante área da matemática computacional.

\section{Otimização Combinatória e Complexidade Computacional ${ }^{1}$}

A Otimização Combinatória é uma importante área da matemática derivada da Análise Combinatória - o estudo matemático do arranjo e ordenação de objetos discretos (dito combinatórios) em conjuntos contáveis ou não-contáveis. A Otimização Combinatória estuda o arranjo e ordenação ótimos de objetos discretos segundo uma ou mais funções ou critérios de otimização.

Um problema de otimização combinatória pode ser definido como sendo uma coleção de instâncias que compartilham entre si a mesma estrutura matemática, mas diferem em tamanho (cardinalidade) e valores numéricos dos parâmetros que caracterizam o problema. Cada instância pode ser definida como $I_{y}=\left(O_{y}, P_{y}, C\right)$,

\footnotetext{
${ }^{1}$ Baseado em PAPADIMITRIOU; STEIGLITZ (1998) e PARKER; RARDIN (1982).
} 
onde $y$ define o número de instâncias, com $y<\infty ; O_{y}$ é a coleção finita dos objetos combinatórios $X_{i}=\left\{x_{j}: j=1, \cdots, n\right\} ; P_{y}=\left\{p_{x_{j}}: p_{x_{j}} \in \mathfrak{R}\right\}$ é o conjunto dos parâmetros e atributos de entrada; $n$ é o número máximo de elementos (cardinalidade) de $X_{i} ; C\left(\right.$.) é a função de otimização, com $C: V_{y} \rightarrow \mathfrak{R}$, onde $V_{y}=\left\{v_{x_{j}}: v_{x_{j}}=v\left(x_{j}\right), v_{x_{j}} \in \mathfrak{R},\right\}$ é o conjunto de variáveis ou critérios de otimização cujos valores são internamente calculados durante o processo de otimização para compor o valor de $C\left(\right.$.) . A solução do problema é dada por $S_{y} \subseteq O_{y}$, onde $S_{y}=\left\{s_{j}\right\}$ é o conjunto dos objetos-solução, para os quais $C\left(v_{s_{j}}\right) \leq C\left(v_{x_{j}}\right)$, se minimização, e $C\left(v_{s_{j}}\right) \geq C\left(v_{x_{j}}\right)$, se maximização, para todo $x_{j} \in X$. Se a solução para o problema implicar na ordenação (permutação) dos objetos-solução dentro de $S_{y}$ este toma a forma de uma lista. Então, $S_{y}=\left(s_{j \sigma}\right)$, onde $\varpi$ estabelece a ordem do objeto $s_{j}$ dentro de $S_{y}$.

Especificamente para o problema estudado nesta pesquisa, cada instância $I_{y}$ é formada da seguinte maneira. Cada conjunto $X_{i}$ é composto pelas operações $o_{i j k}^{t}$ executadas em uma determinada máquina $M_{k}$ e pelas relações de precedência entre elas. O conjunto $O_{y}$ é formado pela concatenação dos subconjuntos $X_{i}$. O conjunto $P_{y}$ inclui o tempo de processamento da operação $p_{i j}$, a data de liberação da ordem $r_{j}$ e a data de entrega $d_{j}$. O conjunto $V_{y}$ inclui os tempos de conclusão das ordens $C_{j}$ e os atrasos $T_{j}=\max \left\{C_{j}-d_{j}, 0\right\}$. A função de otimização é $C()=.\bar{T}$

Para cada instância de um problema de otimização pode-se construir uma versão computacional e solucioná-la através de um algoritmo - uma sequência de instruções precisas e universalmente entendidas que solucionam qualquer instância de um problema computacional rigorosamente definido. 
Uma característica inerente a todo problema de otimização é a sua complexidade ou dificuldade de resolução. A complexidade por ser intrínseca é sempre transmitida à versão computacional do problema.

A complexidade da versão computacional está diretamente relacionada à complexidade $\Xi$ do algoritmo de busca da solução $C\left(v_{s_{j}}\right)$. Por sua vez, $\Xi$ é função do tamanho de $I_{y}$. Denotando $\varphi$ como sendo o tamanho de $I_{y}$, tem-se que $\Xi=\Xi(\varphi)$.

Fundamentada nas definições acima, a análise de complexidade algorítmica busca classificar o quão difíceis são as versões computacionais dos problemas de otimização com base na quantidade de computação (número de passos, iterações ou tempo de processamento) requerida para solucioná-los por um modelo abstrato de computação denominado Máquina de Turing.

A Máquina de Turing define um padrão de codificação para entrada, manipulação e saída de dados que independe da linguagem e do método de programação. Neste modelo, a eficiência de um algoritmo é mensurada pelo máximo (pior caso) número de passos computacionais $\wp$ necessários para se obter a solução do problema, sendo $\wp=\wp(\varphi)$. Cada passo computacional é uma instrução elementar (operação aritmética, comparação, instrução de laço, instrução de fluxo), sendo que o tempo de processamento é expresso em termos do número de passos computacionais requeridos pelo algoritmo para obter a solução ótima. Quanto maior o número de passos computacionais, maior o tempo de processamento, menor a eficiência do algoritmo e, portanto, maior a sua complexidade.

Na prática, o número de passos computacionais pode ser expresso em termos do máximo número de iterações realizadas pelo algoritmo, também uma função de $\varphi$.

Em um problema de programação job shop, pode-se definir grosseiramente $\varphi=J \times O \times M$ para 0 pior caso, onde $J, O$ e $\boldsymbol{M}$ representam, no instante $\boldsymbol{t}$, 
respectivamente, o número de ordens, o número máximo de operações por ordem e o número de recursos produtivos.

Um limite-superior para o número de programas possíveis para uma instância de porte $\varphi=J \times O \times M$ pode ser calculado imaginando-se que todas as ordens possuam o mesmo número de operações e que o número de operações a ser executado em cada máquina é o mesmo, não sendo considerada a estrutura de precedência entre operações. Neste caso, o limite-superior é igual a $[(J \times O) !]^{M}$.

A versão computacional $\Pi$ de um problema de otimização é denominada versão de reconhecimento (recognition version). Por definição, a versão de reconhecimento é uma questão, cuja resposta é binária, ou seja, para qual se tem sempre 'Sim' ou 'Não' como resposta e a seguinte estrutura interrogativa: "dada a instância $I_{y}$ de $\Pi$ e um inteiro $L$, existe uma solução viável $S_{y}=\left\{s_{i}\right\} \subseteq O_{y}$ tal que $C\left(v_{s_{i}}\right) \leq L$ ?"

$\mathrm{Na}$ análise da complexidade de um algoritmo, o interesse reside na avaliação de seu comportamento quando ele é suprido com instâncias de grande porte, pois são estas que determinam o limite de aplicabilidade do algoritmo. Existe a concordância geral matematicamente respaldada de que um determinado algoritmo é útil na solução de um problema computacional somente se sua complexidade cresce polinomialmente com relação à $\varphi$, ou seja, este algoritmo codificado para ser executado em uma Máquina de Turing é processado em um número de passos computacionais (quantidade de computação) que cresce polinomialmente $\operatorname{com} \varphi$. Em outras palavras, $\Xi(\varphi)$ cresce em tempo polinomial.

A Teoria de Complexidade Computacional define duas grandes classes de problemas ou versões de reconhecimento: a classe $P$ e a classe $N P$.

A classe $P$ (polinomial) engloba todos os problemas de reconhecimento que são completamente (todas as instâncias) e "eficientemente" resolvidos por algoritmos em tempo polinomial, ou seja, $\Xi(\varphi)=O\left(\varphi^{p}\right)$, com $p \in \mathrm{Z}^{+}$, para todo $I_{y}$. Neste 
contexto, $\Xi(\varphi)$ denota mais precisamente a taxa de crescimento da complexidade do algoritmo em função de $\varphi$ e a notação $O\left(\varphi^{p}\right)$ é a ordem de $\Xi(\varphi)$, e significa dizer que $\Xi(\varphi)$ está limitada superiormente por um múltiplo positivo de $\varphi^{p}$ (forma polinomial). Considerando $\varphi$ suficientemente grande, tem-se que $\Xi(\varphi) \leq a \varphi^{p}$, onde $a>0$.

A classe $P$ inclui os problemas em programação linear, os problemas de fluxos em rede, árvores geradoras (spanning trees), emparelhamentos (matching) e muitos dos problemas de programação em uma única máquina.

Os problemas da classe $P$ são os "fáceis" no contexto computacional, pois para eles existem algoritmos eficientes que os resolvem completamente, ou seja, encontram as suas soluções exatas em tempo polinomial.

Para um problema de reconhecimento pertencer à classe NP (polinomial não determinístico) não é necessário que todas as suas instâncias sejam solucionadas por algum algoritmo em tempo polinomial. Para um problema NP o que é requerido é que se a resposta (solução) para uma dada instância do problema é 'Sim', então deve existir uma prova de que a resposta é 'Sim' a qual pode ser verificada (certificada) por um algoritmo executado em tempo polinomial por uma Máquina de Turing. Por esta definição, conclui-se que $P \subseteq N P$. Mas NP contém também um conjunto enorme de problemas não pertencentes a $P$ (a maior parte dos problemas de otimização combinatória) para os quais não existem algoritmos de tempo polinomial.

À classe NP pertencem os problemas "intratáveis" no contexto computacional, tais como, os problemas em programação inteira e o caso geral do problema de programação job shop. Para eles, não são conhecidos algoritmos eficientes (executados em tempo polinomial) que os resolvam completamente, ou seja, algoritmos que encontrem a solução exata para qualquer tamanho de instância. Para os problemas desta natureza, pode-se escrever que $\Xi(\varphi)=O\left(p^{\varphi}\right)$. Isto significa dizer que $\Xi(\varphi)$ está limitada superiormente por um múltiplo positivo de $p^{\varphi}$, devido 
ao fato da complexidade nesta classe crescer exponencialmente $\operatorname{com} \varphi$. Considerando $\varphi$ suficientemente grande, tem-se que $\Xi(\varphi) \leq a p^{\varphi}$, onde $a>0$.

Em muitas situações teóricas e práticas, algoritmos que solucionam uma determinada classe de problemas podem ser utilizados eficientemente na solução de outras classes de problemas. Sejam $\Pi_{1}$ e $\Pi_{2}$ versões de reconhecimento de problemas de otimização. É dito que $\Pi_{1}$ reduz em tempo polinomial para $\Pi_{2}$, ou $\Pi_{1} \propto \Pi_{2}$, se e somente se existir um algoritmo $\alpha_{1}$ para $\Pi_{1}$ que utiliza como subrotina um algoritmo $\alpha_{2}$ para $\Pi_{2}$. Em outras palavras, $\alpha_{1}$ é uma redução tempo polinomial de $\Pi_{1}$ para $\Pi_{2}$.

Um caso particular de redução é a transformação polinomial. É dito que $\Pi_{1}$ transforma-se polinomialmente para $\Pi_{2}$, ou $\Pi_{1} \propto_{T} \Pi_{2}$, se a partir de uma dada instância $I_{y^{*}}^{\Pi_{1}}$ de $\Pi_{1}$ constrói-se em tempo polinomial a instância $I_{y^{*}}^{\Pi_{2}}$ de $\Pi_{2}$. Demonstra-se que se $\Pi_{1} \propto_{T} \Pi_{2}$, então se $\Pi_{1} \in P \Rightarrow \Pi_{2} \in P$ ou $\Pi_{1} \notin P \Rightarrow \Pi_{2} \notin P$. Pode-se dizer neste caso que $\Pi_{1}$ é um caso particular de $\Pi_{2}$ e que a solução de $\Pi_{2}$ é tão difícil quanto a de $\Pi_{1}$.

Com base nas definições de redução e transformação dadas acima, pode-se melhor identificar e caracterizar os problemas da classe NP através de duas importantes subclasses: a subclasse dos problemas NP-Completo $(N P-C)$ e a subclasse dos problemas NP-Árduo (NP-A).

Um problema $\Pi \in N P$ é dito $N P$ - $C$ se todos os problemas em NP transformamse polinomialmente em $\Pi$, ou seja, podem-se gerar instâncias de $\Pi$ a partir de instâncias de outros problemas em NP.

Se $\Pi$ é NP-C, a seguinte propriedade é verdadeira: se existir um algoritmo eficiente (executado em tempo polinomial) para $\Pi$, então existirá um algoritmo eficiente para todo problema em $N P$, e se isto acontecer, então $P=N P$. Esta 
propriedade reforça ainda mais a complexidade de um problema $N P-C$ e apresenta uma das mais importantes conjecturas da análise matemática: a conjectura $P \neq N P$.

Para um problema $\Pi$ ser NP-A, a redução polinomial de todos os problemas em NP para $\Pi$ pode ser demonstrada em tempo polinomial através de uma Máquina de Turing, porém não se pode demonstrar que $\Pi \in N P$, ou seja, a prova de sua inclusão no rol NP não pode ser verificada em tempo polinomial por uma Máquina de Turing. Apesar disto, indubitavelmente $\Pi$ é tão difícil quanto qualquer problema NP$C$ e, portanto, muito provavelmente intratável no contexto computacional.

Na teoria da programação (scheduling), o conhecimento do fato de ser um problema NP-A ou NP-C é de grande valia, pois nestes casos os esforços devem ser direcionados para o desenvolvimento de algoritmos eficientes que implementem métodos aproximados ou heurísticos de solução, ao invés de serem direcionados para o desenvolvimento de algoritmos que prometam otimalidade ao custo da baixa eficiência.

\section{Classificação dos problemas de programação job shop quanto à complexidade computacional}

Ao longo das três últimas décadas, esforço considerável foi realizado na tentativa de se estabelecer uma hierarquia de complexidade entre as centenas de problemas de programação.

CONWAY; MAXWELL; MILLER (1967, p.6) propõem um dos primeiros esquemas de classificação de problemas de programação. Esta classificação não levava em consideração a complexidade de solução, algo que surgiria apenas no início da década de 1970 com o trabalho de KARP (1972).

LAGEWEG et al. (1981, 1982) propõem um dos primeiros esquemas de classificação de complexidade de problemas de programação. De fato, o esquema 
geral de Lageweg é composto de um esquema de classificação de problemas modificado e extensivamente refinado a partir do esquema proposto por CONWAY; MAXWELL; MILLER (1967) - e de um esquema de hierarquização (redução) de complexidade baseado em 6 grafos de redução elementar de complexidade.

LAWLER et al. (1993) apresentam uma extensão do esquema de LAGEWEG et al. $(1981,1982)$.

PINEDO (2002, p.27) apresenta uma classificação ainda mais abrangente que a de LAGEWEG et al. (1981, 1982). A classificação de Pinedo é apresentada a seguir.

O esquema de classificação de Pinedo faz uso de três atributos $(\alpha, \beta, \gamma)$ para estabelecer, respectivamente, o tipo de sistema de produção, as restrições do processo e a função objetivo. O esquema de hierarquização de complexidade é formado por 11 grafos $\left(G_{i}\right)$ de redução elementar de complexidade, cujos vértices são definidos pelos valores de $\alpha, \beta$ e $\gamma$.

A classificação de determinado problema é feita utilizando-se a expressão $\alpha|\beta| \gamma==\alpha_{1}, \alpha_{2}\left|\beta_{1}, \beta_{2}, \beta_{3}, \beta_{4}, \beta_{5}, \beta_{6}, \beta_{7}, \beta_{8}, \beta_{9}\right| \gamma$, onde:

1. $\alpha_{1}=\{1, P, F, O, J, Q, R, F F, F J\}$, com $\alpha_{1}=1$ para máquina única, $\alpha_{1}=P$ para máquinas idênticas em paralelo, $\alpha_{1}=F$ para flow shop, $\alpha_{1}=O$ para open shop, $\alpha_{1}=J$ para job shop, $\alpha_{1}=Q$ para máquinas em paralelo com diferentes velocidades não dependentes da operação (máquinas uniformes), $\alpha_{1}=R$ para máquinas em paralelo com diferentes velocidades dependentes da operação, $\alpha_{1}=F F$ para flow shop flexível, $\alpha_{1}=F P$ para job shop flexível;

2. $\alpha_{2}=\{\varnothing, m\}$, com $\alpha_{2}=m$ quando o número de máquinas é explicitado e $\alpha_{2}=\varnothing$ para o caso geral;

3. $\beta_{1}=\left\{\varnothing, r_{j}\right\}$, com $\beta_{1}=r_{j}$ quando as datas de liberação forem explicitamente consideradas no problema e as ordens não puderem ser liberadas antes 
destas, e $\beta_{1}=\varnothing$ quando as ordens puderem iniciar seu processamento a qualquer momento;

4. $\beta_{2}=\left\{\emptyset, s_{j k}\right\}$, com $\beta_{2}=s_{j k}$ quando a sequência de execução das ordens $\boldsymbol{j}$ e $\boldsymbol{k}$ for dependente do tempo de setup e $\beta_{2}=\varnothing$ caso contrário;

5. $\beta_{3}=\{\varnothing, p r m p\}$, com $\beta_{3}=$ prmp quando a preempção for permitida e $\beta_{3}=\varnothing$ caso contrário;

6. $\beta_{4}=\{\varnothing$, prec $\}$, com $\beta_{4}=$ prec quando houver alguma forma de precedência entre ordens e $\beta_{4}=\emptyset$ caso contrário;

7. $\beta_{5}=\{\emptyset, b r k d w n\}$, com $\beta_{5}=b r k d w n$ quando as máquinas não estiverem continuamente disponíveis para alocação (quebras, paradas programadas ou turnos forem explicitamente considerados) e $\beta_{5}=\varnothing$ quando as máquinas estiverem continuamente disponíveis no sistema;

8. $\beta_{6}=\left\{\emptyset, M_{j}\right\}$, com $\beta_{6}=M_{j}$ quando houver restrições de processamento de ordens em determinadas máquinas e $\beta_{6}=\emptyset$ caso contrário;

9. $\beta_{7}=\{\varnothing$, block $\}$, com $\beta_{7}=$ block quando o bloqueio de máquinas for considerado explicitamente e $\beta_{7}=\varnothing$ caso contrário;

10. $\beta_{8}=\{\varnothing, n w t\}$, com $\beta_{8}=n w t$ quando não se puder formar fila entre máquinas consecutivas e $\beta_{8}=\varnothing$ caso contrário;

11. $\beta_{9}=\{\varnothing, r e c r c\}$, com $\beta_{9}=$ recrc quando houver recirculação, ou seja, mais do que uma operação da ordem é executada em uma mesma máquina durante o processamento da ordem, e $\beta_{9}=\varnothing$ quando a recirculação não existir;

12. $\gamma=\left\{f_{\text {max }}, \sum f_{j}\right\} \quad$ com $\quad f_{\text {max }}=\left\{C_{\text {max }}, L_{\text {max }}\right\}$ $\sum f_{j}=\left\{\sum C_{j}, \sum T_{j}, \sum U_{j}, \sum w_{j} C_{j}, \sum w_{j} T_{j}, \sum w_{j} U_{j}\right\}, C_{\max }$ é a data máxima de conclusão das ordens, $L_{\max }$ é o atraso máximo dentre todas as ordens, $\sum C_{j}$ é a soma dos tempos de conclusão das ordens, $\sum w_{j} C_{j}$ é a soma ponderada dos tempos de conclusão de ordens, $\sum T_{j}$ é a soma dos atrasos, 
$\sum w_{j} T_{j}$ é a soma ponderada dos atrasos, $\sum U_{j}$ é a soma das ordens atrasadas, $\sum w_{j} U_{j}$ é a soma ponderada das ordens atrasadas.

A Figura 20 apresenta o esquema de hierarquização de complexidade. O grafo $G_{0}$ representa o tipo de sistema de produção. Os grafos $G_{1}$ a $G_{9}$ representam o conjunto de restrições do processo e o grafo $G_{10}$ representa as funções-objetivo. Os arcos direcionados determinam o sentido das reduções elementares entre os problemas. $O$ índice $\boldsymbol{m}$ é o número (explícito) de máquinas, $\boldsymbol{j}$ e $\boldsymbol{k}$ são os índices da ordem e da máquina.

Utilizando o esquema de classificação de Pinedo, o problema estudado nesta pesquisa pertence à classe $J|\operatorname{prec}, \operatorname{recrc}| \Sigma T_{j}$.

PAPADIMITRIOU; STEIGLITZ (1998, p.363) apresentam a prova de que o problema de programação job shop (critério makespan) é NP-C. Com base nisto, pode-se conjecturar que o problema $J \mid$ prec, recrc $\mid \sum T_{j}$ também é $N P-C$ e, consequentemente, intratável sob o enfoque computacional. Encontrar a sua solução exata com um esforço computacional satisfatório ou, em outras palavras, gerar o programa de produção viável que alcance o valor ótimo da medida de desempenho, atendendo plenamente ao conjunto de restrições e em um tempo de execução computacional aceitável, supostamente seria possível para casos bem particulares de pequeno porte e de estrutura especial onde certamente algumas de suas restrições deveriam ser relaxadas e as dimensões de suas possíveis instâncias teriam que ser profundamente diminuídas. 


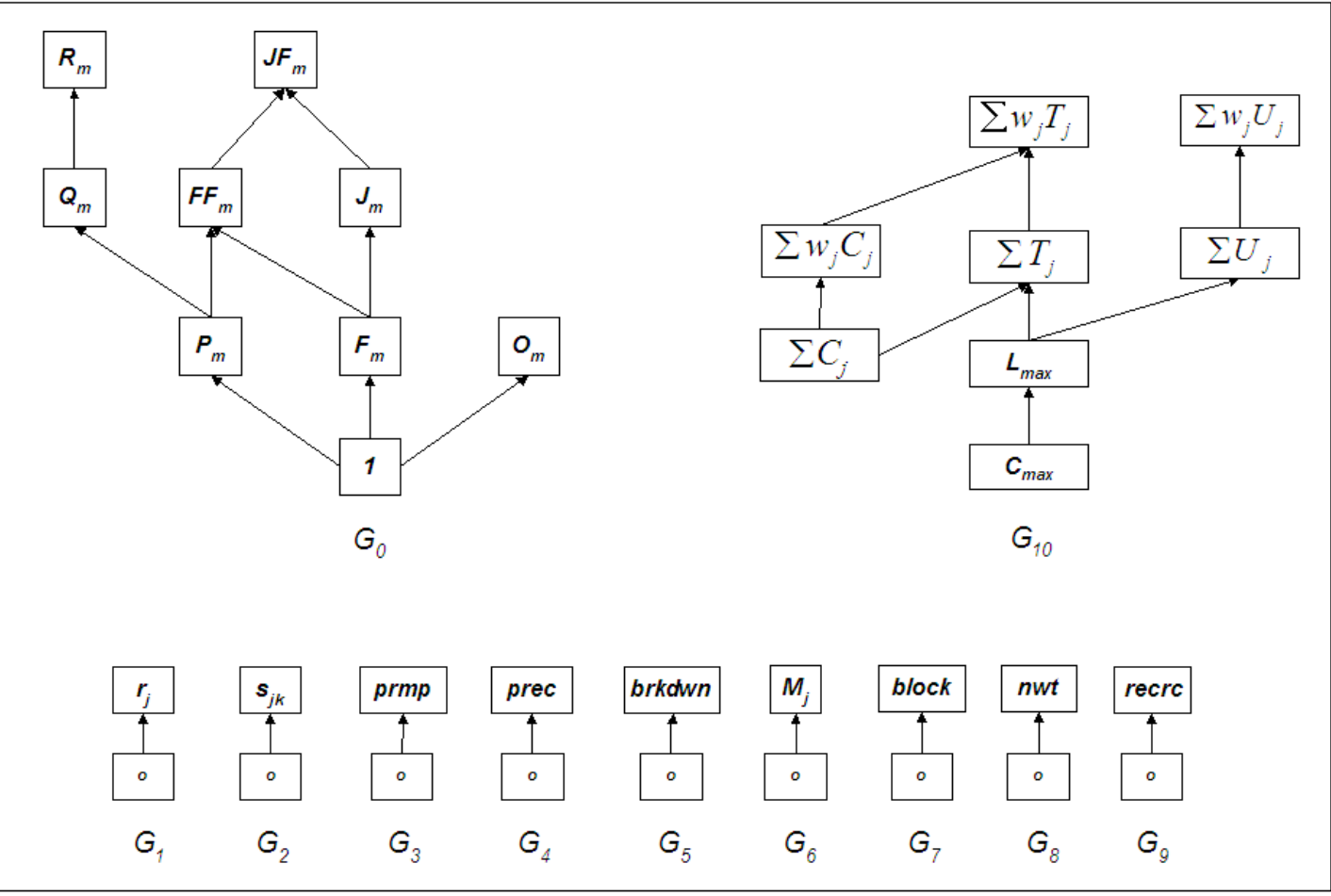

Figura 20 - Hierarquização da complexidade dos problemas job shop. 